Universidade de São Paulo

Instituto de Física

\title{
Processamento de InformaÇão em Neurônios Motores de um Centro Gerador de Padrões
}

Ludmila Brochini Rodrigues

Orientador: Prof. Dr. Reynaldo Daniel Pinto

Tese de doutorado apresentada ao

Instituto de Física para a obtenção

do título de Doutor em Ciências

\section{Banca Examinadora}

Prof. Dr. Antônio Carlos Cassola (ICB-USP)

Prof. Dr. Leandro R. S. Barbosa (IFUSP)

Prof. Dr. Nestor Felipe Caticha (IFUSP)

Prof. Dr. Reynaldo Daniel Pinto (IFSC-USP)

Prof. Dr. Sidarta Tollendal Gomes Ribeiro (UFRN)

São Paulo 
FICHA CATALOGRÁFICA

Preparada pelo Serviço de Biblioteca e Informação do Instituto de Física da Universidade de São Paulo

Rodrigues, Ludmila Brochini

Processamento de informação em neurônios motores de um centro gerador de padrões. - São Paulo, 2011.

Tese (Doutorado) - Universidade de São Paulo. Instituto de Física - Depto. de Física Geral

Orientador: Prof. Dr. Reynaldo Daniel Pinto

Área de Concentração: Sistemas dinâmicos neurais

Unitermos: 1. Neurofisiologia; 2. Eletrofisiologia;

3.Teoria da Informação e Comunicação; 4. Sistemas Dinâmicos; 5. Física Computacional 
Ao meu marido

Roberto 



\section{Agradecimentos}

Ao prof. Dr. Reynaldo Daniel Pinto por ter sido um excelente orientador, um modelo de cientista e pela sua amizade.

Aos meus pais e meu irmão pelo apoio e contribuição para a minha formação científica durante toda a minha vida. Ao meu marido Roberto Carvalhaes por todo o suporte e incentivo durante todos esses anos.

Ao prof. Dr. José Carlos Sartorelli pelos aconselhamentos e a todos os alunos que passaram pelo LFNL e pelo lab. de Neurodinâmica do IFSC pela convivência agradável e pela promoção de discussões enriquecedoras, em especial ao Pedro Carelli, Boris Marin, Rafael Viegas e Caroline Forlim pelas contribuições com experimentos, simulações, discussões e suporte.

Aos meus supervisores e colaboradores no exterior por terem me oferecido oportunidades enriquecedoras, pela ajuda no laboratório e pela receptividade e acolhimento: prof. Dr. Pablo Varona, prof. Dr.Francisco de Borja Rodríguez e Pablo Chamorro do grupo de Neurocomputación Biologica da Universidad Autónoma de Madrid e ao prof. Allen Selverston e prof. Dr. Marcelo Reyes do Institute for Non Linear Sciences, University of California, San Diego.

Ao sr. José Cipriano e a todos os meus educadores que contribuiram para a minha formação e aos familiares e amigos que me apoiaram e incentivaram durante o período de desenvolvimento deste projeto.

À Fundação de Amparo à Pesquisa do Estado de São Paulo e à Coordenação de Aperfeiçoamento do Ensino Superior pelo financiamento de nossa pesquisa. 

O caos é uma ordem por decifrar

J. Saramago 



\section{RESUMO}

A atividade de neurônios em rajadas de disparo (bursts) é onipresente em sistemas nervosos. No entanto, o papel funcional dos bursts na codificação de informação ainda não é completamente compreendido. A dinâmica de burst tem sido intensivamente estudada em centros geradores de padrões (CPGs) que são exemplos clássicos de sistema nervoso autônomo em que a atividade em bursts está diretamente associada ao controle motor. Estudos recentes investigaram pequenas perturbações na dinâmica aparentemente periódica de neurônios com atividade em burst (bursters): padrões sutis nos tempos de disparo (spikes) dentro de um mesmo burst. Padrões de spikes intraburst (PSIBs) são tradicionalmente negligenciados por falta de relação com a função motora do CPG, no entanto, esses estudos mostraram que PSIBs são específicos para cada tipo de célula do CPG estomatogástrico de crustáceos e além disso, são capazes de refletir mudanças na conectividade da rede, indicando um possível papel na codificação de informação. Nesse trabalho, abordamos esse assunto investigando como um neurônio motor com atividade em bursts expressa informação a respeito de outros neurônios da rede através dos PSIBs.

Realizamos experimentos registrando a atividade de neurônios pilóricos do gânglio estomatogástrico tanto na rede intacta como em uma rede híbrida na qual um neurônio pilórico interage em tempo real com um neurônio modelo através de uma sinapse artificial. Para inferir a sensibilidade dos PSIBs pós sinápticos aos pré-sinápticos desenvolvemos uma ferramenta de análise base- 
ada em Teoria da Informação para encontrar padrões de máxima informação (ou seja, encontrar o bin que produz PSIBs de máxima entropia) e calcular informação mútua média entre eles (IMM) ao longo do burst de cada neurônio. Esta ferramenta também é potencialmente útil à análise de outros tipos de processos puntuais por fornecer um método de revelar informação oculta em padrões de eventos.

Encontramos que um único neurônio motor é capaz de expressar no início de seu burst informação contida nos PSIBs do início do burst anterior do neurônio pré-sináptico. Esse fenômeno é observado em diferentes espécimes e espécies, o que sugere um mecanismo geral de codificação de informação. Além disso, esse efeito foi reproduzido em experimentos com uma rede híbrida, onde os estímulos pré-sinápticos são totalmente controlados, livre de qualquer influência de outros elementos no circuito. Esses resultados sugerem que a microestrutura dos padrões de disparo pré-sinápticos são codificadas se dá através de uma única sinapse, de maneira não linear e não homogênea nos PSIBs pós sinápticos.

Dessa forma, neurônios motores são capazes de usar escalas de tempo diferentes para expressar dois tipos de informação: o ritmo de burst (associado à taxa de disparo) carrega informação sobre a contração motora, enquanto que em uma escala de tempo muito menor, os PSIBs (associados à codificação temporal) expressam informação sobre o comportamento de outros neurônios do CPG.

Além disso, encontramos que a informação dos PSIBs de um neurônio pilórico é codificada na estrutura temporal de disparo das unidades ativas registradas em um nervo do sistema estomatogástrico que projeta em áreas sensoriais do cérebro do animal. Assim, o mecanismo de codificação descrito pode ser parte de uma via de transmissão de informação previamente desco- 
nhecida, sugerindo que a codificação de informação através dos PSIBs poderia ser aproveitada para a regulação dos padrões de disparo em circuitos remotos pelo sistema nervoso central. 


\section{ABSTRACT}

Burst firing is ubiquitous in nervous systems. However, the functional role of burst firing in information coding is mostly unknown. Bursting dynamics have been intensively studied in Central Pattern Generators (CPGs), classical examples of autonomous nervous circuits in which the most conspicuous bursting activity is clearly associated to motor function. Recent studies have investigated small perturbations embedded in the otherwise seemingly periodic bursting: the subtle intra-burst spike timing patterns (IBSPs), traditionally neglected for their lack of relation to the CPG motor function. Moreover, IBSPs were found to be cell-type specific and able to reflect changes in $\mathrm{CPG}$ connectivity, indicating a potential role in information coding. Here we addressed this matter by investigating how a bursting motor neuron expresses information about other neurons in the network.

We performed experiments on the crustacean stomatogastric pyloric CPG, both in control conditions and when interacting in real-time with computer model neurons. The sensitivity of post- to pre-synaptic IBSPs was inferred by computing their average mutual information along each neuron burst.

We found that a single motor neuron is able to express, at the beginning of its burst, information about the IBSPs of the beginning of the pre synaptic neuron's burst. This phenomenon is observed in different specimens and species, sugesting a genera information coding mechanism. Moreover, this effect was reproduced in a hybrid circuit, in which the presynaptic stimuli are com- 
pletely controled by the experimenter free of any influence of other elements in the circuit. These results suggest that the presynaptic spiking microstructure are non-linearly and inhomogeneously encoded through a single synapse in the post synaptic IBSPs.

This way, motor neurons are able to use different time scales to express two types of information simultaneously: muscle contraction (related to bursting rate), and the behavior of other CPG neurons (in a much smaller timescale by using IBSPs as information carriers).

Therefore, the coding mechanism described takes part in a previously unsuspected information pathway, providing evidence of the general physiological role of information coding through IBSPs in the regulation of neuronal firing patterns in remote circuits by the central nervous system. 


\section{Lista DE SigLAS}

$\begin{array}{ll}\text { aln } & \text { lateral anterior nerve } \\ \text { CoG } & \text { Comissural Ganglion } \\ \text { CPG } & \text { Central Pattern Generator } \\ \text { IBSP } & \text { Intraburst Spike Pattern } \\ \text { ion } & \text { inferior oesophageal nerve } \\ \text { IPSP } & \text { Inhibitory Post Synaptic Potential } \\ \text { ISI } & \text { Interspike Intervals } \\ \text { ivn } & \text { inferior ventricular nerve } \\ \text { LP } & \text { Lateral Pyloric neuron } \\ \text { lvn } & \text { lateral ventricular nerve } \\ \text { mvn } & \text { medial ventricular nerve } \\ \text { OG } & \text { Oesophageal Ganglion } \\ \text { PD } & \text { Pyloric Dilator } \\ \text { PRC } & \text { Phase Response Curve } \\ \text { son } & \text { superior oesophageal nerve } \\ \text { STG } & \text { Stomatogastric Ganglion } \\ \text { stn } & \text { stomatogastric nerve } \\ \text { STNS } & \text { Stomatogastric Nervous System } \\ \text { VD } & \text { ventricular dilator }\end{array}$





\section{SUMÁRIO}

1 Introdução 13

1.1 O código neural . . . . . . . . . . . . . . . . . . 13

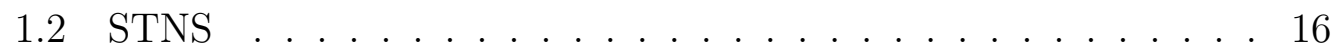

1.3 Neurônios motores . . . . . . . . . . . . . . . . . . . 18

2 Métodos Experimentais $\quad 23$

2.1 Animais . . . . . . . . . . . . . . . . . 23

2.2 Procedimento de dissecação . . . . . . . . . . . . . . . 25

2.3 Eletrofisiologia . . . . . . . . . . . . . . . . . . . 28

2.4 Circuito Intacto . . . . . . . . . . . . . . . . . 33

2.5 Circuito híbrido . . . . . . . . . . . . . . . . . 35

2.6 Congelamento das dinâmicas lentas . . . . . . . . . . . . . . . 38

3 Método de análise $\quad 43$

3.1 Motivação e desenvolvimento . . . . . . . . . . . . . . . . . 43

3.2 Teoria da Informação . . . . . . . . . . . . . . . . . . . . . 45

3.3 Correções na entropia . . . . . . . . . . . . . . . . . . . . . . . . 48

3.4 Algoritmo . . . . . . . . . . . . . . . . . 50 50

3.4.1 Conjuntos de estímulo e resposta .................... 50

3.4 .2 Detecção de spikes e digitalização . . . . . . . . . . . . . 51 
3.4.3 Maximização da entropia . . . . . . . . . . . . . . . 53

3.4.4 Cálculo da Informação Mútua Média . . . . . . . . . . . 55

3.4.5 Apresentação dos resultados . . . . . . . . . . . . 58

3.4.6 Escolha do número de bits . . . . . . . . . . . 58

3.5 Controle estatístico . . . . . . . . . . . . . . . . 60

3.6 Discussão do método . . . . . . . . . . . . . . . . . . . . 61

3.6.1 Matriz de probabilidades conjuntas

e correções . . . . . . . . . . . . . . . . . . . 61

3.6.2 Vantagens, limitações e potencial do método . . . . . . . 62

$\begin{array}{lll}4 & \text { Resultados } & 67\end{array}$

4.1 PSIBS do neurônio PD . . . . . . . . . . . . . . . 67

4.1.1 Padrões e assinaturas dos neurônios

pilóricos . . . . . . . . . . . . . . . . . . . 68

4.1.2 Distribuição dos PSIBs, entropias e IMM . . . . . . . . . 69

4.1.3 IMM, correções e dados surrogados . . . . . . . . . . 73

4.2 Informação LP $\rightarrow \mathrm{PD}$. . . . . . . . . . . . . . . 76

4.3 IMM no circuito híbrido . . . . . . . . . . . . . . . . . 79

4.4 IMM relativa ao estímulo . . . . . . . . . . . . . . . . . 82

4.5 Referências e sentido do fluxo . . . . . . . . . . . . . 84

4.5.1 Referências temporais . . . . . . . . . . . . 84

$4.5 .2 \mathrm{PD} \rightarrow \mathrm{LP} \ldots \ldots \ldots 66$

4.5.3 Reaproveitamento da Informação . . . . . . . . . . . . . 87

4.6 Fluxo de informação para o cérebro . . . . . . . . . . . . . 89

4.7 Número de bits e alfabeto . . . . . . . . . . . . . . . . . 91

4.8 Entropia e número de bits . . . . . . . . . . . . . . . . . . 94

4.9 O alfabeto . . . . . . . . . . . . . . . . . 94 
4.10 Condutâncias lentas e codificação de informação . . . . . . . . 96

5 Discussão 101

6 Conclusões 109

$\begin{array}{ll}\text { Referências } & 111\end{array}$

$\begin{array}{lll}7 & \text { Apêndice } & 123\end{array}$

Anexo: Artigo publicado

128 


\section{INTRODUÇÃO}

\subsection{O CÓDIGO NEURAL}

A compreensão do código neural é uma questão central em neurociência que, com o atual surgimento de novas e sofisticadas técnicas de registro eletrofisiológico in vivo e tecnologias de interface cérebro-máquina, tem ganhado crescente atenção, motivando o desenvolvimento de novos métodos de análise de sinais neurais e a expansão do campo da neurociência computacional.

A capacidade de percepção e interação de um indivíduo com o ambiente depende de como a atividade elétrica de seu sistema nervoso representa estímulos externos e coordena o comportamento: toda informação sensorial é necessariamente codificada por neurônios em pulsos de voltagem chamados potenciais de ação (também disparos ou "spikes"), assim como todo o movimento reflete a atividade em spikes de um neurônio motor traduzida em atividade muscular. Por isso, para entender o código neural é preciso compreender como um neurônio ou uma população de neurônios pode codificar informação em trens de spikes (Rieke et al., 1997).

Há muito se conhece a capacidade de codificação de informação na taxa de disparo, reportada em estudos seminais de Adrian e Sherrington sobre observações em neurônios sensoriais (Adrian e Zotterman, 1926) e motores (Sherrington, 1907), mas somente mais recentemente outras formas de codificação de informação têm sido sugeridas (como codificação temporal) baseadas em 
fortes evidências experimentais. Muitos estudos mostraram que células do córtex visual de mamíferos respondem a determinados estímulos visuais com variações na taxa de disparo (Hubel e Wiesel, 1965), de modo que o comportamento da frequência (normalmente medida como a média de disparos em um período da ordem de segundos) é bem reprodutível para um mesmo tipo de estímulo, enquanto que os intervalos entre spikes apresentam ampla variação (Tolhurst et al., 1983; Softky e Koch, 1993; Shadlen e Newsome, 1994). A aparente imprecisão dos instantes de disparo levara à crença de que os spikes seriam aleatoriamente distribuídos de forma que a variação na frequência seria o único mecanismo de resposta robusto.

Entretanto, mais recentemente, muitos outros trabalhos têm reportado a existência de microestruturas nos trens de spikes. Bair e Koch mostraram, através da análise detalhada do registro no córtex de macacos, que estímulos dinâmicos podem modular a resposta neural em uma escala de tempo da ordem de 10 ms (Bair e Koch, 1996). Hoje, sabe-se que a representação de estímulos por padrões de disparo na resposta neural é onipresente em sistemas sensoriais. Esse tipo de fenômeno foi reportado em grandes populações de neurônios em redes complexas como no córtex auditivo primário de gatos (Nelken et al., 2005), sistema visual de mamíferos (Reinagel et al. 1999, Bair e Koch 1996, Butts et. al. 2007, Rullen e Thorpe, 2001), e em circuitos talamo-corticais (Steriade et al 1993, Fanselow et al., 2001, Sherman e Guillery, 2002, Lundstrom et al., 2010). Butts et al. propuseram um papel funcional para a precisão temporal de spikes, mostrando que a acurácia da resposta de neurônios do núcleo lateral geniculado em gatos depende da escala de tempo do estímulo visual (Butts et al.,2007).

No entanto, não são apenas redes complexas responsáveis por processamento de informação em alto nível que apresentam essas propriedades. Po- 
pulações (Gollisch e Meister, 2008), pares (Esteves et al., 2011) ou até mesmo um único neurônio sensorial primário (Eyherabide et al., 2008) são capazes de codificar informação através das estruturas temporais dos disparos. Portanto, o fenômeno de codificação de informação em padrões de spikes parece estar presente em diversos tipos de sistemas e em diversas escalas, desde neurônios individuais até redes complexas.

Esse panorama explica o crescente interesse no estudo de codificação de informação em padrões de spikes, a busca por novas técnicas de análise de dados eletrofisiológicos e o desenvolvimento de novos modelos computacionais.

Existe um conceito bem estabelecido de que a codificação em padrões de spikes consiste em definir "o quê" está sendo codificado e "quando" (Theunissen e Miller, 1995; Borst e Theunissen, 1999; Krahe e Gabbiani, 2004, Rieke et al., 1997). O "quê" está tipicamente associado às características dos padrões de estímulo enquanto a posição temporal desses padrões corresponde a "quando" (Eyherabide e Samengo, 2010). Os padrões podem ser, por exemplo, compostos por tempos relativos entre spikes em neurônios de atividade tônica (disparo contínuo) ou entre rajadas de disparo, também chamados de bursts (trens de spikes de duração definida intercalados por períodos de silêncio).

Sistemas nervosos podem usar diferentes estratégias de processamento de informação aproveitando a riqueza da dinâmica intrínseca de cada tipo de neurônio e diversas propriedades de circuitos neurais. Um modo de excitabilidade muito importante é atividade em bursts que permite a codificação de informação em (ao menos) duas escalas de tempo distintas: uma na frequência de burst e outra nos disparos intra-burst (Kayser et al., 2009; Panzeri et al., 2010). Esta é uma propriedade de excitabilidade importante relacionada ao controle motor em centros geradores de padrão (do inglês: "central pattern generators", CPGs) (Brocard et al., 2010; Selverston, 2010), processamento 
de informação sensorial em sistemas auditivos e visuais (Reinagel et al., 1999; Eyherabide et al., 2008; Sabourin e Pollack, 2009) e é conhecida por melhorar a detecção de sinais em circuitos talamo-corticais (Steriade et al., 1993; Sherman, 2001) .

Tantas evidências experimentais de mecanismos sofisticados de processamento de informação em circuitos neurais nos colocam diante de um dos maiores desafios da neurociência que diz respeito à compreensão da neurodinâmica. Há um entendimento de que a complexidade dos sistemas nervosos evoluiu de acordo com a necessidade de codificação de informação e processamento de sinais complexos. A maquinaria celular responsável pela excitabilidade das células nervosas é invariante: todos os neurônios apresentam canais iônicos sensíveis a voltagem e específicos para tipo de íon, bem como sinapses químicas ou elétricas com outras células (ver Apêndice). O que diferencia e determina o repertório dinâmico de diferentes tipos de células e circuitos neurais são fatores como a variedade de condutâncias iônicas, densidade de canais e geometria da membrana celular, bem como propriedades do circuito como distribuição e tipos de sinapses na rede. Além disso, as propriedades intrínsecas específicas de cada circuito são reguladas dinamicamente pela ação de neuromoduladores que atuam diretamente em condutâncias e sinapses.

\subsection{Sistema Nervoso Estomatogástrico}

Centros geradores de padrão são paradigmas de como dinâmica complexa emerge de circuitos simples (Clarac e Pearlstein, 2007, Marder e Bucher, 2007). São redes responsáveis pelo controle de movimentos rítmicos como os observados em locomoção em crustáceos, moluscos e alguns vertebrados, digestão mecânica em crustáceos e respiração em mamíferos. Todos os CPGs, tanto em 
invertebrados quanto em vertebrados, seguem os mesmos princípios gerais de funcionamento, utilizando o mesmo modelo de circuitaria com predominância de sinapses inibitórias entre neurônios motores de dinâmica bastante flexível que exibem atividade em bursts.

O gânglio estomatogástrico (do inglês "stomatogastric ganglion", STG) do sistema nervoso estomatogástrico (do inglês: "stomatogastric nervous system", STNS) de crustáceos possui dois CPGs: o gástrico coordena a trituração do alimento na moela gástrica e o pilórico, principal alvo de nosso estudo, é responsável pela filtragem e bombeamento do alimento para o intestino.

O STNS é um dos sistemas neurais mais bem descritos e tem sido intensivamente estudado por algumas décadas (Maynard, 1966, Maynard e Selverston, 1975, Selverston e Mulloney 1974). É um sistema de fácil acesso experimental, podendo manter-se funcional mesmo quando completamente isolado do restante do sistema nervoso ou na ausência de retroalimentação sensorial.

Apesar da aparente simplicidade da rede e do pequeno número de neurônios motores e conexões, esses CPGs têm se revelado cada vez mais complexos da escala celular à sistêmica. Qualquer neurônio pilórico apresenta uma enorme diversidade de condutâncias lentas e rápidas e, apesar de serem responsáveis por manter um comportamento periódico na rede, quando isolados sinapticamente apresentam comportamento irregular e caótico (Selverston et al., 2000). No circuito pilórico, 14 desses neurônios motores estão interconectados por sinapses químicas inibitórias colinérgicas (com receptores muscarínicos de acetilcolina) e glutamatérgicas (com receptores ionotrópicos inibitórios de glutamato, IGluRs, Cleland e Selverston, 1995), sinapses elétricas e elétricas retificadoras.

Além da complexidade intrínseca do circuito, existem mecanismos sofisticados de modulação que permitem que a rede seja reconfigurada para gerar comportamentos diferentes de modo a atender às necessidade do animal de se 
adaptar ao ambiente, por exemplo, mudando o padrão de contração muscular de acordo com a consistência do alimento. No STNS existem mais de 100 tipos de neuromoduladores (peptídeos e aminas) que atuam em cadeias de mensageiros para alterar condutâncias iônicas em neurônios e músculos, agindo em escalas de tempo diferentes com abrangência local ou sistêmica (Swensen e Marder, 2001; Nusbaum e Beenhakker, 2002). Os mecanismos de neuromodulação são tão complexos que estão até mesmo sujeitos a meta-modulação, ou seja, a liberação de neuromoduladores é regulada pela ação sistêmica de alguns dos mesmos neuromoduladores (Stein, 2009). Mais recentemente, trabalhos experimentais e com simulações computacionais têm investigado mecanismos de co-regulação de condutâncias e como diferentes parâmetros do circuito podem evocar comportamentos similares (Prinz et al., 2004; Taylor et al., 2009).

De fato, muito do que se conhece hoje sobre sincronização em redes neurais, bem como de biofísica de canais iônicos dependentes de voltagem e mecanismos de neuromodulação, surgiu em estudos nos CPG pilórico de crustáceos (Clarac e Pearlstein, 2007). No entanto, diante de tamanha complexidade do sistema, atualmente pesquisadores têm adotado estratégias diferentes no estudo dessa rede (Grashow et al., 2010, Taylor et al., 2009). No panorama atual, uma das perguntas mais importantes é como o CPG pilórico pode gerar ritmo estável com tantas possibilidades de parâmetros e substâncias modulatórias e como a atividade do circuito pode ser regulada.

\subsection{CODIFICAÇÃO DE INFORMAÇÃO EM NEURÔNIOS MOTORES}

Outra propriedade interessante da dinâmica de neurônios pilóricos diz respeito à estrutura temporal dos spikes dentro de cada burst. Embora o re- 
pertório rítmico do circuito pilórico e as relações de fase entre neurônios tenham sido muito estudados durante décadas, as propriedades dos padrões de intervalos entre spikes (do inglês: "interspike intervals", ISI) intraburst só despertaram o interesse de alguns pesquisadores mais recentemente. Isso porque os músculos pilóricos são do tipo lento (Morris e Hooper, 1997), então a força da contração muscular depende apenas do número de spikes por burst, sendo insensível a pequenas variações nos tempos de disparo intraburst. Alguns estudos, porém, indicam que a estrutura temporal dos trens de disparo deve ter importância na rede, exibindo aspectos da conectividade sináptica (Hooper e Weaver, 2000) que determina a relação das fases de disparo dos neurônios da rede.

Um estudo anterior em lagostas mostrou, através da construção dos mapas de primeiro retorno dos ISIs dentro de um mesmo burst de neurônios mutuamente inibitórios lateral pilórico (LP) e dilatador pilórico (do inglês: "pyloric dilator", PD), que na rede intacta cada neurônio apresenta uma assinatura, ou seja, uma região do espaço de fase com formato característico no qual os ISIs estão mais presentes (Szücs et al., 2003). Além disso, outros estudos revelaram estruturas tridimensionais características em mapas de segundo retorno de ISI do PD de lagostim (Segundo et al., 1998).

E mais, essas assinaturas dependem da conectividade da rede pois desaparecem ou mudam de forma quando um dos neurônios é inibido, quando as conexões sinápticas entre esses elementos são desligadas ou alteradas, ou ainda quando a rede é sujeita a alterações nas concentrações de neuromoduladores (Szücs et al., 2003 e 2005). Esses resultados indicam que os padrões de spikes intraburst (PSIBs) são complexos e dependem intimamente das conexões sinápticas, apontando para a capacidade dos neurônios do STG de detectar e reagir a pequenas variações no padrão temporal de potenciais de ação inibidores 
(Szücs, 2001). Dessa forma, além de expressarem informação imediata sobre contração motora, os neurônios do CPG também têm potencial de expressar outros tipos de informação através dos PSIBs. Neste trabalho, utilizamos uma ferramenta de análise baseada em teoria da informação desenvolvida especialmente para investigarmos em profundidade o papel dos PSIBs na codificação de informação nesses neurônios.

Grande parte dos resultados deste trabalho diz respeito a experimentos realizados no par de neurônios LP e PD do CPG pilórico do STG do siri azul, os quais são acoplados por mútua inibição e têm atividade em antifase. Nosso principal interesse neste par de neurônios é devido à importância do PD que, por ser um marcapasso, determina o ritmo pilórico, bem como do LP, que é o único neurônio do circuito pilórico a fazer sinapse química com o PD, além de inervar um dos músculos mais importantes sem o qual o piloro perde sua funcionalidade. Além disso, de todos os neurônios pilóricos, LP é (de longe) o que mais recebe e faz sinapses de todos os tipos: recebe 9 inibitórias glutamatérgicas, 3 inibitórias colinérgicas, faz 3 sinapses inibitórias glutamatérgicas e faz sinapses elétricas retificadoras com um grupo de aproximadamente 8 neurônios PY. Por isso, a interação entre LP e PD pode ser vista como um mecanismo de realimentação importantíssimo para a manutenção do ritmo. De fato, encontramos que o neurônio PD é capaz de expressar dinamicamente informação detalhada sobre a estrutura temporal dos spikes do burst imediatamente anterior do LP (Brochini et al., 2011).

Uma técnica experimental bastante útil no estudo da dinâmica neural é o protocolo de dynamic clamp (Sharp et al., 1993, Pinto et al., 2001, Nowotny et al. 2006, Destexe et al., 2009) que permite a criação de redes híbridas: um neurônio pilórico interagindo em tempo real com um neurônio modelo através de uma sinapse artificial. Usando essa ferramenta, observamos que o PD é 
capaz de codificar em seus PSIBs informação sobre a estrutura temporal não apenas do LP na rede intacta, mas também de estímulos artificiais em uma rede híbrida.

Além disso, a informação expressa nos PSIBs não é homogeneamente distribuída ao longo do burst, revelando a habilidade de um único neurônio motor em codificar informação através de uma única sinapse de forma não-linear. Mas qual seria o papel fisiológico desse mecanismo de codificação?

Encontramos evidências de que conteúdo informacional dos PSIBs do neurônio LP não apenas afeta a dinâmica do PD, como também aparece na atividade do nervo inferior ventricular (do inglês: "inferior ventricular nerve", ivn). Diversos neurônios do STNS enviam fibras através do ivn que arborizam em áreas sensoriais do cérebro, especialmente as relacionadas ao olfato (Bohm et al., 2001). Em princípio, essa informação poderia ser aproveitada para auxiliar no controle do funcionamento do STG (o qual depende de mecanismos intrincados de modulação) de maneira mais rápida do que a informação que chega ao cérebro pela realimentação sensorial por mecanocepção (neurônios sensoriais na parede interna do músculo que possuem canais iônios sensíveis a estiramento). Isso sugere que neurônios motores intrinsecamente complexos têm capacidade de codificar informação de modo não-linear, um mecanismo potencialmente útil para levar informação sobre o funcionamento do CPG a centros responsáveis pela modulação da rede. 


\section{MÉtodos Experimentais}

O objetivo dos procedimentos experimentais é obter o STNS isolado a ser utilizado em experimentos in vitro, que envolvem o registro intra e extracelular, bem como a estimulação em tempo real dos neurônios pilóricos. Todo o processo de dissecação, isolamento do tecido nervoso e exposição dos corpos celulares é denominado preparação.

A despeito de variações anatômicas interespecíficas, o sistema nervoso estomatogástrico dos crustáceos é funcionalmente invariante entre espécies como lagostas, siris, caranguejos e lagostins que, apesar de filogeneticamente distantes, apresentam circuitarias dos CPGs essencialmente. Neste trabalho, realizamos experimentos obtendo registros eletrofisiológicos da atividade de neurônios do STNS do siri azul Callinectes sapidus e da lagosta californiana Pannulirus interruptus.

\subsection{Animais}

Durante a execução do projeto foram usados siris azuis adultos Callinectes sapidus(200-300 g cada) coletados no canal do Valo Grande no litoral sul de São Paulo por pescadores locais. Os animais adquiridos eram transportados ao laboratório e mantidos em cativeiro até o uso: aproximadamente 80 espécimes em um tanque de 1000 l de água salina separados individualmente por caixas e telas de proteção de modo a evitar que esses animais causassem danos uns aos 
A

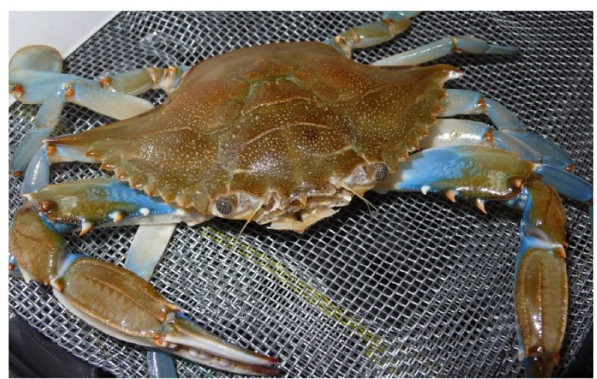

B

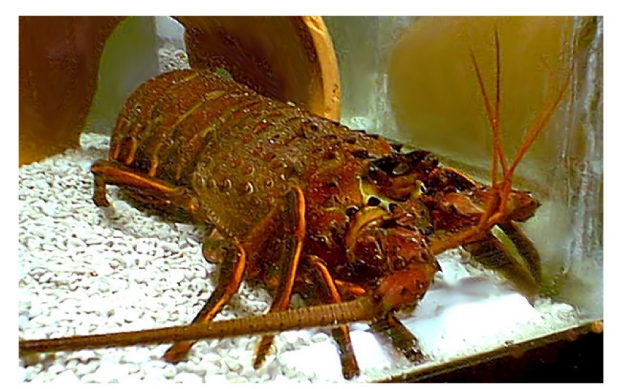

Fig. 2.1 - A-Callinectes sapidus conhecido como siri azul, animal comum da costa paulista. B-Panulirus interruptus lagosta presente no oceano pacífico coletada no litoral da Califórnia. Ambas espécies foram usadas em preparações do STNS

outros. Para obtermos água com salinidade próxima à encontrada no habitat natural do animal (aproximadamente 1/3 da salinidade do mar) usávamos 20 Kg de sal marinho (Read Sea, Israel) dissolvidos em 1000 l de água de torneira. A água era constantemente filtrada e oxigenada e o tanque mantido em ambiente fechado no mesmo edifício do laboratório, estando sujeito a uma amplitude térmica menor que a do ambiente externo. Nesse arranjo de cativeiro, os animais são capazes de sobreviver por vários meses.

Alguns experimentos foram feitos com lagostas Panulirus interruptus (Fig. 2.1 B) na Universidade da Califórnia San Diego-CA, EUA no Institute for Non Linear Sciences (INLS-UCSD) sob a supervisão do prof. Allen Selverston.

Em todos os procedimentos experimentais envolvendo animais, seguimos os princípios éticos sugeridos pelo Comitê de Ética em Experimentação Animal da Univesidade Federal de São Carlos. Os experimentos foram planejados de modo a usar o menor número de animais possível, ao mesmo tempo minimizando o tempo e os danos causados ao animal em vida. 


\subsection{Procedimento de dissecaÇão}

A preparação, originalmente desenvolvida para a lagosta Panullirus interruptus, foi adaptada à anatomia do Callinectes sapidus com a ajuda do prof. Allen Selverston (Universidade da Califórnia, San Diego - UCSD).

Cada preparação experimental envolve o uso de um animal por vez, que é retirado do tanque 25-35 min antes do início do procedimento e mantido envolto em uma camada espessa de gelo durante esse período. Como é um animal pecilotérmico, seu metabolismo, bem como a atividade do sistema nervoso, diminuem com a temperatura.

A preparação consiste em duas fases. Durante a preparação grossa o conjunto do cérebro, juntamente com o esôfago, moela gástrica, estômago e piloro são separados do restante do animal e só na preparação fina é que o STNS é isolado dos tecidos remanescentes.

Com o animal "adormecido" retira-se os perópodes (patas) e quelas de modo a manter o animal imóvel. Primeiramente rompe-se a carapaça externa do exoesqueleto dorsal abrindo uma área de aproximadamente $5 \mathrm{~cm}$ de diâmetro no sentido central posterior entre o coração e o céfalo, evitando lesar a membrana que envolve o ambiente interno.

Em seguida, essa mesma membrana deve ser retirada, tornando visível a estrutura interna do estômago e moela gástrica. Piloro e esôfago estão em posição mais ventral e serão revelados em seguida. Todo tecido conjuntivo e músculos adutores entre a superfície da moela gástrica e as câmaras branquiais devem ser removidos.

Então, retira-se a região da carapaça próxima ao cérebro que, por sua vez, encontra-se em posição dorsal com relação ao aparelho bucal. O cérebro (em conjunto com tecidos que o envolvem) é isolado através de uma incisão 
muito próxima da carapaça anterior e rompendo sua ligação com ossículos que articulam os olhos. Para isolar o esôfago deve-se desconectar todo o seu perímetro que envolve as mandíbulas. Finalmente, segurando a extremidade do esôfago, deve-se separar todo o conjunto (esôfago, cérebro, estômago e piloro) de qualquer tecido ventral.

Aqui termina a preparação grossa. Todo esse conjunto é lavado com solução salina em abundância. Em seguida, faz-se uma incisão ântero-posterior de modo a abrir a moela gástrica, estômago e esôfago. Esse conjunto é fixado em uma placa de cera onde se inicia a dissecação fina, quando os nervos e gânglios do STNS são isolados dos tecidos remanescentes, sendo visualizados através de um microscópio estereoscópico (Nikon SMZ 1000) de magnificação 150x. A preparação é mantida em solução salina que deve ser oxigenada e renovada a cada 15 min e mantida resfriada a aproximadamente $15^{\circ} \mathrm{C}$.

A solução salina normal é preparada com antecedência em água destilada com 479mM de $\mathrm{NaCl}, 13 \mathrm{mM}$ de $\mathrm{KCl}, 14 \mathrm{mM} \mathrm{CaCl} 2,6 \mathrm{mM} \mathrm{MgSO} 4,4 \mathrm{mM}$ Na2SO4, 5mM HEPES, e 5mM TES (Sigma-Aldrich). É deixada em agitação para máxima dissolução e em seguida ajusta-se o pH (tipicamente demasiadamente ácido logo após o preparo) da solução para 7.4 usando Trizma Base (Sigma-Aldrich).

Ao final da dissecação fina, permanecem apenas o STG e os gânglios anteriores esofágico (do inglês: "oesophageal ganglion", OG) e comissurais (do inglês: "commisural ganglion" CoGs) (Fig. 2.2), os quais são importantes para conferir neuromodulação aos circuitos do STG, gerando uma atividade in vitro similar à exibida no animal em vida. Os nervos a serem isolados são os nervos motores lateral ventricular (lvn), medial ventricular (mvn) e anterior lateral $(a l n)$; o nervo estomatogástrico $(s t n)$ que conecta o gânglio estomatogástrico aos gânglios superiores; os nervos esofágico superior e inferior (son e ion) 


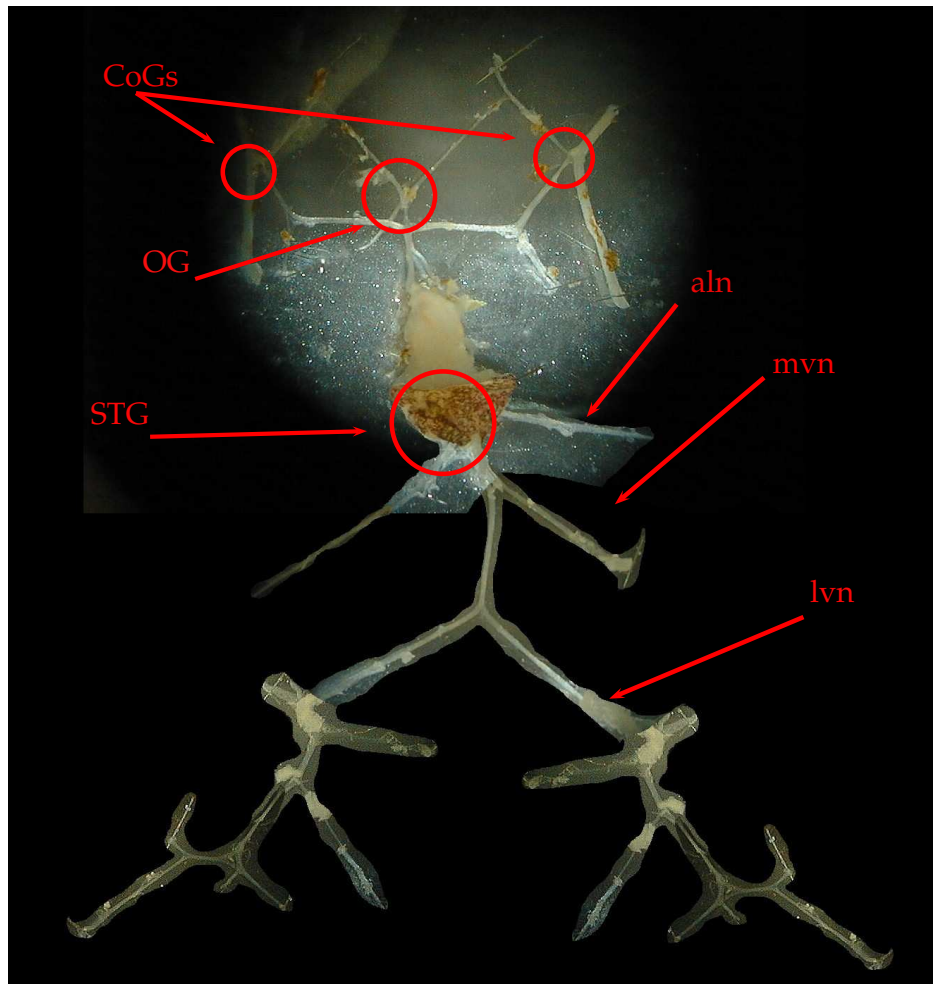

Fig. 2.2 - Foto: resultado da dissecação fina. Circulos e setas indicam a posição dos gânglios esofágico (OG), comissurais (CoGs) e estomatogástrico (STG), bem como dos nervos anterior lateral (aln), lateral ventricular (lvn) e medial ventricular (mvn)

bem como o nervo inferior ventricular (ivn) que conecta o gânglio esofágico ao cérebro. Este último é tipicamente o nervo mais curto, portanto deve ser cortado o mais próximo possível junto ao cérebro de modo a obter-se comprimento suficiente para que seja possível fazer medida extracelular.

A preparação é então transferida para uma placa de petri com o fundo revestido de uma camada de elastômero de silicone transparente (Sylgard 184, Dow Corning, MI), sendo mantida em solução salina oxigenada e resfriada. Já na placa de petri, remove-se qualquer tecido conjuntivo remanescente e o sistema é fixado no sylgard por pinos de aço inoxidável de $5 \mathrm{~mm}$ de comprimento e $0.2 \mathrm{~mm}$ de espessura que perfuram as extremidades nos nervos, levando a uma disposição do sistema como na Fig. 2.2. 
O último passo é extremamente delicado e consiste na exposição do gânglio estomatogástrico de modo a obter-se acesso aos corpos celulares (disheathing). Com pinças bem afiadas, a membrana que reveste o gânglio deve ser rasgada de um lado a outro com cuidado para não lesar os corpos celulares. Neste ponto a preparação está pronta para os registros eletrofisiológicos. Todo esse processo de preparação desde a dissecação grossa até o disheating dura aproximadamente 4hs (a qualidade da preparação só pode ser avaliada após o registro eletrofisiológico)

Exemplos desse tipo de procedimento no caranguejo Cancer borealis e na lagosta Panullirus interruptus podem ser encontrados em vídeo (Gutierrez e Grashow, 2009; Tobin e Bierman, 2009).

\subsection{Eletrofisiologia}

O aparato de eletrofisiologia consiste em uma mesa pneumática, um suporte com amplificadores e interfaces de aquisição de dados além de dois computadores. Sobre a mesa se encontram um microscópio estereoscópico (magnificação 300x), micromanipuladores, controlador de temperatura e bomba peristáltica. A mesa deve ser pneumática para evitar que a preparação sofra qualquer tipo de perturbação mecânica e deve ser devidamente aterrada e parcialmente envolta por uma tela metálica de modo a minimizar ruído elétrico externo sobre os eletrodos, os quais estão conectados aos amplificadores. Existem 2 tipos de amplificadores, um para sinal extracelular (A-M systems 1700 diferencial AC amplifier) e outro para intracelular (A-M systems 1600 Neuroprobe amplifier). O sinal de saída dos amplificadores é digitalizado por uma placa Digidata 1322 (Molecular Devices, Sunnyvale, CA.) de baixo ruído e alta resolução que adquire a $500 \mathrm{kHz}$ e 16 bits e faz interface com os computadores. Um deles 
é exclusivamente dedicado à aquisição dos dados no qual pode-se visualizar o sinal durante o experimento com programa Axoscope (Molecular Devices, Sunnyvale, CA.), enquanto o outro computador é dedicado protocolo de dynamic clamp (Pinto, 2001) usando uma placa de interface de aquisição de dados Digidata 1200B (Molecular Devices, Sunnyvale, CA.).

Durante o experimento, a preparação é mantida em perfusão contínua da solução salina oxigenada com um fluxo de aproximadamente $2 \mathrm{ml} / \mathrm{min}$ e mantida em $22 \pm 1^{\circ} \mathrm{C}$ através de um controlador de temperatura feito no laboratório, que consiste em um controlador PID agindo em uma placa Peltier (placa termoelétrica) em contato térmico com dutos de aço inox por onde passa a solução salina.

Primeiramente é feita uma medida extracelular dos nervos ivn e lvn (e eventualmente também o mvn). Pelo lvn, o qual enerva os principais músculos pilóricos, passam axônios dos neurônios LP, PD e pilórico (PY), sendo que o mvn corresponde ao sinal dos neurônios cardíaco inferior (IC) e dilatador ventricular (VD). Diferentes neurônios podem ser identificados em um mesmo nervo por diferenças em fases e amplitudes de disparos. O sinal é medido por um eletrodo metálico encostado no nervo isolado do restante da solução por uma camada de vaselina. A diferença de potencial elétrico é medida entre este eletrodo e um eletrodo em contato com a solução devidamente aterrada.

A leitura do sinal extracelular permite saber se o sistema pilórico está com ritmo adequado e estável, o que indica que a preparação foi bem sucedida de modo que podemos passar para a próxima etapa. Os neurônios LP, PD e PY têm atividade rítmica e disparam em rajadas (bursts), com diferenças de fase bem características entre um e outro. Os potenciais de ação dos axônios de cada tipo de neurônio chegam ao eletrodo com amplitudes bem diferentes, sendo que o sinal de maior amplitude corresponde sempre ao neurônio LP. 
A medida intracelular é feita através da penetração de um microeletrodo no corpo celular que consiste de uma micropipeta preenchida com uma solução $3 \mathrm{M}$ de $\mathrm{KCl}$ ( ou $3 \mathrm{M}$-Kacetate $+0.1 \mathrm{M} \mathrm{KCl}$ ) que deve ser feita no momento do experimento: um capilar de borosilicato (Suttter Instruments Co, USA) puxado por um puxador de micropipeta de precisão Sutter P-92 ou P-60 (Sutter Intrument Co, CA). A ponta da micropipeta deve ter um diâmetro (da ordem de centenas de nanômetros) tal que a resistência do microeletrodo esteja por volta de $20 \mathrm{M} \Omega$ para permitir uma boa medida sem danificar a membrana celular.

O microeletrodo é posicionado em um suporte (holder) também cheio de solução 3M $\mathrm{KCl}$ que conecta o microeletrodo ao headstage do amplificador através de um pino de ouro. Esse conjunto microeletrodo/headstage é fixado no micromanipulador que, por sua vez, é posicionado na mesa pneumática de tal forma que a ponta do microeletrodo esteja dentro da solução e próxima ao gânglio.

O micromanipulador permite que o eletrodo seja deslocado em 4 direções, tanto nos eixos ortogonais $(\mathrm{X}, \mathrm{Y}, \mathrm{Z})$ quanto na própria direção do eletrodo. Olhando pelo microscópio, a ponta do eletrodo deve ser posicionada próxima ao corpo celular a ser empalado utilizando os reguladores ortogonais e em seguida deve ser gradualmente mais aproximada da membrana usando o regulador na direção do eletrodo para que este penetre o mais perpendicular possível na membrana celular (Fig. 2.3) Não é possível observar a penetração visualmente, no entanto esse momento é marcado pela queda abrupta do potencial registrado pelo amplificador.

Como os neurônios não podem ser identificados pela morfologia ou pela sua posição no gânglio, a medida extracelular é essencial para que seja possível identifica-los através da comparação entre o sinal intra e o extracelular. O 


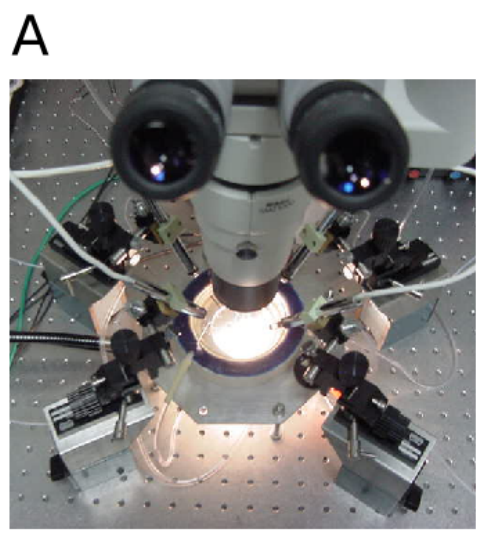

\section{B}
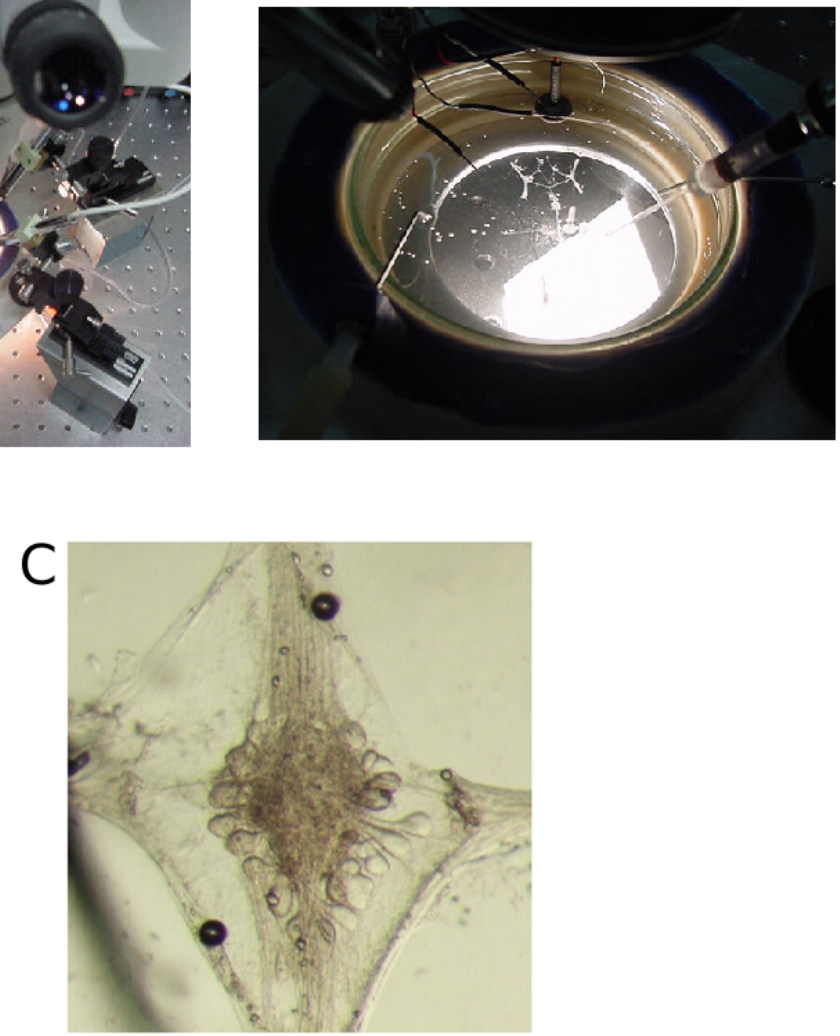

Fig. 2.3 - Foto: $A$ e B-Preparação sob o microscópio e micromanipuladores posicionados para a inserção dos eletrodos nos corpos celulares. C-STG após disheating, pequenas formas esféricas translúcidas são corpos celulares (com tamanhos variando de 40 a $80 \mu \mathrm{m}$ ).

sinal extracelular do neurônio LP tem amplitude tipicamente maior que as outras unidades disparando no lvn sendo, então, o neurônio mais simples de ser identificado (Fig. 2.4). Sabe-se que o PD trabalha em anti-fase com o LP, portanto o sinal extracelular também ajuda na identificação desse neurônio. No entanto, pode ser difícil de discriminar os sinais entre PD e PY visualmente no traço extracelular, mas pode-se observar o potencial envoltório do burst - que em uma preparação saudável deve ser bem estereotipado para o PD - ou ainda submeter o neurônio à estimulação contínua, que é um teste inequívoco: resposta desse neurônio a uma corrente positiva deve ser o au- 


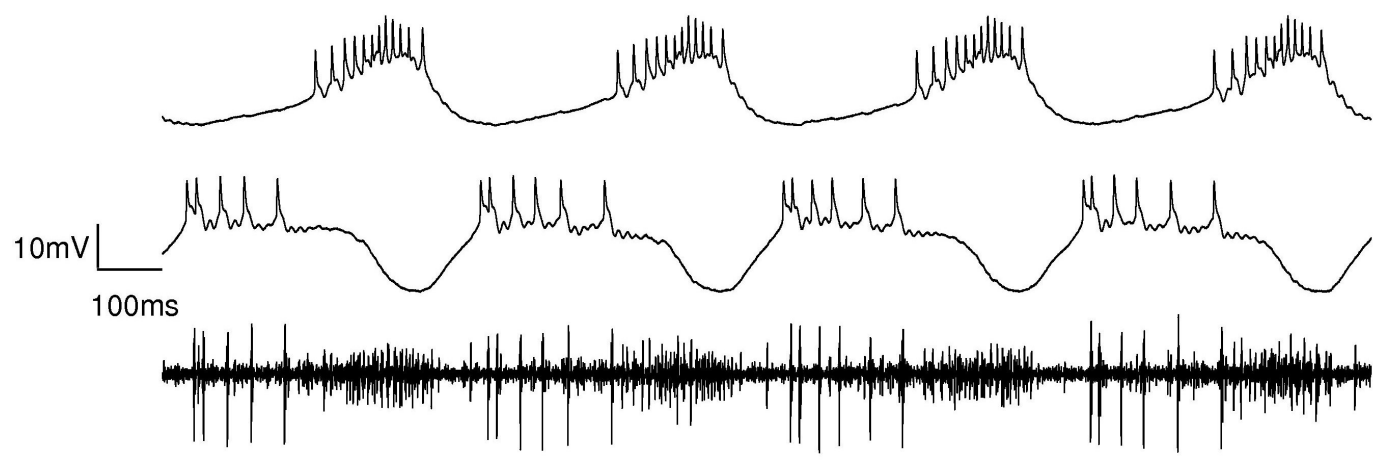

Fig. 2.4 - Traço intracelular do registro do potencial de membrana do PD(cima), $L P($ centro) e do sinal extracelular do lvn(baixo).

mento da frequência pilórica e, como PD é o único neurônio motor que faz parte do grupo marcapasso cujo sinal aparece no lvn, deve ser o único a apresentar esse tipo de resposta à estimulação. O registro do nervo mvn também pode ser útil para distinguir entre $\mathrm{PD}$ e VD.

A preparação pilórica é extremamente robusta e, enquanto mantida em condições adequadas, os neurônios podem manter-se em atividade rítmica por muitas horas. Neste trabalho, apenas foram utilizados registros longos (mais de 30 min) com o ritmo estacionário com respeito à frequência de burst, duração e número de spikes por burst de cada neurônio registrado e relação de fase entre esses neurônios. Não é sempre que se pode observar o ritmo pilórico estável por longos períodos de tempo, o qual muitas vezes é abruptamente reconfigurado (por exemplo, é possível observar mudança de frequencia de $1 \mathrm{~Hz}$ para $0.5 \mathrm{~Hz}$ em aproximadamente 10 ciclos). O decaimento da qualidade da preparação se observa normalmente com adição de período de burst ou com a mudança do comportamento de algumas unidades de burst para tônicas ou apresentando progressivamente um número menor de spikes por burst. 

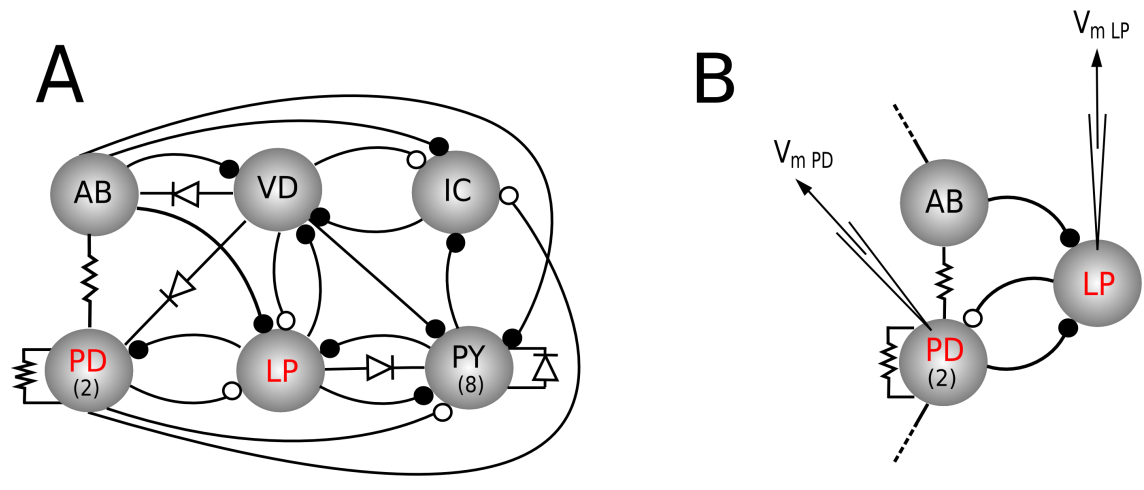

Fig. 2.5 - A- circuito pilórico completo indicando as sinapses inibitórias glutamatérgicas (circulos preenchidos), colinérgicas(circulos sem preenchimento), sinapses elétricas (símbolo de resistor) e elétricas retificadoras (símbolo de diodo). $A B$ e PDs formam o grupo marcapasso e LP é o único neurônio pilórico a fazer sinapse química com neurônios do grupo marcapasso. Além disso, LP recebe sinapses inibitórias de $A B, P D, V D$ e $P Y$. B-Circuito simplificado indicando os eletrodos de registro.

\subsection{Registro DA ATIVIDADE DE NEURÔNiOs PILÓRICOS NO CIRCUITO INTACTO}

Parte dos experimentos foi feito com o STG intacto. Uma versão simplificada do circuito pilórico está ilustrada na Fig. 2.5. Estão representados o grupo marcapasso, composto por dois PDs e um interneurônio burster anterior $(\mathrm{AB})$ e o LP, único neurônio pilórico a fazer sinapse química com o grupo marcapasso.

Nesses experimentos, conduzido tanto em Callinectes sapidus quanto em Panulirus interruptus, medimos a atividade intracelular do LP e um neurônio PD gravando séries temporais longas do potencial de membrana de 30 min a 2 hs, de acordo com a estabilidade da preparação.

Algumas medidas foram feitas apenas com eletrodos extracelulares para registro da atividade no ivn e lvn para obtenção de séries temporais de tem- 


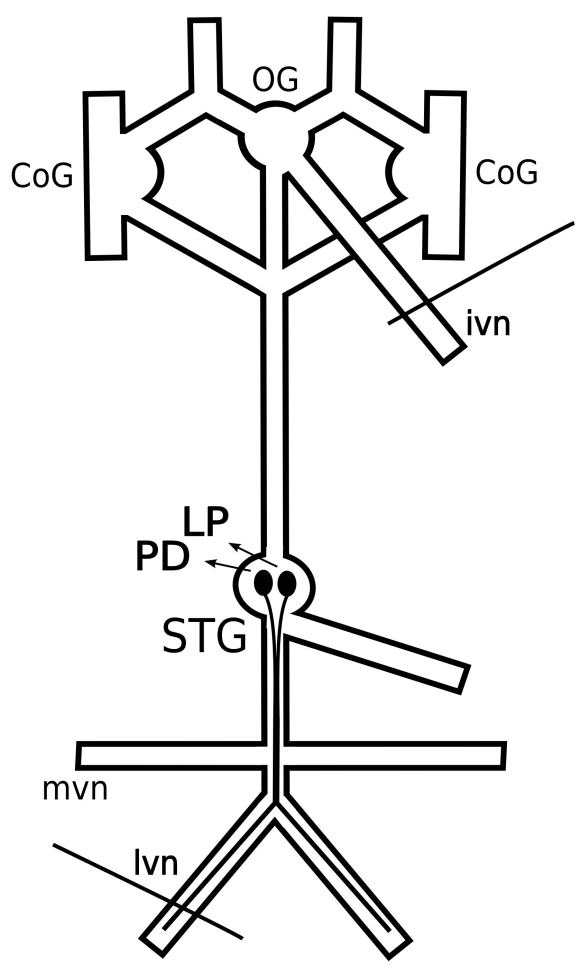

Fig. 2.6 - Desenho esquemático da disposição do STG, dos gânglios superiores responsáveis pela neuromodulação OG e CoGs. Traços indicam as posições dos eletrodos nos nervos lvn (onde se registra a atividade dos neurônios LP e PD) e ivn.

pos de disparo de LP e ivn para cálculo de fluxo de informação. Como não há penetração dos corpos celulares, a atividade do STNS mantém-se estável por mais tempo, sendo possível adquirir séries com várias horas de duração. Algumas vezes essas medidas extracelulares foram feitas simultaneamente com as intracelulares, no entanto, nesses casos a atividade se mantem estacionária por menos tempo em geral. 


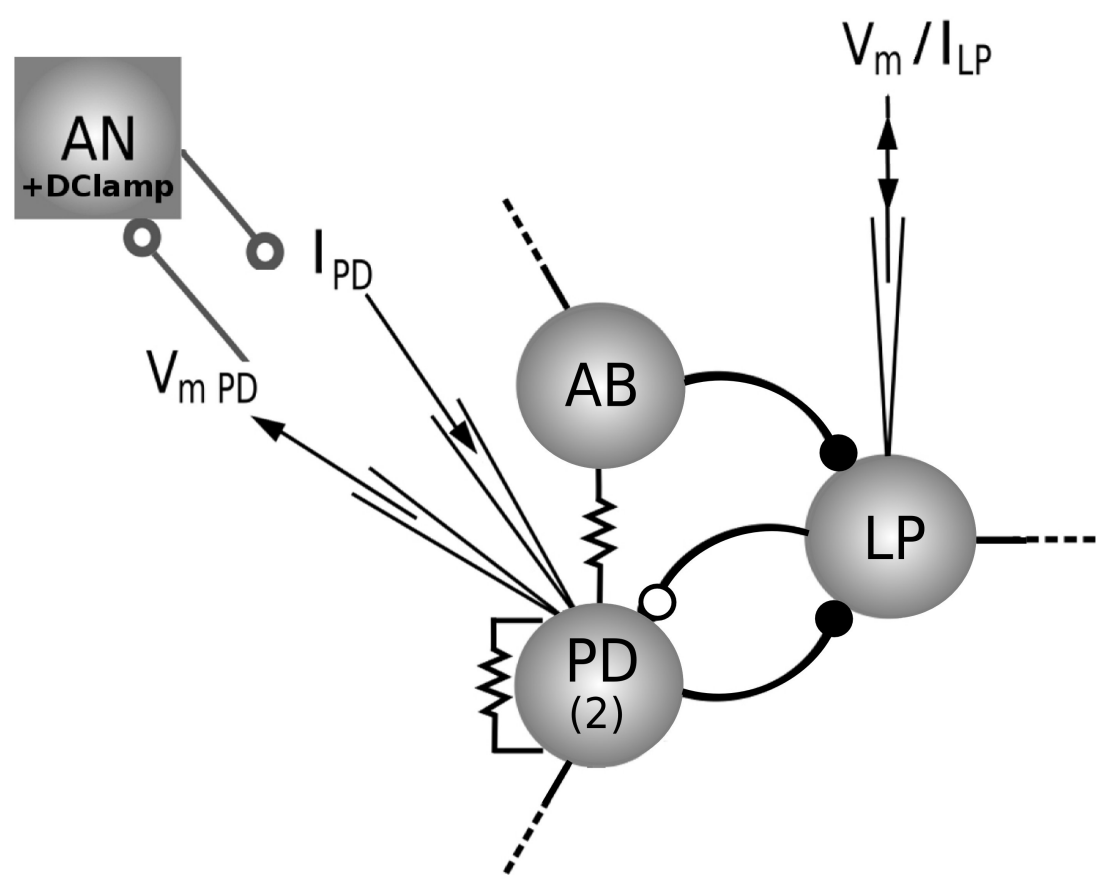

Fig. 2.7 - Circuito híbrido: Circuito pilórico simplificado com LP e o grupo marcapasso. LP é hiperpolarizado por injeção de corrente pelo eletrodo mais à direita. Os eletrodos à esquerda acoplam o neurônio PD ao neurônio artificial, um responsável pela leitura do Vm e outro por injeção de corrente.

\subsection{Substituindo O NEURÔNIO LP POR UM NEURÔNIO ARTIFICIAL}

O método de dynamic clamp (Sharp et al., 1993, Pinto et al., 2001, Nowotny et al. 2006, Destexe et al., 2009) é uma técnica de eletrofisiologia que permite introduzir artificialmente condutâncias sinápticas ou de membrana em neurônios biológicos a partir de simulações computacionais. O protocolo consiste em estabelecer um "loop" entre a corrente injetada e o potencial de membrana registrado. É uma ferramenta poderosa que permite a criação de circuitos híbridos de neurônios reais conectados a artificiais. Ainda mais, permite o estudo da dinâmica neural através da introdução de condutâncias artificiais em um neurônio real (Viegas, 2011).

Em nossos experimentos, utilizamos um protocolo de dynamic clamp desenvolvido em nosso laboratório (Carelli, 2008) para simular uma rede pequena 
em que o neurônio PD é conectado em mútua inibição a um neurônio computacional que substitui o neurônio LP biológico. O protocolo é baseado em uma versão anterior previamente publicada (Pinto et al., 2001; Nowotny et al., 2006) e usa uma placa de interface de aquisição Digidata 1200B (Molecular Devices).

No dynamic clamp original, um computador simula sinapses entre neurônios monitorando seus potenciais de membrana $(\mathrm{Vm})$ e gerando as correntes a serem injetadas. Essas correntes são calculadas pelas equações que modelam as condutâncias sinápticas dependentes do tempo e de Vm. Este computador é dedicado apenas à aquisição dos dados, registrando o Vm do neurônio biológico $V m_{-} P D$ e do neurônio artificial $V m_{-} N A$ e a corrente injetada $I_{i n j}$.

O neurônio artificial foi implementado em tempo real, podendo ser de dois tipos: um modelo estocástico ou uma sequência de bursts com tempos de spikes aleatórios. Em ambos os casos, o NA foi ajustado para reproduzir em média o comportamento do neurônio LP original na preparação. Primeiramente, registra-se uma breve série temporal estacionária do potencial de membrana LP/PD em atividade espontânea na rede intacta por aproximadamente 10 min. Em seguida, o LP é hiperpolarizado até atingir um estado quiescente (corrente de -10 nA dependendo da preparação). Então, o PD é conectado através de uma sinapse artificial ao NA, cujos parâmetros são ajustados empiricamente de modo a fazer com que seu comportamento seja o mais semelhante possível ao do LP original com respeito à fase de disparo, duração do burst e número de spikes por burst.

O modelo determinístico é baseado em um modelo Hodgkin-Huxley tradicional (Apêndice). O modelo estocástico e sua implementação em tempo real foi desenvolvido em nosso laboratório (Carelli et. al 2005) baseado em um modelo determinístico de condutâncias conhecido (Turrigiano et al., 1995, Prinz et al., 
2003), adaptado para considerar os efeitos da dinâmica estocástica de certos canais iônicos na variabilidade dos instantes de disparo.

Devido à sua natureza estocástica, o modelo naturalmente apresenta variabilidade nos tempos de disparo de burst para burst. Em sua implementação no dynamic clamp, foram feitos ajustes em alguns parâmetros de máxima condutância de modo a aproximar o comportamento do NA ao do LP original de cada preparação $\left(\mathrm{em} \mathrm{mS} / \mathrm{cm}^{2}\right)$ : cálcio lenta $\left(3.0<G_{-} C a s<4.0\right)$, transiente de cálcio $\left(0.9<G_{-} C a_{t}<1.1\right)$ e cálcio dependente de potássio $\left(3.5<G \_K[C a]<\right.$ 4.5). Esses ajustes foram feitos durante a medida por comparação visual entre os traços dos potenciais de membrana do NA com o do LP original. Todos os valores dos outros parâmetros utilizados foram mantidos iguais aos originalmente descritos em Carelli et al., 2005. O NA recebe uma forte inibição do PD de tal maneira que o NA, assim como acontece com o LP, só é permitido disparar quando PD está na fase hiperpolarizada. A sinapse artificial do PD para o NA estocástico foi ajustada para hiperpolarizar o NA quando o neurônio PD começa um burst. Valores típicos dessa condutância estão em torno de $G_{-}$syn $_{P D \rightarrow N A}=200 \mathrm{mS} / \mathrm{cm}^{2}$.

O NA aleatório consiste simplesmente em uma sequência de bursts nos quais os instantes dos spikes são determinados a partir de estatísticas da série temporal do LP previamente registrada. São calculadas as médias do instante do primeiro e do último spike do LP após a hiperpolarização do PD (LP_start / LP_end), o número máximo e mínimo de spikes em um burst (max_spk e min_spk) e o mínimo intervalo entre spikes do LP (min_ISI). Além disso, determinamos o número de bursts de NA $(N b)$ de acordo com o tempo planejado do experimento. Os valores destes parâmetros variam bastante entre preparações, mas podemos dar um exemplo de um conjunto de valores possível: max $\_s p k=6$, min_spk $=4$, min_ISI $=15 \mathrm{~ms}, L P \_s t a r t=50 \mathrm{~ms}$, LP_end 
$=400 \mathrm{~ms}$ com $\mathrm{Nb}=1800$ (30 minutos de registro com ritmo pilórico a $1 \mathrm{~Hz}$ ). Então, geramos uma sequência longa de $N b$ bursts na qual são escolhidos aleatoriamente (distribuição uniforme), para cada burst: n_spk, o número se spikes daquele burst (min_spk $\leq n \_s p k \leq$ max_spk), a posição do primeiro spike $t_{1}$ no intervalo $\left[L P \_s t a r t, L P \_s t a r t+\left(L P \_e n d-L P \_s t a r t\right) / n \_s p k\right]$, e uma sequência de $I S I_{i}$ no intervalo $\left[t_{i}+\min _{-} I S I, t_{i}+\right.$ min_l $I S I_{+}\left(L_{\text {P_end }}-t_{i}\right.$ - min_ISI)/(N_spk-i)], onde $1 \leq i \leq\left(n \_s p k-1\right)$. Essa sequência de bursts é armazenada em um arquivo usado pelo dynamic clamp para implementar o NA aleatório em tempo real. Durante os experimentos, o protocolo identifica o final do burst do PD (hiperpolarização) e injeta corrente negativa de acordo com a ocorrência de spikes do NA.

A força da sinapse do NA para o PD foi ajustada no dynamic clamp para que os IPSPs tivessem amplitude similar aos produzidos pela atividade original do LP. Em experimentos com siri não se observa os IPSPs vindos do LP no registro do PD porque o sítio da sinapse é distante de onde o eletrodo penetra o soma. No caso dos experimentos com lagosta, a amplitude dos IPSPs observada no PD é tipicamente da ordem de 10-20\% da amplitude total entre o menor valor de Vm (aproximadamente na metade da fase de hiperpolarização) e o valor de Vm em que o primeiro spike do burst se inicia. Assim, nas preparações com lagosta mantivemos essa proporção e escolhemos fazer o mesmo nos experimentos com siri. Valores típicos de condutância sináptica $G_{-} \operatorname{syn}_{P D \rightarrow N A}$ estão no intervalo $[50 ; 200] \mathrm{mS} / \mathrm{cm}^{2}$.

\subsection{COnGElamento DAS DinÂMiCAS LENTAS}

Tendo em vista a necessidade de estudar o papel das dinâmicas lentas na codificação de informação em neurônios pilóricos, utilizamos um método 
proposto por B. Marin (Marin, 2009) para "dissecar" a dinâmica neural, i.e. estudar o comportamento do potencial de membrana ao desacoplar o efeito das variáveis dinâmicas rápidas das lentas. Temos chamado esse método de "conductance clamp" ou de "congelamento de condutâncias" (Viegas, 2011).

Em um experimento ideal, esse protocolo seria o equivalente a registrar um neurônio com diversas condutâncias iônicas em condições que pudéssemos fazer com que uma condutância específica X tivesse subunidades de ativação e inativação insensíveis a perturbações.

O que fazemos no experimento computacional é realizar uma simulação do modelo submetido a perturbações, mas nesse caso a série temporal das variáveis dinâmicas de ativação e inativação da condutância X são equivalentes ao caso não-perturbado.

Desse modo, obtemos séries temporais do potencial de membrana muito parecidas, diferentes apenas com relação à sensibilidade a perturbações: ao apresentar estímulos idênticos ao neurônio nos dois casos, no primeiro o comportamento do neurônio deve depender da resposta das condutâncias lentas e rápidas, já no segundo, o neurônio deve refletir apenas o efeito das perturbações nas condutâncias rápidas.

Esse protocolo foi implementado em simulações computacionais de um modelo de marcapasso (Turrigiano et al. 1995, Prinz et al., 2003) ajustado para exibir um comportamento observado experimentalmente para o PD com relação ao período, duração do burst e número de spikes por burst. Para isso, escolhemos uma condição inicial e valores de condutância máxima $\bar{g}$ de cada condutância $g$ do modelo, enquanto outros parâmetros $\left(\tau_{m}, \tau_{h}, m_{\infty}\right.$ e $h_{\infty}$ e potenciais de reversão, Ver apêndice) são mantidos como descrito no modelo original (Prinz et al., 2003). Primeiramente, realizamos uma simulação do modelo não perturbado e gravamos séries temporais longas do potencial de 
membrana e de com todas as variáveis dinâmicas $m_{i}$ e $h_{i}$ (Ver Apêndice) de cada condutância $i$ a ser congelada.

Em seguida, realizamos uma nova simulação em que o do modelo com todas as variáveis dinâmicas responde espontaneamente a trens de IPSPs provocados na fase hiperpolarizada. O número de IPSPs, suas amplitudes, variabilidade, duração e fase são escolhidos de modo a se assemelherarem aos provocados pelo LP observado experimentalmente. A seguir, é feita uma nova simulação submetendo o neurônio modelo a trens de IPSPs similares ao caso anterior, mas com condutâncias lentas congeladas, ou seja $m_{i}(t)$ e $h_{i}(t)$ correspondem às séries temporais previamente registradas.

As séries temporais são posteriormente analisadas da mesma forma que os dados experimentais: os bursts de estímulo correspondem aos trens de IPSPs e os bursts de resposta correspondem ao burst do neurônio modelo subsequente ao trem de estímulos.

Viegas desenvolveu um protocolo experimental de "conductance clamp", utilizando o dynamic clamp para simular uma condutância artificial de dinâmica lenta e uma sinapse artificial (similar à descrita na secção anterior). Esta técnica, descrita em sua dissertação de mestrado (Viegas, 2011), consiste em adicionar uma condutância artificial lenta $g_{\text {art }}$ do tipo Hodgkin-Huxley e aplicar uma corrente senoidal a uma célula do STG tônica ou quiescente, fazendo com que passe a exibir atividade em bursts. Aplica-se então o mesmo protocolo descrito anteriormente para simulações. Primeiramente são gravadas longas séries temporais dos valores das variáveis dinâmicas $m_{\text {art }}$ e $h_{\text {art }}$; em seguida, a célula é submetida a perturbações com trens de pulsos de corrente inibitória na fase hiperpolarizada, registrando-se uma longa série temporal de $V m$; logo depois, é realizado um novo ciclo de perturbação, mas neste caso as variáveis dinâmicas $m_{\text {art }}$ e $h_{\text {art }}$ da condutância artificial são substituídas pelos 
valores previamente gravados. 


\section{MÉTOdo DE ANÁLISE}

O desenvolvimento do método de análise baseado em teoria da informação teve como objetivo investigar duas questões centrais desse trabalho:

- se existe fluxo de informação de um neurônio pré para um pós sináptico.

- como a informação do estímulo é codificada na resposta.

Neste capítulo serão explicados a motivação, o método, suas aplicações e perspectivas.

\subsection{MotivaÇÃo e Desenvolvimento}

A Teoria da Informação (TI) (Shannon, 1948) tem sido largamente utilizada em neurociência nos últimos anos, principalmente por apresentar conceitos simples e poderosos que permitem inferir de modo direto a quantidade de informação de um sistema. Em nosso estudo, usamos medidas de entropia e informação mútua média para que, a partir de escolhas convenientes de conjuntos de estímulo e resposta, possamos inferir fluxo de informação entre neurônios.

Segundo a TI, a inferência de quantidade de informação presume o conhecimento do código, no entanto, no nosso caso, o código neural é desconhecido. Sabe-se que neurônios motores carregam informação de contração motora no número de spikes por burst e na fase de disparo, no entanto, não queremos assumir que esses neurônios expressem apenas esse tipo informação. Ou seja, ao 
invés de assumir que o código neural diz respeito apenas à contração motora, consideramos que um neurônio motor é também capaz de expressar outros tipos de informação.

De fato, estudos anteriores mostraram que neurônios pilóricos apresentam padrões de disparo intraburst que, apesar de irrelevantes para a contração muscular, são sensíveis à conectividade da rede e a neuromodulação(Szücs et al., 2003, 2005; Morris e Hooper, 1997).

Neste trabalho queremos dar um passo adiante, investigando se esses neurônios expressam informação não só no número de spikes ou nas relações entre um ISI e o ISI anterior, mas também em outros tipos de padrões de disparo ainda mais refinados.

Mas como buscar informação em padrões de disparo desconhecidos? Objetivamente, buscamos inferir quais os padrões de disparo intraburst têm maior capacidade de expressar informação, que em teoria da informação, é medida pela entropia.

A partir daí, buscamos se tais padrões de máxima entropia de um determinado neurônio podem carregar informação a respeito do funcionamento de outro neurônio através do cálculo da informação mútua.

Essa estratégia permite inferir o fluxo de informação do neurônio pré para o pós sináptico fazendo o menor número possível de hipóteses a respeito do código ("o quê"), ou seja, sem assumir que a informação é codificada em padrões pré determinados por observações precedentes à análise (como tipicamente se faz em análises informacionais de dados sensoriais), e além disso, assumindo que ela pode ser codificada a qualquer momento ("quando"). 


\subsection{TEORIA DA INFORMAÇÃO}

Seja uma variável aleatória discreta $X$ para a qual $\mathbb{X}$ é o conjunto de os eventos possíveis $\left\{x_{1}, x_{2}, \ldots, x_{n}\right\}$ e $p(x)$ é a probabilidade associada a um evento $x \in \mathbb{X}$. O conteúdo informacional de uma ocorrência (em bits) é (Shannon, 1948)

$$
h(x)=\log _{2} \frac{1}{p(x)}
$$

e a entropia (também em bits) é definida como

$$
H(X)=-\sum_{x \in \mathbb{X}} p(x) \log _{2} p(x)
$$

que é a média das informações de todos os eventos no conjunto $\mathbb{X}$ e é a máxima informação possível de ser extraída desse conjunto. Pode ser também entendida como uma medida da variabilidade: a entropia é máxima quando a distribuição de probabilidades é uniforme.

A informação mútua média (ou informação mútua) entre duas variáveis aleatórias discretas $S$ e $R$ (que podem representar a atividade de um neurônio de estímulo e de resposta respectivamente) é o principal conceito utilizado em nossa análise e pode ser escrita e interpretada de muitas maneiras (McKay, 2003). Segundo a definição,

$$
\operatorname{IMM}(S ; R) \equiv \sum_{s \in \mathbb{S}} \sum_{r \in \mathbb{R}} p(s, r) \log _{2}\left(\frac{p(s, r)}{p(s) p(r)}\right)
$$

é uma grandeza não-negativa. O uso da expressão "média"se justifica pois a IMM de fato corresponde à média do conteúdo informacional das ocorrências conjuntas de $r$ e $s$ ponderada pelas probabilidades conjuntas. 
A IMM diz o quanto a variabilidade do conjunto de respostas é relacionada com a variabilidade do conjunto de estímulos. Também pode ser escrita como a divergência de Kulbach-Leibler entre o produto das distribuições de probabilidades marginais $p(s)$ e $p(r)$ e a distribuição de probabilidades conjuntas $p(r, s)$ :

$$
I M M(S ; R)=D_{K L}(p(s, r) \| p(s) p(r)) .
$$

Essa relação pode ser interpretada como uma medida de quão "distantes" as variáveis $R$ e $S$ estão de serem independentes uma da outra.

Para ganhar ainda um pouco mais de intuição, podemos escrever a IMM em termos da entropia conjunta

$$
H(S, R)=-\sum_{s \in \mathbb{S}} \sum_{r \in \mathbb{R}} p(s, r) \log _{2}(p(s, r))
$$

e da entropia condicional

$$
H(S \mid R)=-\sum_{s \in \mathbb{S}} \sum_{r \in \mathbb{R}} p(s, r) \log _{2}(p(s \mid r))
$$

a qual mede a incerteza média que resta a respeito de $R$ uma vez que $S$ é conhecido. Pelas equações 3.3, 3.6 e 3.7 temos que

$$
\begin{array}{r}
I M M(S ; R)=H(R)+H(S)-H(R, S) \\
=H(S)-H(S \mid R) \\
=H(R)-H(R \mid S)
\end{array}
$$

o que implica que

- IMM é simétrica com relação a $S$ e $R$.

- IMM é máxima se $S=R$. 


\section{$H(S, R)$}

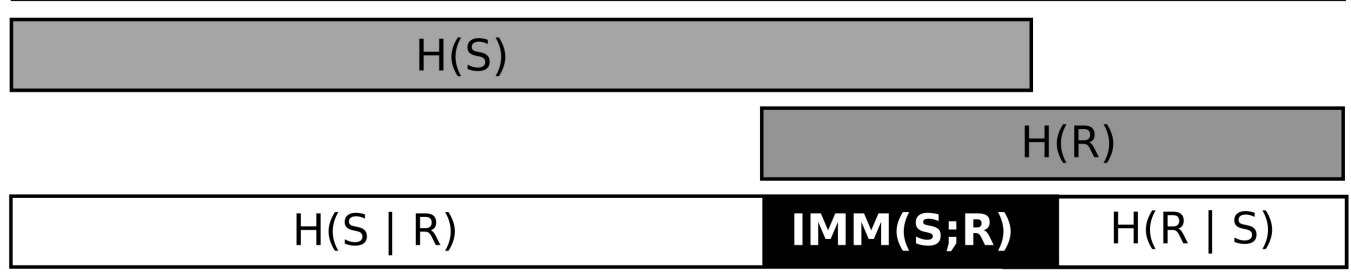

Fig. 3.1 - Relação entre entropias conjuntas $H(S, R)$, entropias marginais $H(S)$ e $H(R)$, entropias condicionais $H(S \mid R)$ e $H(R \mid S)$ e informação mútua média $\operatorname{IMM}(S ; R)$ para as variáveis aleatórias $S$ e $R$ (estímulo e resposta, respectivamente). Para essa representação, o estímulo apresenta conteúdo informacional maior que a resposta. A IMM relativa ao estímulo $(I M M(S ; R) / H(S))$ é pequena, o que significa que apenas uma pequena parte do estímulo está codificado na resposta. Já a IMM relativa à resposta $(I M M(S ; R) / H(R))$ está em torno de 0,5 , assim, metade dos eventos de resposta podem ser preditos uma vez que se conhecem os estímulos.

- Como a entropia condicional é sempre positiva, a IMM nunca é maior que o valor da menor entropia.

- Se entendermos que $H(R)$ indica a ignorância sobre $R$ (ou o quanto $R$ é imprevisível), então pode-se dizer que a IMM mede a "diminuição de ignorância"a respeito de $R$ uma vez que $S$ é conhecido (e vice-versa).

As relações entre IMM, entropias marginal, conjunta e condicional estão sumarizadas na Fig. 3.1.

Ao aplicar esses conceitos à análise de dados, muitas vezes o valor absoluto de IMM em bits não tem muito significado. Para termos uma interpretação mais útil, é necessário comparar os valores da IMM com as entropias das variáveis observadas. Neste trabalho, lidamos como o conceito de informação mútua média relativa $\left(\mathrm{IMM}_{r e l}\right)$ que permite comparar a informação mútua à 
capacidade informacional de $S$ e $R$ individualmente.

$$
\begin{aligned}
& I M M_{r e l, S}=\frac{I M M(S ; R)}{H(S)} \\
& I M M_{r e l, R}=\frac{I M M(S ; R)}{H(R)}
\end{aligned}
$$

A $I M M_{r e l, S}\left(\right.$ ou $\left.I M M_{r e l, R}\right)$ dá quanto da capacidade informacional total de $S$ (ou $R$ ) é dedicada a codificar $R$ (ou $S$ ), ou ainda, quanto do sinal de $S(R)$ pode ser predito uma vez que $R$ (ou $S$ ) é conhecido. Em nossa análise, costumamos interpretar $I M M_{r e l}$ à luz da relação causal entre estímulo e resposta: $I M M_{r e l, S}$ dá qual a fração do estímulo é expressa na resposta e $I M M_{r e l, R}$ dá quanto o neurônio de resposta está dedicado a codificar o estímulo.

Essas medidas de "aproveitamento" de informação facilitam a comparação entre resultados para diferentes sistemas o que é muito útil à nossa análise pois, para a maioria dos casos, a entropia varia consideravelmente ao longo do burst. Na maior parte desse manuscrito, $I M M_{\text {rel }}$ se refere a $I M M(S ; R) / H(R)$, a não ser que seja especificado o contrário.

\subsection{CorreÇÃo DE H PARA AMOSTRAGEM Finita}

A formulação clássica desta teoria pressupõe um universo discreto de eventos possíveis cujas probabilidades são completamente conhecidas. Do ponto de vista experimental, é impossível determinar o valor exato da probabilidade de um evento devido à finitude da série temporal: o valor da probabilidade estimada será tão mais preciso quanto maior o número de ocorrências deste evento. Para levar em conta essa limitação, podemos acrescentar correções à expressão da entropia que levem em conta o fato de a amostragem de eventos ser limitada. 
Roulston (Roulston, 1999) propõe um método simples de estimar o erro aleatório e sistemático da entropia observada de uma série de valores. Seja um conjunto de séries com $N$ valores cada série. Cada valor da série pode ser atribuído a um de $B$ estados possíveis, chamado de $i(i=1,2 \ldots, B)$. Digamos que a probabilidade de um valor corresponder a um estado $i$ é $p_{i}$ e o número de valores observados no estado $i$ é $n_{i}$. Considerando cada membro da série como uma "tentativa", $n_{i}$ deve ser uma variável aleatória binomial (a probabilidade do valor estar no $i$-ésimo estado é $p_{i}$ e de não estar no $i$-ésimo estado é $\left(1-p_{i}\right)$ ). A entropia real é

$$
H_{\infty}=-\sum_{i=1}^{B} p_{i} \log p_{i}
$$

enquanto que a entropia observada é

$$
H_{o b s}=-\sum_{i=1}^{B} q_{i} \log q_{i}
$$

onde $q_{i}=n_{i} / N$. Introduzimos uma variável $\varepsilon_{i}=\left(q_{i}-p_{i}\right) / p_{i}$ cujo valor esperado é zero. A partir das propriedades da distribuição binomial, fazendo uma mudança de variáveis na eq. 3.13, expandindo a expressão em Taylor com relação a $\varepsilon_{i}$ e desprezando termos de terceira ordem e superiores obtemos que

$$
H_{\infty} \approx H_{o b s}+\frac{B^{*}-1}{2 N} \pm \sigma_{H}
$$

onde $B^{*}$ é o número de eventos em que o número de estados de ocorrência é não-nula e $\sigma_{H}$ é o desvio padrão associado à entropia:

$$
\sigma_{H}=\sqrt{\frac{1}{N} \sum_{k=1}^{B}\left(\ln q_{k}+H_{o b s}\right)^{2} q_{k}\left(1-q_{k}\right)}
$$


De 3.8 e 3.14 temos que a expressão corrigida da Informação Mútua Média é

$$
I M M_{\infty} \approx I M M_{o b s}+\frac{B_{S}^{*}+B_{R}^{*}-B_{S, R}^{*}-1}{2 N} \pm \sigma_{I M M},
$$

e o desvio padrão

$$
\sigma_{I M M}=\sqrt{\frac{1}{N} \sum_{k=1}^{B_{S}} \sum_{l=1}^{B_{R}}\left(\ln q_{k}^{S}+\ln q_{l}^{R}+\ln q_{k, l}+I M M_{o b s}\right)^{2} q_{k, l}\left(1-q_{k, l}\right)},
$$

em que $q^{S}$ e $q^{R}$ são as distribuições observadas de $\mathrm{S}$ e $\mathrm{R}$ respectivamente, isto é,

$$
q_{k}^{S}=\sum_{j=1}^{B_{R}} q_{k j}, q_{l}^{R}=\sum_{i=1}^{B_{S}} q_{i l}
$$

onde $B_{S}^{*}, B_{R}^{*}, B_{R, S}^{*}$ é o número de eventos de ocorrência não-nula para as distribuições marginais de $S$, de $R$ e da distribuição conjunta de $(R, S)$, respectivamente.

\subsection{Algoritmo}

\subsubsection{DefiniÇÃo Dos CONJUntos De EStímulo E RESPOSta}

A informação mútua média é uma medida simétrica, ou seja, não é possível discernir estímulo de resposta a posteriori, assim, a relação de causalidade deve ser inferida pela relação temporal entre os sinais. Portanto, é necessário conhecer a priori qual o sinal de estímulos e qual o de resposta. Os neurônios do CPG pilórico têm atividade em burst e tipicamente operam em antifase. Por isso, pode-se definir com clareza o que é o sinal de estímulo, que consiste no trem de disparos (burst) do neurônio pré sináptico (N1), e o sinal de resposta, que corresponde ao trem de disparos do neurônio pós sináptico (N2) subsequente ao estímulo. A partir da série temporal integral do registro de $V m$ de 
ambos neurônios, extraímos todos os pares de bursts de estímulo e resposta.

\subsubsection{DetecÇÃo DE SPIKES E DigitalizaÇÃo}

O potencial de membrana é gravado integralmente de acordo com o registro intracelular (Fig. 2.4). No entanto, ao invés de considerar o registro contínuo do potencial de membrana, trabalhamos apenas com a série temporal de instantes de disparo.

A análise é feita a partir de séries temporais de registro de $V m$ de ambos neurônios N1 e N2 que devem ser suficientemente longas para garantir boa estatística e estacionárias com respeito a parâmetros fisiológicos importantes, como o número de spikes por burst, período pilórico, duração dos bursts e fase que devem ter médias e desvios padrão constantes ao longo da série toda.

Primeiramente os dados são tratados usando um algoritmo simples que detecta todos os spikes de cada neurônio para a série temporal inteira. Neurônios pilóricos têm tipicamente spikes bem definidos que podem ser identificados até mesmo visualmente. No caso do sinal extracelular, pode-se definir o instante do potencial de ação como o momento em que o potencial registrado supera um determinado limiar. Para o sinal intracelular, no entanto, não é possível detectar spikes por um limiar do potencial de membrana por causa das oscilações lentas da envoltória do potencial no plateau. Nesse caso, é necessário olhar a série da derivada de $V m$ : uma vez que $d V m$ supera um determinado limiar, o instante de disparo é determinado pelo momento em que segunda derivada de $V m$ tem um valor positivo seguido de um negativo.

A partir daí, o programa de análise passa a lidar apenas com a série de instantes de disparo de cada neurônio ao invés da série temporal de $V m$. A ocorrência de um burst é identificada como qualquer sequência de spikes que segue um intervalo entre spikes suficientemente grande ( 0,2 s é um valor 
razoável para a maioria das séries). Bursts podem ser detectados facilmente pois os neurônios trabalham em antifase, o ritmo pilórico é bem definido e além disso a escala de tempo dos intervalos entre spikes é da ordem de 10 vezes menor que a de intervalos entre bursts.

Depois de detectados todos os bursts, o programa separa todos os pares de burst de N1 seguido de um burst de N2 - aos quais chamamos de bursts conjuntos - impondo uma relação de precedência que garante que N1 seja o neurônio de estímulo e N2 o de resposta. O programa detecta um burst conjunto sempre que o início do burst de N1 preceder o início do burst de N2 e o final do burst de N1 preceder o final do burst de N2. Desse modo, podemos associar a medida de informação mútua entre os neurônios a um fluxo de informação de N1 para N2.

Agora, para que seja possível comparar todos os pares de bursts entre si, é necessário impor alguma referência de tempo para cada par de bursts. Por exemplo, na análise dos sinais de LP e PD, o início do burst do PD parece uma escolha de referência de tempo natural, pois, em sendo o marcapasso, dita o momento que outros neurônios são permitidos disparar (essa no entanto não é a única escolha conveniente de referência e esse assunto será revisitado mais adiante). A Fig. 3.2 ilustra a escolha do primeiro spike de N2 como referência de tempo para esse burst conjunto de N1 seguido de N2. Após escolher a referência de tempo comum, é necessário fazer uma estatística de todos os bursts para definir o início e a duração de um burst de N1 ou N2. Pelo mesmo motivo, a distribuição de spikes do LP é bem larga. Para definir o início $s$ e o final $e$ dos bursts, o programa descarta $0,2 \%$ dos spikes nos extremos das distribuições.

Uma vez obtidos os instantes de disparo relativos à referência de tempo para cada burst conjunto, pode-se então digitalizar a série. Para cada burst de 
estímulo e resposta é associada uma string cujo tamanho representa a duração total do burst. A cada bit da string é atribuído o valor 1 representando a ocorrência de um spike ou 0 para a ausência de spike. O intervalo de tempo que cada bit representa (ou seja, o bin) deve ser pequeno o bastante para melhor resolução da análise. Tipicamente trabalhamos com 5 a 10 vezes o intervalo de aquisição. Por exemplo, se a taxa de amostragem é $10 \mathrm{kHz}$ e a duração do burst é de 400 ms então, escolhendo o tamanho do bin como sendo 10 vezes o intervalo de aquisição, a string terá 4000 bits. É importante notar que o tamanho da string deve variar de acordo com a duração do burst, mas, uma vez que a duração é definida a partir da estatística da série, todos os bursts de N1 devem estar representados por strings do mesmo tamanho (o mesmo vale para os bursts de N2).

\subsubsection{MAXIMIZAÇÃO DA ENTROPIA}

Como partimos do pressuposto que o código neural é desconhecido, também consideramos que quaisquer conjuntos de padrões de spikes intraburst (PSIBs) em qualquer parte do burst podem, em princípio, expressar informação. Por isso, o programa faz medidas de informação ao longo de todo o burst de estímulo e todo o burst de resposta.

Primeiramente associamos ponteiros $i$ e $j$ que apontam para o $i$-ésimo bit da string de estímulo e para o $j$-ésimo bit da string de resposta respectivamente. A posição do ponteiro varia do começo ao fim da string, de modo a varrer todos trechos do burst que a string representa.

Em seguida são escolhidas palavras de $n$ bits a partir da posição de cada ponteiro. O número de bits é constante para toda análise e neste trabalho a maioria das análises foi feita com $n=5$ (o critério de escolha de $n$ será explicado mais adiante). 
Para cada par de ponteiros $(i, j)$, dois conjuntos de palavras de 5 bits são escolhidos: um conjunto de estímulos $S_{i}^{1}=\left\{s_{i, 1}^{1}, s_{i, 2}^{1}, \ldots, s_{i, N}^{1}\right\}$ e um conjunto de resposta $R_{i}^{1}=\left\{r_{i, 1}^{1}, r_{i, 2}^{1}, \ldots, r_{i, N}^{1}\right\}$ onde $N$ é o número total de bursts na série temporal. A palavra $s_{i, 1}^{1}$ corresponde a uma sequencia de $n$ bits começando no $i$-ésimo bit da string do primeiro burst de N1. Analogamente, a palavra seguinte $s_{i, 2}^{1}$ também tem $n$ bits mas dessa vez começa no $i$-ésimo bit da string que corresponde ao segundo burst de N1 e assim por diante até o último burst. A mesma lógica se aplica o conjunto de resposta Fig. 3.2.

O passo seguinte consiste em usar o parâmetro $k$, um fator multiplicador que permite a escolha de palavras de mesmo número de bits $n$ a quais, desta vez, apresentam um bin $B$ que é $k$ vezes maior que o bin $b$ da string inicial. A vantagem do uso desse fator multiplicativo é permitir a escolha de palavras que representam um trecho maior do burst. Por exemplo para $k=1$ a palavra $s_{i, 1}^{1}$ representa um trecho do burst de duração $n b$, mas para $k=2$ a palavra $s_{i, 1}^{2}$ representa um trecho maior de $2 n b$. Para cada bit da palavra $s_{i, 1}^{k}$ é atribuído o valor 1 ou 0 de acordo com a ocorrência ou não de (pelo menos) um spike dentro dos $n$ intervalos de tempo $b k$ seguintes à posição do ponteiro $i$. Esse procedimento é repetido para todos os valores possíveis de $k$ gerando um conjunto de estímulos $S_{i}^{k}=\left\{s_{i, 1}^{k}, s_{i, 2}^{k}, \ldots, s_{i, N}^{k}\right\}$ para cada $k$. Analogamente, para um determinado ponteiro $j$ da string se resposta, é computado um conjunto de resposta $R_{i}^{k}=\left\{r_{i, 1}^{k}, r_{i, 2}^{k}, \ldots, r_{i, N}^{k}\right\}$ para todos os valores de $k$ possíveis.

A partir daí, é calculada a entropia do conjunto de estímulos $H\left(S_{i}^{k}\right)$ para cada $k$ baseada na probabilidade de ocorrência de cada palavra $s_{i, m}^{k}$ para $1 \leq$ $m \leq N$ sendo que $p\left(s_{i, m}^{k}\right)$ é igual ao número de ocorrências da palavra dividido por $N$. Da mesma forma, também se calcula a entropia do conjunto de resposta $H\left(R_{i}^{k}\right)$.

O passo seguinte consiste em encontrar os conjuntos de máxima entropia 
a serem usados no cálculo da informação mútua média (IMM). Para o par de ponteiros $(i, j)$, se $H\left(S_{i}^{K}\right)>H\left(S_{i}^{k}\right)$ para qualquer $k \in K$, e $H\left(R_{i}^{K^{\prime}}\right)>$ $H\left(R_{i}^{k}\right)$ para qualquer $k \in K^{\prime}$, então se calcula $\operatorname{IMM}\left(S_{i}^{K} ; R_{i}^{K^{\prime}}\right)$ com base nas probabilidades conjuntas de ocorrência de cada par de palavras $p\left(s_{i, m}^{K}, r_{j, m}^{K^{\prime}}\right)$ para todos os bursts $1 \leq m \leq N$. Vale notar que para $k$ 's pequenos, as palavras representam um trecho muito pequeno do burst e consequentemente a probabilidade de ocorrência de spikes é também pequena, consequentemente, as palavras terão bits predominantemente de valor 0 . $\mathrm{O}$ mesmo acontece para valores muito grandes de $k$ para os quais as palavras devem representar um trecho muito próximo da duração total do burst, ou seja, os bits das palavras serão predominantemente 1 . Assim, tanto para $k$ muito pequeno ou muito grande, a entropia deve ser pequena - a maximização da entropia deve se dar para um valor intermediário de $k$ que apresente palavras de maior variabilidade possível. Esse processo de escolha do $k$ para o qual o conjunto tem máxima entropia é ilustrado na Fig. 3.2 para $n=5$.

\subsubsection{CÁlculo da InformaÇÃo Mútua MÉdia}

O cálculo de IMM é feito para todos os pares de ponteiros $(i, j)$ possíveis gerando uma matriz de valores para todos os trechos de estímulo com todos os trechos de resposta (Fig.3.3)

O procedimento de analise para LP/ivn é um pouco diferente pois o ivn tem sinal tônico e não em bursts com o PD. Primeiro, todos os spikes do ivn e do LP são identificados. O primeiro spike do LP é usado como referência temporal para construção dos conjuntos de estímulo, que consiste em um burst do LP, e de resposta, a qual consiste no trecho do sinal do ivn de -2 a 2 s com respeito à referência temporal. Desse modo, para discernir entre estímulo ou resposta deve-se observar a relação de precedência entre os dois sinais. Por exemplo, 


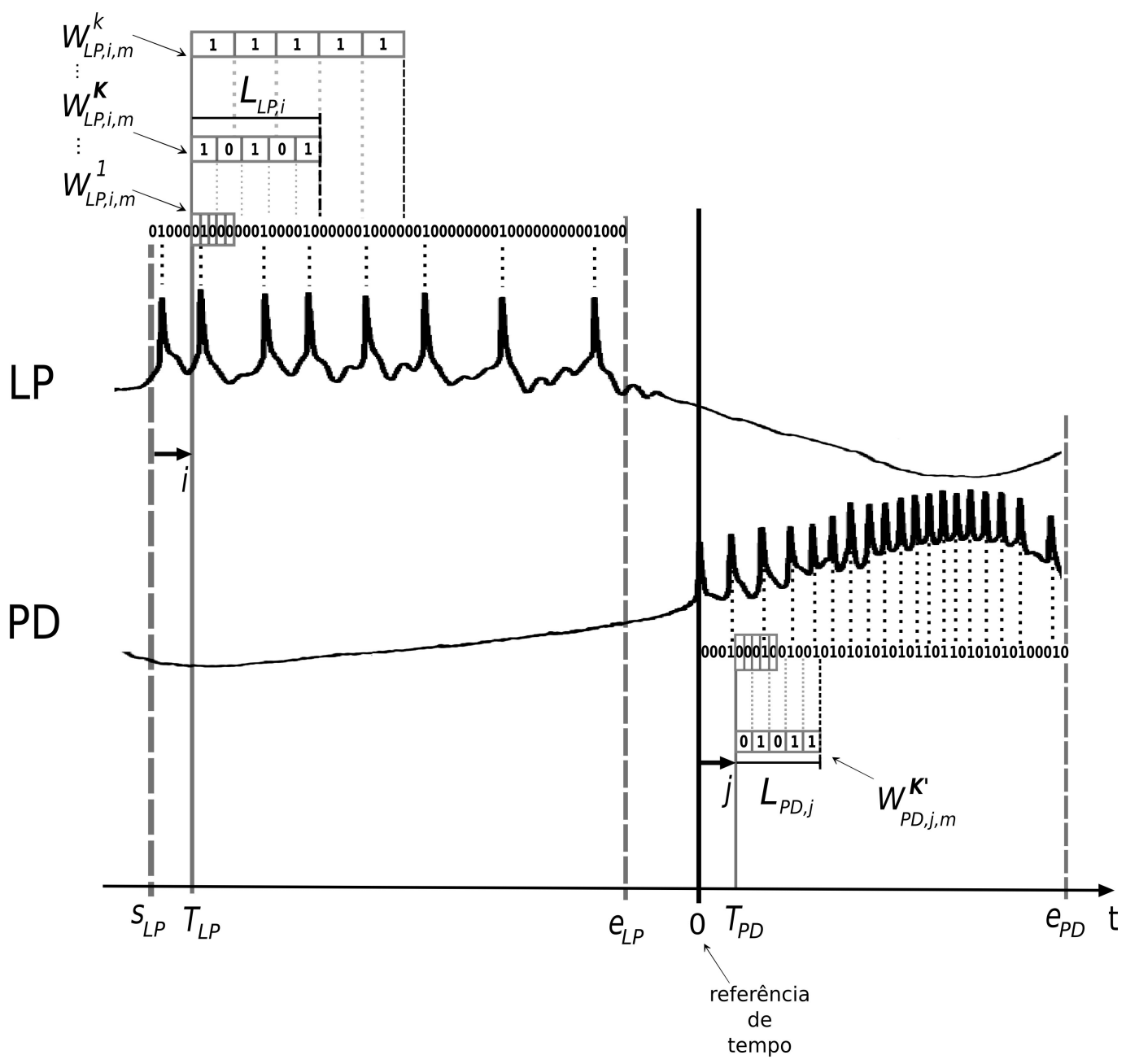

Fig. 3.2 - Ilustração do m-ésimo burst de estímulo (LP) seguido do burst de resposta $(P D)$. Séries temporais de tempos de disparo são transformadas em um vetor binário de zeros e uns de acordo com a ocorrência ou ausência de spikes. A referência de tempo (linha vertical) é colocada no primeiro spike do burst de resposta para cada par de bursts. $s_{L P}$ e $e_{L P}$ indicam o início e fim do burst do $L P$ respectivamente $e_{P D}$ o fim do burst do PD. Palavras de 5 bits de estímulo ou resposta são formadas começando no bit apontado pelos índices $i$ ou j. A primeira palavra de estímulo $W_{L P, i, m}$ é composta pela sequência de 5 bits começando na posição i. O parametro $k$ é usado para selecionar palavras de bins maiores $\left(W_{L P, i, m}^{1}, W_{L P, i, m}^{2}, \ldots, W_{L P, i, m}^{K}, \ldots\right)$. Para $k$ muito pequeno ou muito grande existe a predominância de 1 s ou 0s (entropia baixa). A palavra que maximiza a entropia nesse caso é $k=K . L_{L P, i}$ ou $L_{P D, j}$ é a duração da palavra de estímulo ou resposta que mede qual o trecho do burst que o conjunto de estímulo e resposta representam. 


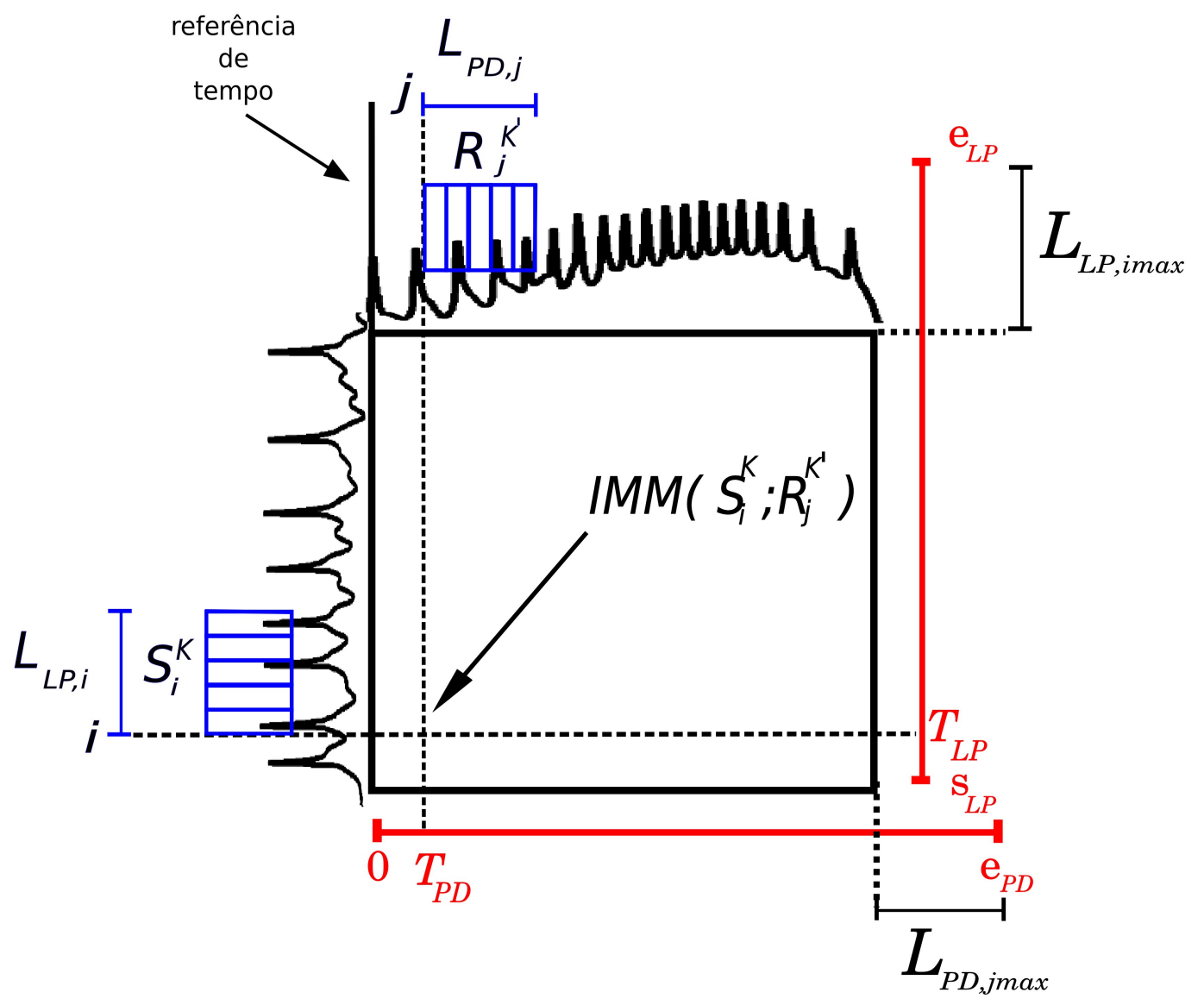

Fig. 3.3 - IMM $\left(S_{i}, R_{j}\right)$ (seta), valores de IMM computados para todos os pares de ponteiros possíveis $(i, j)$. Para o ponteiro $i(j)$, o parâmetro $K\left(K^{\prime}\right)$ determina o tamanho das palavras do conjunto $S_{i}^{K}\left(R_{j}^{K^{\prime}}\right)$ de máxima entropia, cujas palavras tem duração $L_{L P, i}\left(L_{P D, j}\right)$. $s_{L P}$ e $e_{L P}$ indicam o início e fim do burst do $L P$ respectivamente $e_{P D}$ o fim do burst do $P D$. Os índices no tempo $t_{L P} e$ $t_{L P}$ correspondem à posição do ponteiro $i(j)$ convertido em diferença de tempo com relação à referência. Traços do sinal intracelular na vertical e horizontal ilustram posições dos spikes ao longo do burst para um par de bursts. As caixas azuis representam duas palavras que pertencem a $S_{i}^{K}$ e $R_{j}^{K^{\prime}} \cdot i_{\max }$ e $j_{\max }$ são os valores dos ponteiros $i$ e $j$ que correspondem à última porção do burst de estímulo e de reposta aos quais estão associados $L_{L P, \text { imax }}$ e $L_{P D, j m a x}$ (índices no tempo $t_{L P}$ e $t_{P D}$ devem variar dentro do intervalo $\left[s_{L P}: e_{L P}-L_{L P, i m a x}\right]$ and [0: $\left.e_{P D}-L_{P D, j \max }\right]$ respectivamente) 
quando ocorre um pico de IMM na metade do gráfico em que o sinal do ivn é positivo, então sabemos que LP é o sinal de estímulo e ivn o de resposta (o inverso é também verdadeiro). O procedimento de escolha e palavras e cálculo de entropias e IMM é equivalente ao descrito acima.

\subsubsection{ApresentaÇÃo Dos Resultados}

Para facilitar a interpretação dos resultados, preferimos sair do "domínio dos bits" para o domínio de tempo. Assim, ao invés de apresentar os eixos dos gráficos com relação aos ponteiros, usamos uma escala mais intuitiva de "índices no tempo" $T_{S}\left(T_{L P}\right)$ e $T_{R}\left(T_{P D}\right)$ que são proporcionais à posição dos ponteiros $i$ e $j$, indicando o início do trecho do burst que o conjunto de estímulos/resposta representa (Fig. 3.3). Além disso, ao invés de lidar com o conceito de tamanho do bin $b$, preferimos usar uma expressão mais conveniente em termos de "janela" (ou "tamanho da palavra") $L$, que corresponde ao trecho do burst representado pela palavra. O tamanho da janela é $n$ vezes o valor do bin. Por exemplo, para o ponteiro $i$, o conjunto de estímulos que maximiza a entropia é $S_{i}^{K}$ cujas palavras têm bin $B_{i}=K b$, então $L_{S, i}=n B_{i}$. A Fig. 3.3 ilustra a equivalência dos ponteiros e bins com índices no tempo e janelas.

\subsubsection{EsCOLHA DO NÚMERO DE BITS}

Todas as análises nesse trabalho foram feitas com $n=5$ escolhido de acordo com dois critérios: um diz respeito à limitação estatística por causa da finitude da série temporal e outro que define o melhor número de bits para caracterizar o sistema.

Usando $n$ bits, a matriz de probabilidades conjuntas usada para computar IMM deve ter $2^{2 n}$ elementos. Uma vez que não queremos fazer nenhuma 
hipótese a respeito do código temos que supor que, no pior dos cenários, pode não haver correlação nenhuma entre estímulo e resposta e que as distribuições de probabilidades marginais possam ser uniformes. Nesse caso, seria necessário registrar um número de bursts mínimo para que a matriz de probabilidades conjuntas de $2^{2 n}$ elementos seja totalmente populada.

Na prática, sabemos que as matrizes de probabilidades conjuntas sempre têm muitos elementos nulos para $n$ suficientemente grande (tipicamente para $n>3)$. Então, para uma série temporal de 30 min com o ritmo pilórico a $1 \mathrm{~Hz}$ (1800 bursts no total), é bastante razoável usar $n=5$ na análise. Assim, mesmo sabendo que o tamanho da matriz cresce vertiginosamente com o número de bits, como a matriz é sempre muito esparsa ainda seria possível usar um $n$ razoavelmente grande (9 ou 10) na análise.

Outro critério que usamos foi o número de bits que maximiza o ganho de entropia no tempo. Para cada neurônio, variando $n$ de 2 a 12 bits calculamos $d_{i, n}=H_{i, n} / L_{i, n}=H_{i, n} /\left(n . B_{i, n}\right)$ para cada ponteiro $i$ variando ao longo do burst. Essa grandeza mede a taxa com que o neurônio produz informação para determinado $n$.

Por exemplo, para uma variável discreta aleatória de distribuição uniforme, digamos que o bin que maximiza a entropia do sistema para $n=1$ seja $B$ para o ponteiro $i$. Como a probabilidade do próximo bin de tamanho $B$ apresentar um valor 0 ou 1 é $p_{1}=p_{0}=0,5$, então o bin que maximiza a entropia do sistema para $n=2,3,4 \ldots$ também deve ser $B$. Como o limite superior da entropia é $H_{n}=n$, então $d_{n} \leq 1 / B, d_{n}$ é constante para qualquer $n$. Assim, é impossível definir qual o melhor valor de $n$, pois quanto maior a janela, maior o $n$ necessário para descrever o sistema.

Se, por outro lado, o $d_{i, n}$ apresentar um valor máximo para $n=m$, significa que palavras de $m$ bits apresentam um conteúdo informacional proporcional- 
mente maior do que palavras de $m>n$ bits.

\subsection{Controle estatístico}

Além de computar entropia e informação mútua média, nós também aplicamos o método de dados surrogados (do inglês, surrogates Theiler et al.,1992), baseado em embaralhar aleatoriamente os conjuntos de estímulo dos pares de estímulo/resposta. A IMM do conjunto surrogado $I M M_{\text {sur }}\left(A_{i}^{K}, R_{j}^{K^{\prime}}\right)$ é computada usando as probabilidades conjuntas $p\left(s_{i, a}^{K}, r_{j, m}^{K^{\prime}}\right)$ onde a é sorteado aleatoriamente entre 1 e $N$.

Nessa análise, a relação de causalidade (a hipótese nula a ser testada) é imposta quando definimos que, para todos os pares de estímulo/resposta, o burst de estímulo necessariamente precede o de resposta. Ao se embaralhar os estímulos com relação às respostas, as distribuições marginais de probabilidades tanto do estímulo quanto da resposta se mantém, mas a matriz de probabilidades conjuntas já não é a mesma (deve ficar mais "difusa"). Dessa forma, a relação de causalidade é rompida e a IMM que resta pode ser efeito da limitação na amostragem. Para comparar o valor da IMM para a série original $I M M_{o r}$ e para os dados surrogados $I M M_{\text {surr }}$ utilizamos a medida de significância sig $=\left(I M M_{o r}-\left\langle I M M_{\text {surr }}\right\rangle\right) / \sigma_{\text {surr }}$. Como não podemos fazer nenhuma hipótese a respeito da distribuição de probabilidades real, apenas adotamos um valor arbitrário sig $>7$ (bastante grande se comparado com o valor adotado para outros testes estatísticos comuns) para definir se o resultado é significante.

Além disso, existe um erro intrínseco à estimativa da probabilidade de um evento $x$ medida como $q_{x}=n_{x} / N$, onde $n_{x}$ é o número de vezes que $x$ é observado e $N$ é o tamanho da amostragem. Utilizamos as correções propostas 
por Roulston (Roulston, 1999) que levam em conta o efeito da limitação da amostragem nas estimativas de entropia e IMM (eqs. 3.14 a 3.17 ).

Assim, a correção da IMM proposta por Rouslton provê uma estimativa a priori dos erros sistemático e aleatório da IMM, enquanto que o cálculo da IMM para dados surrogados é uma estimativa a posteriori.

\subsection{Discussão DO MÉTOdO}

\subsubsection{Matriz DE PRobabilidades CONJUntas E CORREÇÕES}

O método de correção da entropia observada (eq. 3.14) proposto por Roulston é de certa forma intuitivo, mas apresenta limitações, especialmente no que diz respeito à correção da IMM (eq. 3.16). A estimativa de $I M M_{\infty}$ a partir da entropia observada $I M M_{o b s}$ apresenta um termo de correção que pode ser positivo ou negativo. Segundo a eq. 3.16, temos que quando $\operatorname{IM} M(S ; R)_{o b s}=$ $H(S)_{o b s}=H(R)_{o b s}$ o termo de correção é maximo $\left(B_{S}^{*}-1\right) / 2 N$ que é igual ao termo de correção para a entropia na eq. 3.14. Assim, nesse caso a $I M M_{o b s}$ é tão subestimada quanto a entropia. Por outro lado, a IMM sempre será superestimada quando $B_{S}^{*}+B_{R}^{*}<B_{S, R}^{*}+1$, e para enter melhor essa relação temos que pensar na estrutura das matrizes de probabilidades conjuntas.

Medidas experimentais estão sempre acompanhadas de ruído, portanto, mesmo em um sistema real em que $S$ seja completamente codificado em $R$, a matriz de probabilidades conjuntas obtida $\left(q_{i, j}\right)$ deve tipicamente apresentar mais elementos não nulos do que se as probabilidades conjuntas reais $\left(p_{i, j}\right)$ fossem conhecidas. Como o método de Roulston leva em conta apenas o número de elementos não-nulos da matriz, o termo de correção para a IMM deve ser o mesmo para duas uma matrizes de $B$ elementos não nulos cada, ainda que 
uma apresente alguma estrutura $(I M M>0)$ e a outra tenha todas as probabilidades conjuntas não nulas idênticas com valor $1 / B(I M M=0)$. Assim, a correção de Roulston pode ser excessivamente rigorosa pois considera apenas o quanto e não como a matriz é populada.

Existem outras propostas de correção da entropia (Panzeri e Treves, 1996; Paninski, 2003), no entanto, todas elas apresentam suas próprias limitações e ainda não há um consenso na comunidade científica sobre qual o melhor método geral. Um dos aspectos que diferencia nosso trabalho da maioria que apresenta estimativas de IMM para medidas experimentais de sinais neurais é que nosso interesse principal não é obter uma medida precisa de IMM, e sim em investigar se existe codificação de informação e como (em que parte do burst, em quais neurônios, quais padrões são importantes, etc...). Desse modo, optamos por apresentar resultados que primam por evidenciar a existência de IMM em detrimento de seu valor preciso e, por esse motivo, aplicamos o método de correção de Roulston que parece rigoroso, tanto quanto ao termo de correção quanto ao desvio padrão previsto para $I M M_{\infty}$ (eq. 3.17). Para todas as nossas medidas os termos de correção são (um pouco) negativos, e acreditamos que a $I M M_{\infty}$ é, na verdade, sempre um pouco subestimada por conta do ruído intrínseco associado à medida experimental.

\subsubsection{VAntagens, LimitaÇÕes e Potencial Do MÉtodo}

O método que desenvolvemos tem se mostrado útil e consistente até o momento no entanto, apresenta limitações mesmo com todo o cuidado tomado para torná-lo a mais geral possível. Algumas fragilidades do método são:

- depende de medidas longas e estacionárias,

- número de bits $n$ usado na análise deve ser definido à priori, 
- tipo de distribuição de probabilidades é desconhecido, o que dificulta a aplicação de testes estatísticos ou previsão de valores teóricos.

O problema da estacionariedade não é exatamente uma limitação deste método em particular, mas também de muitos outros métodos de análise de sinais neurais experimentais. No nosso caso, trabalhamos com séries temporais estacionárias com relação a parâmetros fisiológicos, e temos acesso experimental a um sistema que é capaz de manter um ritmo robusto por muitas horas. Em outras aplicações do método, no entanto, é necessário adotar critérios de estacionariedade específicos para cada caso.

De fato, a questão do número de bits na análise é um tanto delicada. A TI permite estimar a quantidade de informação em um sistema de código conhecido sem, no entanto, apresentar qualquer definição do código em si. Se por um lado esse é um dos aspectos que torna TI uma ferramenta poderosa e abrangente, por outro, é também um problema para a análise de dados biológicos, uma vez que o código e o tipo de informação codificada são desconhecidos a priori.

A solução que encontramos foi utilizar um número de bits fixo de acordo com a complexidade do sistema e condizente $(n=5$ com certa folga) com o espaço amostral conseguido experimentalmente . Calculamos a taxa de produção de informação $d_{i, n}$ em função de $n$ e elegemos o valor $n=m$ se $m$ é o maior valor de $n$ para o qual $d_{i, n}$ é máxima para qualquer região do burst $(i)$. Isso não garante que $m$ é o melhor número de bits possível para caracterizar o sistema todo, mas sim que palavras de $n>m$ bits devem ser proporcionalmente menos informativas que palavras de $m$ bits $(m=5$ para a maioria dos experimentos, ver capítulo de Resultados).

Apesar da escolha do número de bits ser arbitrária, uma vez fixado o valor de $n$, o método é coerente com respeito a $n$ e $L$ pois em todas as nossas análises 
essa relação demonstrou ser recíproca: se $L=L_{m}$ é a duração da palavra que maximiza entropia para $n=m$ bits, então $m$ é o número de bits que maximiza a entropia para $L=L_{m}$ (ver capítulo de Resultados).

A terceira limitação do método mencionada não diz respeito ao método em si, mas sim à presunção de que o código neural é desconhecido por princípio. Por isso, optamos por usar um estimador "ingênuo" (ou plug-in) de IMM calculada a partir da definição (eq. 3.8) adicionando termos de correção e desvio padrão que levam em conta a finitude da amostra e o desconhecimento das distribuições de probabilidades tanto marginais quanto conjuntas. Dessa forma podemos dizer se existe ou não informação codificada, sem nos ater a seu valor absoluto. Mas esta abordagem não é única: o algoritmo permite que se use outros tipos de estimadores e/ou correções de H e IMM de acordo com a conveniência da aplicação.

Nosso método ainda apresenta vantagens por ser mais flexível que boa parte dos métodos baseados em TI mais comumente utilizados em análise de sinais neurais (Samengo, 2010; Tiesinga et al., 2008; Kumar et al. 2010; Butts et al., 2007) pois:

- identifica fluxo de informação sem depender de hipóteses fortes a respeito do código: outros métodos dependem da definição de padrões com significado específico ("o quê") de acordo com observações experimentais a priori da análise;

- identifica qualquer período de resposta no qual a informação de qualquer período do estímulo pode estar codificada ("quando").

Além disso, o método atual pode ser aplicado ao estudo de outros tipos de sistemas e adaptado para investigar outros problemas, pois:

- pode ser usado para análise de séries temporais de processos puntuais no 
geral;

- poderia ainda ser expandido para o caso multivariado e adaptado para investigar relações de causalidade (a posteriori);

- outras estratégias de busca do melhor $n$ poderiam ser agregadas ao método. 
3. MÉtodo De ANÁlise 


\section{Resultados}

Em um primeiro conjunto de experimentos, registramos a atividade antifásica dos neurônios LP e PD e adquirimos séries temporais longas e estacionárias do potencial de membrana de cada neurônio no circuito intacto.

Em um segundo conjunto de experimentos trabalhamos com redes híbridas em que o neurônio LP era hiperpolarizado enquanto o PD era acoplado em tempo real a um neurônio-modelo. Nos últimos experimentos, registramos simultaneamente a atividade do LP (ou apenas do nervo lvn) e do ivn que conecta o gânglio esofágico (do inglês: oesophageal ganglion, OG) ao cérebro, tanto na situação da rede intacta, quanto na rede híbrida.

Em seguida apresentamos a análise comparativa entre resultados de IMM de simulações computacionais e registros experimentais nos quais estudamos o papel das correntes lentas no mecanismo de transmissão de informação observado experimentalmente na rede intacta.

\subsection{PD É SENSÍVEL AOS PSIBS PRÉVIOS DO NEURÔNIO PRÉ-SINÁPTICO LP}

Nesta seção apresentamos resultados do estudo dos padrões de spike intrabust dos neurônios LP e PD, bem como do procedimento de análise baseado em teoria da informação, com cálculos de entropia e informação mútua média, as estimativas de correções teóricas dessas grandezas e o resultado da análise 
de dados surrogados.

\subsubsection{PADRÕES E ASSINATURAS DOS NEURÔNIOS PILÓRICOS}

Ao longo deste trabalho realizamos diversas medidas da atividade dos neurônios LP e PD, registrando séries temporais (Fig. 4.1 A) durante 30 min a 2hs contendo de 1200 a 6000 pares de bursts, dependendo do ritmo pilórico. Os neurônios trabalham em atividade antifásica e o LP só é permitido disparar durante a fase de hiperpolarização do PD. No exemplo da Fig. 4.1 A fica claro que o comportamento de disparo de cada um dos neurônios é bem distinto e observamos que, a despeito de grandes variações nas relações de fase e período entre os dois neurônios, o aspecto geral dos bursts é bastante estereotipado. Via de regra, o Vm do neurônio PD sempre apresenta uma envoltória suave: os spikes intraburst tipicamente apresentam um aumento seguido de diminuição na frequência de disparo, sendo que esse padrão é uma das características que ajuda o eletrofisiologista a identificar o marcapasso. Além disso, os neurônios PD também apresentam esse mesmo estereótipo em outras espécies de crustáceos como nas lagostas Pannulirus interruptus e Homarus americanus, nos carangueijos Carcinus maenas e Cancer boralis e no lagostim Orconectes limosus.

Outro aspecto interessante da atividade dos neurônios pilóricos é que estes apresentam padrões nos mapas de primeiro retorno dos intervalos entre spikes intraburst. A Fig. 4.1 B mostra um exemplo desse mapa para uma série temporal do neurônio PD onde se observa claramente uma estrutura em "V". Os ramos abaixo e acima da reta identidade correspondem respectivamente ao aumento e diminuição da frequência de disparo. Entretanto, a estrutura não é uniforme, apresentando ilhas (aglomerados) bem definidas que, diferentemente 
do formato em "V" que claramente corresponde ao padrão de frequência de spikes, não podem ser associadas a nenhuma característica que seja visualmente identificável no traço intracelular.

Esse tipo de estrutura já foi reportada em outros trabalhos com animais diferentes e alguns desses mapas de primeiro retorno de ISI têm sido chamados de assinaturas dos neurônios pilóricos pois são muito similares para um mesmo tipo de neurônio em diferentes preparações, porém distintos para cada tipo de neurônio (Szücs et al., 2003; Latorre et al., 2006; Campos et al., 2007). Além disso, as posições das ilhas dependem da conectividade da rede: Szücs et al. mostraram que a assinatura do PD muda de acordo com a força da sinapse do LP com o PD, com estimulação artificial (Szücs et al.,2003) ou ainda com a ação da dopamina (Szücs et al.,2003), neuromodulador que atua em canais de potássio dependentes de voltagem e modifica as sinapses de LP para PD (e vice-versa). A Fig. 4.1 C mostra o mapa de primeiro retorno dos ISI para o PD da lagosta em um circuito intacto de um trabalho anterior (Szucs et al., 2003), muito semelhante à estrutura do mapa para o PD do siri azul que obtivemos de nossos experimentos.

\subsubsection{DistribuiçÃo Dos PSIBs, Entropias E IMM}

Para cada experimento, calculamos a distribuição de spikes para todos os pares de burst do PD precedido por um burst do LP usando o primeiro spike do PD como referência de tempo (como descrito no capítulo de Métodos)(Fig. 4.2 A). Os primeiros spikes do PD apresentam um padrão que consiste em uma sequência de ISI que ocorrem de maneira reprodutível com média e desvios bem definidos, enquanto que a distribuição dos spikes do LP não apresentam um padrão bem definido. A porção final da distribuição mostra que os tempos de disparo são progressivamente menos precisos ao longo do burst. Já a dis- 


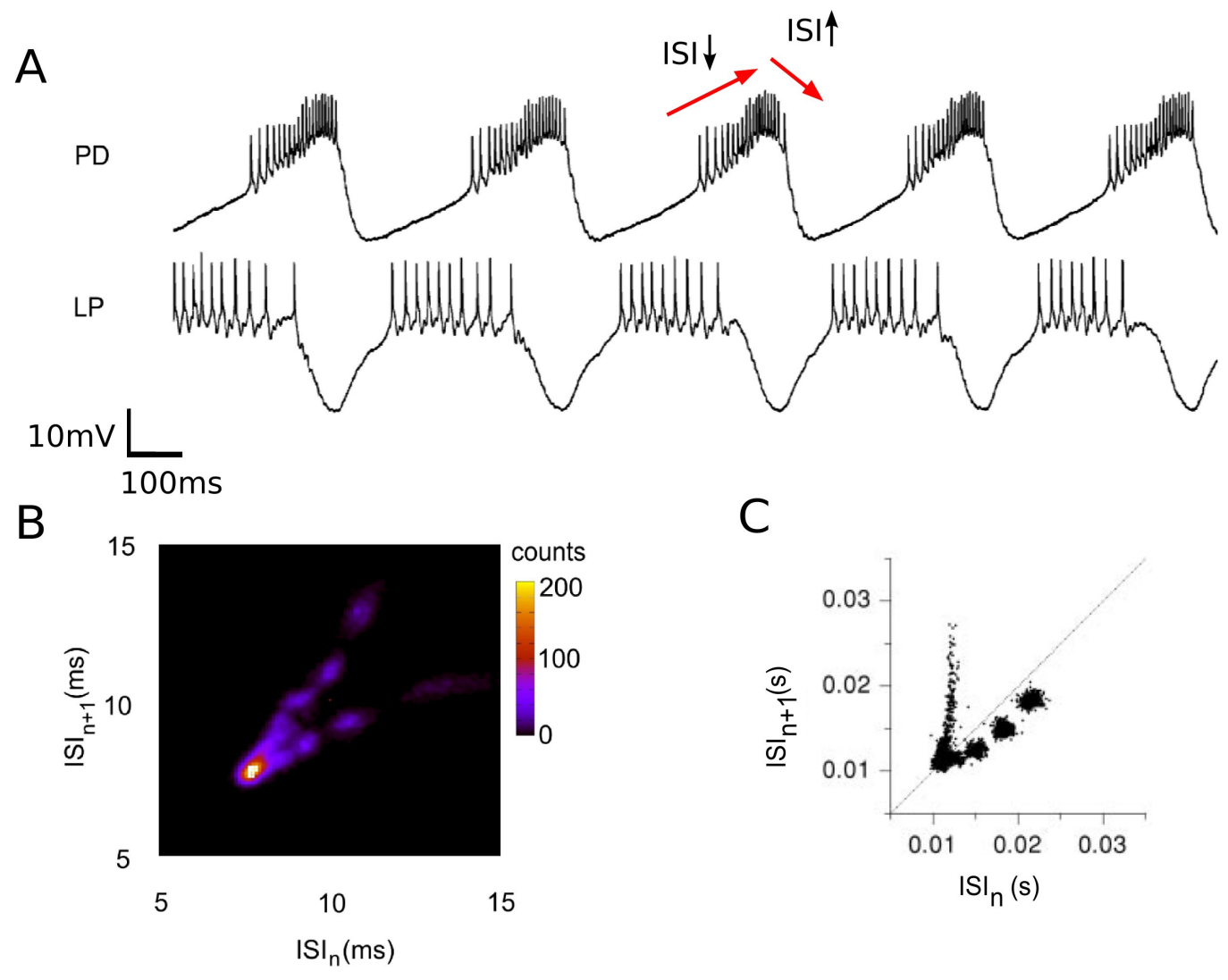

Fig. 4.1 - A - Trecho das séries temporais de LP e PD apresentando atividade típica de bursts em antifase. As flechas vermelhas ascendentes e descendentes representam o aumento seguido da diminuição da frequência (ISIs consecutivamente menores seguidos de ISI consecutivamente maiores). B- Mapa de primeiro retorno para uma série temporal do PD de Callinectes sapidus: histograma bidimensional de contagens com bins de $1 \mathrm{~ms} \times 1 \mathrm{~ms}$. C- Mapa de primeiro retorno de ISI para Panulirus interruptus (Szücs et al., 2003). Ambos os mapas apresentam formato em "V"com "ilhas"bem definidas.

tribuição do LP não apresenta um padrão nítido, pois a flutuação natural no intervalo de tempo entre o início do burst do LP e o primeiro spike do próximo burst do PD adiciona variabilidade aos tempos de disparo intraburst.

Assim, podemos encontrar diferentes tipos de padrões de spike intraburst dependo da ferramenta de observação: no traço intracelular vemos o comportamento estereotipado da frequência, nas distribuições de spikes vemos padrões nos instantes de disparo no início do burst e nos mapas de primeiro retorno 
vemos assinaturas típicas de cada neurônio.

No entanto, essas ferramentas não são equivalentes: o mapa de primeiro retorno é o que revela os padrões mais complexos que não podem ser observados nas distribuições, nem tampouco no traço intracelular. Será possível observar padrões de mais alta ordem através de uma ferramenta mais sofisticada?

Construindo mapas de $n$-ésimo retorno, seria possível observar estruturas ainda mais detalhadas? Se sim, será que esses padrões $n$-dimensionais estariam correlacionados com propriedades dos neurônios e da rede da mesma maneira que os agrupamentos dos mapas de primeiro retorno (Szucs et al., 2003)? Com essa motivação, desenvolvemos uma ferramenta de análise baseada em teoria da informação que permite revelar microestruturas nos trens de disparo intraburst e seu potencial de carregar informação.

Nossa abordagem difere de trabalhos anteriores principalmente em dois aspectos. Primeiramente, amplia o conceito de padrão apresentado na questão anterior. De maneira geral, estamos interessados em saber se existem PSIBs que carregam informação sejam quais forem esses padrões. Em segundo lugar, ao invés de olhar correlações gerais desses padrões com o comportamento dos neurônios e/ou com a conectividade da rede, formulamos uma questão mais objetiva: queremos saber se PSIBs do neurônio pós sináptico são capazes de carregar informação a respeito da atividade do neurônio pré-sináptico.

Portanto, ao invés de olhar para padrões específicos (como por exemplo estruturas detalhadas em um mapa de $n$-ésimo retorno) e depois perguntar se carregam informação, nossa análise adota a estratégia inversa: buscamos, para quaisquer padrões, quais PSIBs carregam mais informação, ou seja, os que têm maior entropia $(H)$, e em seguida, verificamos se essa informação diz respeito à atividade do neurônio pré-sináptico calculando a informação mútua média (IMM). 
Resumidamente, buscamos, para cada instante $\mathrm{T}$ ao longo do burst, qual o conjunto de PSIBs com maior conteúdo informacional, i.e., com maior entropia. Assim, para um dado T, é escolhido o tamanho da janela $L_{\max }$ que maximiza a entropia, ou seja, dado T, os PSIBs que maximizam a entropia são palavras de $n$ bits aos quais são atribuídos valores zeros e uns de acordo com a ocorrência de spikes entre $\mathrm{T}$ e $\mathrm{T}+L_{\text {max }}$. Em nosso método, ao invés de definir $L_{\max }$ como uma constante, L é variável ao longo do burst (função de T) pois levamos em conta que a informação pode ser codificada de forma não homogênea ao longo do burst. Utilizamos $n=5$ nos cálculos apresentados em todos as seções deste capítulo (essa escolha está justificada na seção 4.7).

Ambos neurônios apresentam valores altos de entropia $H_{L P}$ e $H_{P D}$ ao longo dos bursts, próximo ao valor máximo possível de 5 bits. A entropia é claramente não homogênea ao longo do burst do PD e existe alguma flutuação ao longo burst do LP. A Fig. 4.2 B e C mostra a variação ao longo do burst do parâmetro $l_{L P}\left(l_{P D}\right)$, que é o $L_{\max }$ normalizado pela duração total do burst. Os valores de $l_{L P}\left(l_{P D}\right)$ apresentam suaves flutuações que não têm relação direta com as oscilações na entropia $H_{L P}\left(H_{P D}\right)$. Esse fato justifica permitir que L seja um parâmetro livre ao longo do burst.

Dos valores de T e L é possível encontrar quais spikes contribuem para a maximização da entropia. Por exemplo, a duração da palavra que maximiza a entropia para $T_{P D}=0.03$ s é $L_{m a x}, \mathrm{PD}=0,11 \mathrm{~s}$, e o valor normalizado correspondente é $l_{P D}=0.22$ (Fig. $4.2 \mathrm{C}$ ). Isso quer dizer que os spikes que acontecem no intervalo de $[0.03 ; 0.14] \mathrm{s}$ do histograma do PD, onde o segundo, terceiro e quarto spikes podem ser visualmente discriminados (Fig. 4.2 A), codificam até $H_{P D}=2,8$ bits de informação em seus PSIBs.

Para inferir quanto a variabilidade dos PSIBs do LP e do PD estão correlacionadas, computamos a IMM. A Fig. 4.2 D apresenta o resultado da IMM 
para a mesma série LP e PD representado em um mapa 2D colorido (ver na Fig. 3.3 a representação esquemática deste diagrama). Essa grandeza não é uniforme ao longo do burst do PD e LP, e seu máximo valor de 0.66 bits corresponde ao um trecho na primeira metade do burst do LP em $T_{L P}=-0.36$ $\mathrm{s}\left(\right.$ região azul na Fig. $4.2 \mathrm{~A}$ ) com o início do burst do PD em $T_{P D}=0.03 \mathrm{~s}$ (região vermelha na Fig. 4.2 A). O pico da IMM é três vezes maior que o valor médio nos vales do diagrama, em contraste, as entropias não apresentam uma variação tão brusca (Fig. $4.2 \mathrm{~B}$ e C).

\subsubsection{IMM, CORREÇÕES E DADOS SURROGADOS}

A Fig. 4.3 mostra um exemplo de análise para uma outra série experimental de LP e PD, da qual extraímos pares de bursts de LP precedendo o PD, com referência de tempo no primeiro spike do PD (assim como no caso anterior). Como já foi discutido no capítulo Método de Análise, utilizamos uma aplicação "plug in" da teoria da informação, ou seja, inferimos grandezas como entropia e informação mútua média a partir das definições clássicas (eqs. 3.2 e 3.8) e por isso devemos considerar o efeito de erros consequentes da amostragem finita de dados. O diagrama de IMM na Fig. $4.3 \mathrm{~A}$ corresponde à $I M M_{o b s}$, calculada a partir da definição (eq. 3.8). Fica claro que a IMM é não homogênea ao longo dos bursts de estímulo e resposta. Diferentemente do caso anterior, o pico de IMM nesse caso fica numa região do diagrama que corresponde ao início LP com o final do bursts do PD.

O estimador de IMM proposto por Roulston (Roulston, 1999) corresponde ao valor inferido da IMM a partir da definição somado a um termo de correção que é inversamente proporcional ao número de dados e diretamente proporcional ao número de eventos observados. Como consequência da eq. 3.14, a entropia medida a partir da definição sempre subestima o valor real que seria 

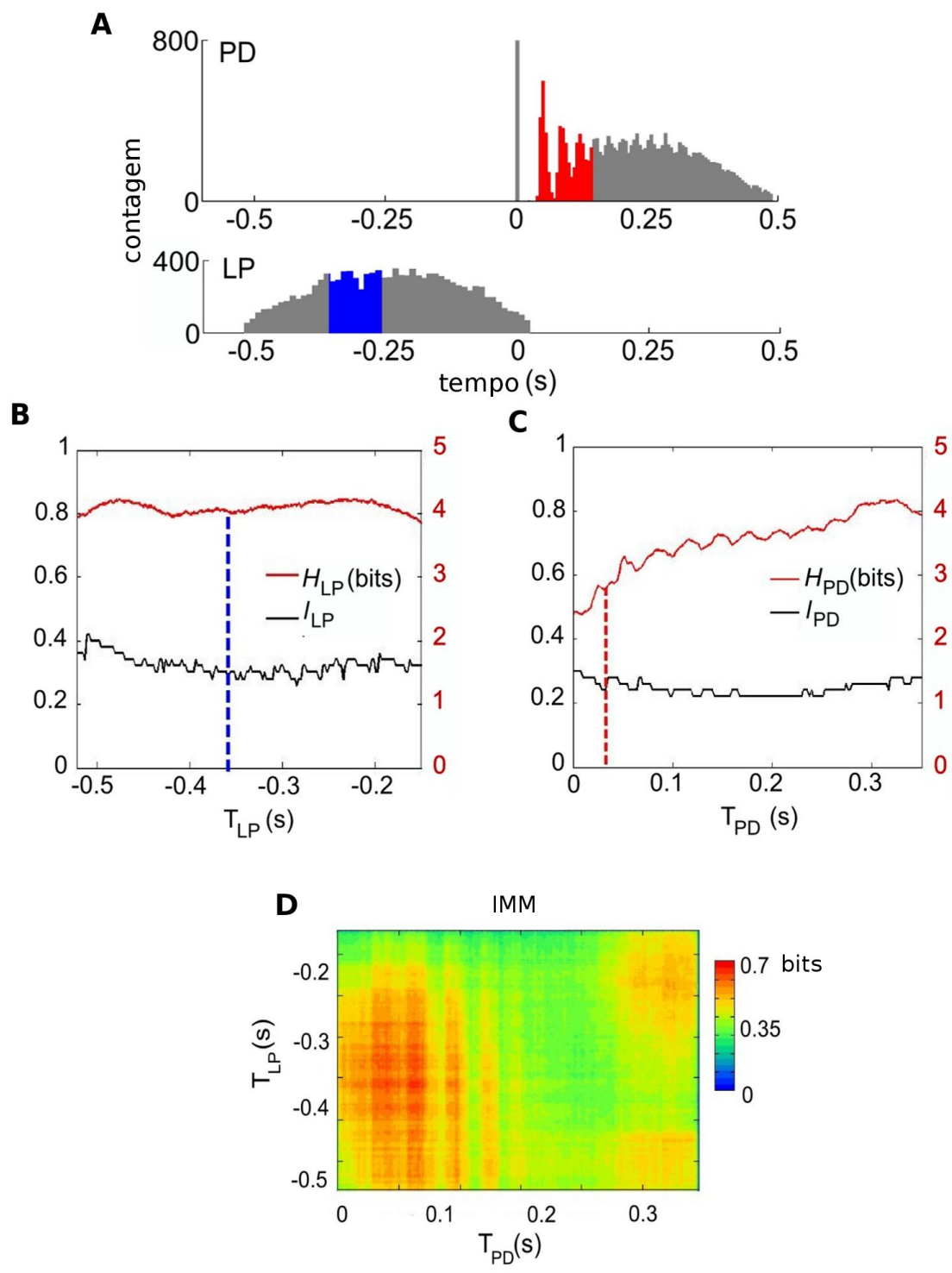

Fig. 4.2 - A - Distribuições de spikes de PD e LP usando o primeiro spike do $P D$ como referência de tempo. Os primeiros spikes do PD acontecem em uma sequência razoavelmente previsível, enquanto que os últimos spikes do $P D$ ou todos os spikes do LP apresentam distribuições mais largas. B - Entropia $H_{L P}$ (em bits) e a duração da palavra normalizada pela duração do burst $l_{L P}$ (adimensional). C- $H_{P D}$ e $H_{P D} . \quad D$ - Diagrama de IMM (em bits) $2 D \mathrm{em}$ cores. $O$ pico de $I M M$ de 0.66 bits acontece em $T_{L P}=-0.36 \mathrm{~s}$ e $T_{P D}=0.03 \mathrm{~s}$ e as porções dos bursts correspondentes estão selecionadas em azul e vermelho (das distribuições em A) 
obtido caso a amostragem fosse infinta. Em todas as nossas análises, tanto o termo de correção quanto o desvio padrão relativo para a entropia estimados a partir das eqs. 3.14 e 3.15 são sempre menores que $0.1 \%$ e $0.6 \%$ de $H_{o b s}$ respectivamente (e por isso não estão representados na Fig. 4.2).

Em contrapartida, a correção estimada para a IMM (Fig. 4.3 B) de acordo com a eq. 3.16 é sempre negativa por todo o diagrama para todas as séries e tipicamente representa uma porcentagem pequena da $I M M_{o b s}$ (de 3 a $10 \%$ do valor do pico). A Fig. 4.3 C mostra o diagrama de $\left(I M M_{\infty}\right)$ com valores um pouco mais baixos, mas com formato muito semelhante ao de $I M M_{o b s}$ em A. O gráfico do desvio padrão estimado (eq. 3.17) para $I M M_{\infty}$ (Fig. $\left.4.3 \mathrm{D}\right)$ tem um formato muito diferente dos diagramas apresentados em A, B e C, com valores variando de 0 a 0.11 bits. Apesar de chegar a valores bem expressivos, o desvio padrão relativo no pico é menor que $1 \%$ de $I M M_{\infty}$ em qualquer experimento.

A IMM é, por definição, simétrica com respeito a estímulo e resposta, por isso, não implica causalidade. Aqui, a causalidade é garantida pela relação de precedência do burst do LP com relação ao burst seguinte do PD. Além disso, calculamos IMM para os dados surrogados onde a ordem dos bursts do LP são embaralhados, rompendo a causalidade. Nesse caso, as distribuições marginais de probabilidades são exatamente iguais, apenas as distribuições de probabilidades conjuntas são distintas.

A IMM para um conjunto de dados surrogados $\left(I M M_{\text {surr }}\right.$ Fig. 4.3 E) cai para apenas $15 \%$ do valor original. Isso significa que os valores conspícuos para a série original se devem de fato à relação de causalidade entre os PSIBs do LP que precedem os PSIBs do PD. Para avaliar a significância estatística da IMM calculada para o conjunto original $I M M_{o r}\left(=I M M_{o b s}\right.$ nesse caso), calculamos $I M M_{\text {surr }}$ para 20 conjuntos surrogados para cada experimento e avaliamos sig $=\left(I M M_{\text {or }}-\left\langle I M M_{\text {surr }}\right\rangle\right) / \sigma_{\text {surr }}$. Os valores de sig na Fig. 4.3 
F variam de 15 a 800. Em todo o manuscrito, valores de IMM considerados significantes têm $\operatorname{sig}>7$.

Valores absolutos da IMM podem ser difíceis de interpretar, por isso, calculamos também a $I M M_{r e l}=I M M_{\infty} / H_{\infty}(P D)($ valor máximo $=1)$ que dá o quanto o PD dedica de sua capacidade informacional para codificar o sinal de estímulo. A Fig. $4.3 \mathrm{G}$ mostra que para esse experimento, até $21 \%$ dos PSIBs do neurônio de resposta são dedicados a codificar o estímulo (ou que $21 \%$ dos PSIBs do PD podem ser preditos uma vez que os PSIBs do LP são conhecidos). Comparando as Figs. 4.3 C e G, vemos que a região de máximo sofre um grande deslocamento (em $\mathrm{C}$ aparece no final do PD e em $\mathrm{G}$ se desloca para o início do burst do PD).Isso se deve a flutuações nos valores de entropia: ambos os picos estão em regiões no início do burst do LP, no entanto, o pico de $I M M_{\infty}$ aparece no final do burst do PD e o pico absoluto da $I M M_{r e l}$ se encontra precisamente no início do burst do PD.

A incerteza da $I M M_{\text {rel }}$ pode ser estimada a partir das incertezas da $I M M_{\infty}$ (eq. 3.15) e $H_{\infty}$ (eq. 3.17). O pico de $I M M_{\text {rel }}$ da Fig. 4.3 apresenta um desvio padrão relativo (não mostrado na figura) de $5 \%$, o que é um valor bastante tolerável. Todos os valores de pico da $I M M_{r e l}$ mencionados nesse manuscrito apresentaram desvio padrão relativo $\leq 12 \%$.

\subsection{Fluxo De InformaÇÃo do LP PARA o PD SE DÁ POR UM ME- CANISMO GERAL}

$\mathrm{Na}$ seção anterior mostramos que existe fluxo de informação de LP para PD para em um experimento em particular, mas quão geral é esse resultado em diferentes preparações? Para abordar essa questão, aplicamos a mesma análise para diversas séries temporais de LP e PD para experimentos feitos 

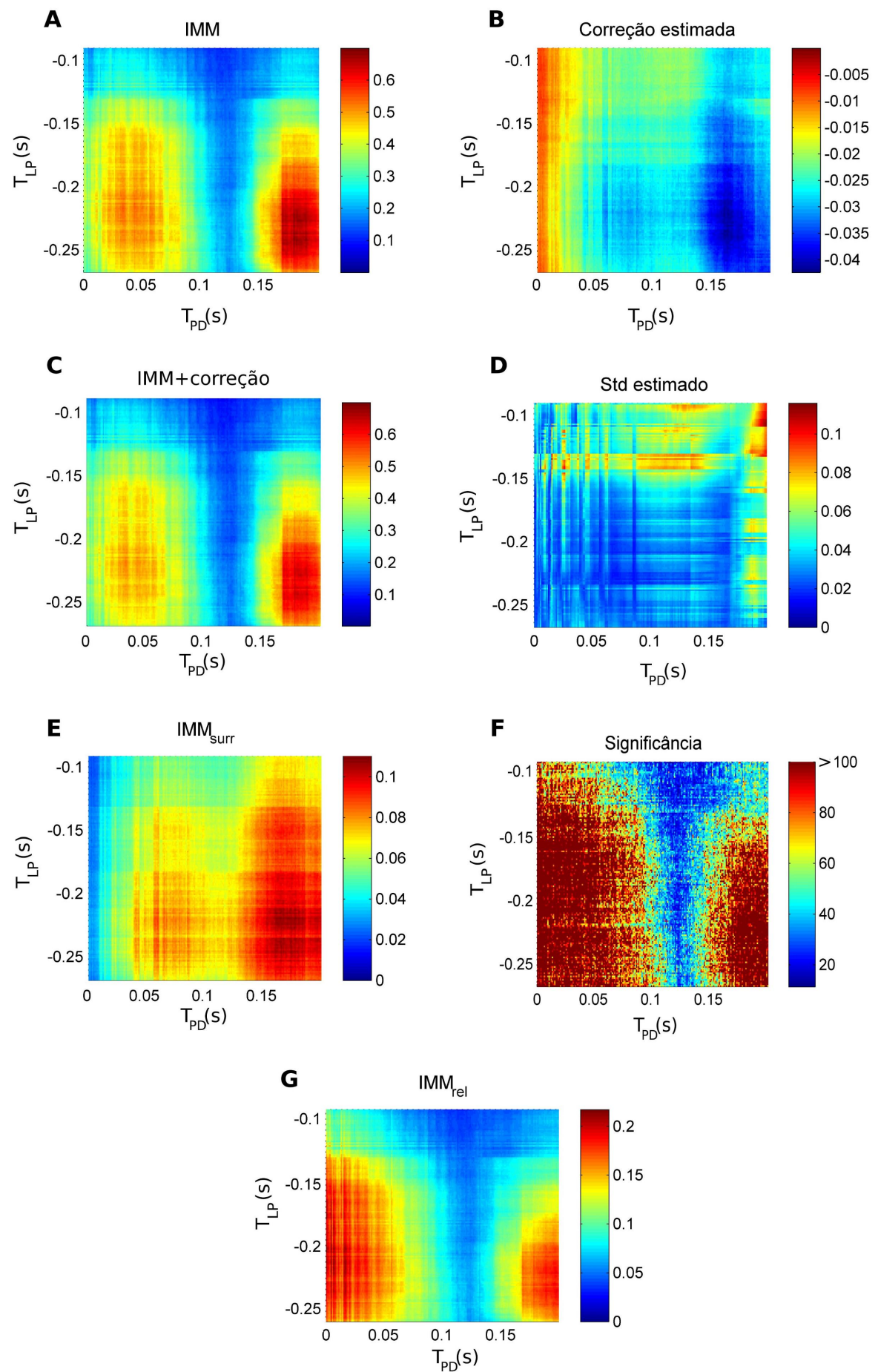

Fig. 4.3 - A-IMM $M_{o b s}$ (calculada à partir da definição, o mesmo que $I M M_{o r}$ ), $B$ - termo de correção, $C$ - $I M M_{\infty}$ (valor corrigido), $D$ - desvio padrão estimado, E- IMM $M_{\text {surr }}$ (IMM $M_{\text {obs }}$ calculada para um conjunto de dados surrogados), F- Significância $\left(\right.$ sig $\left.=\left(I M M_{o r}-<I M M_{\text {surr }}>\right) / \sigma_{\text {surr }}\right), G-I M M_{\text {rel }}=$ $I M M_{\infty} / H_{\infty}(P D)$. O pico de $I M M_{\text {rel }}$ aparece no início do burst do LP com o início do burst do $P D$ (unidades: bits de $A-E$ e adimensional em $F$ e $G$ ). 
com Callinectes sapidus e Panullirus interruptus. Queríamos investigar se o fenômeno observado em uma preparação poderia ser relacionado a um mecanismo mais geral de codificação de informação para diferentes preparações ou animais.

Para isso, coletamos dados de diversas preparações até obtermos uma variação de 3 vezes em algumas características pilóricas como período (de 0.44 $\pm 0.03 \mathrm{~s}$ a $1.3 \pm 0.7 \mathrm{~s}$ ), número de spikes por burst do neurônio LP ( de $4.4 \pm$ 0.5 a $15 \pm 3$ ) e do PD (de $7.5 \pm 0.5$ a 20土1). Todas as séries registradas são estacionárias com respeito à média e desvio padrão desses parâmetros.

Existem algumas diferenças visíveis na conformação dos diagramas de $I M M_{r e l}$, sendo que alguns gráficos apresentam regiões mais pronunciadas que correspondem a vales em outros diagramas. Para que se possa observar acuradamente a posição do pico, é necessário considerar qual porção de cada burst de estímulo e resposta estão associados ao valor máximo de $I M M_{\text {rel }}$. Os valores podem variar em cada caso, mas para a maioria dos experimentos, a posição do pico global é próxima ao início dos bursts de estímulo (LP) e resposta (PD). Na Fig. 4.4 os pares de retângulos representam os bursts do LP (acima) e PD (abaixo), normalizados pelo período pilórico. O deslocamento de um retângulo com relação ao outro corresponde à fase de disparo do LP com relação ao PD. As duas faixas cinza em cada par de retângulos representam as porções dos bursts de estímulo e resposta que correspondem ao pico de $I M M_{\text {rel }}$. Nesta representação, fica claro que os picos de $I M M_{\text {rel }}$ estão sempre no início dos bursts de LP e PD em todos os casos.

Apesar da grande diferença no comportamento geral do sistema pilórico, os resultados de $I M M_{r e l}$ são qualitativamente muito similares para diferentes preparações. O valor máximo de $I M M_{\text {rel }}$ varia entre as preparações, mas a posição do pico é tipicamente próxima do início de ambos os bursts de estímulo 
(LP) e resposta (PD) (Fig. 4.4). De um total de 16 séries temporais analisadas de diferentes preparações em siris $(\mathrm{N}=13)$ e lagostas $(\mathrm{N}=3), 14(87,5 \%)$ têm máximo local ou absoluto de $I M M_{\text {rel }}$ no início do LP e 13 (81\%) têm pico local ou absoluto no início do LP com o início do PD. Em todos os casos, os picos de $I M M_{\text {rel }}$ são estatisticamente significantes. Esses resultados se mostraram bastante similares em diferentes espécimes e espécies a despeito de diferenças nas fases de burst, número médio de spikes e frequências, o que sugere a existência de um mecanismo geral que rege o fluxo de informação de LP para PD.

\subsection{Circuitos híbridos COM RESUltados Similares} AOS DA REDE INTACTA

Mostramos que os PSIBs do neurônio PD expressam informação a respeito dos PSIBs do burst anterior do LP, mas qual via que essa informação percorre? Essa informação é transmitida diretamente do LP para o PD, ou será que percorre uma via indireta?

Pensando nisso, fizemos uma série de experimentos com redes híbridas para testar se a informação medida é transmitida através da sinapse LP/PD ou se existe um terceiro neurônio ou subcircuito que envia informação para ambos neurônios.

Para construir a rede híbrida, o neurônio LP foi mantido hiperpolarizado até atingir um estado quiescente enquanto o PD interagia em tempo real com um neurônio artificial (NA) através de uma única sinapse inibitória do NA para o PD, implementada com um protocolo de dynamic clamp (Pinto et al., 2001; Nowotny et al., 2006). Dessa forma, o neurônio PD deixa de receber qualquer informação através de sinapse biológica, estando apenas acoplado ao 


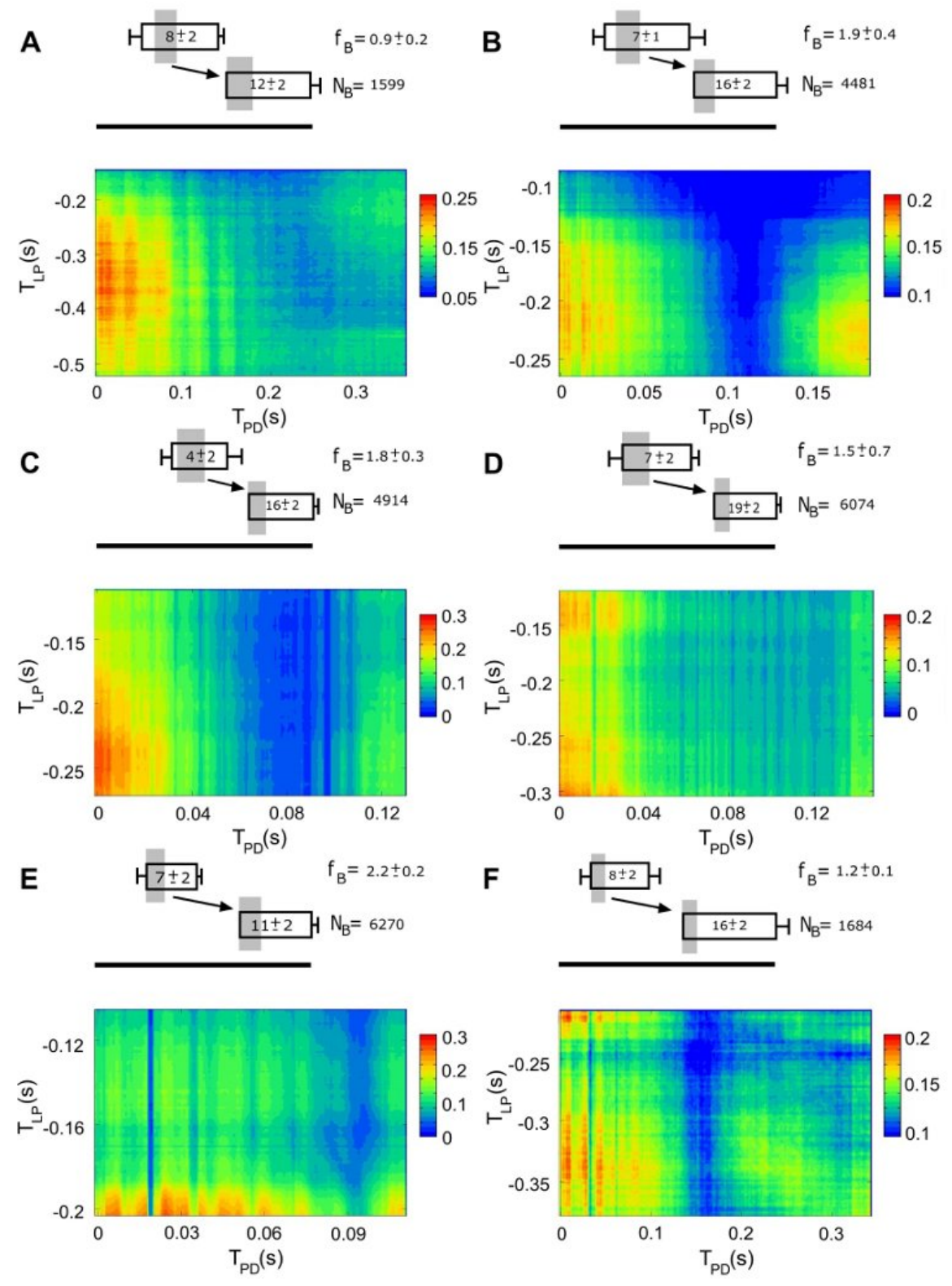

Fig. 4.4 - Resultados de $I M M_{\text {rel }}(L P ; P D)$ em difererentes preparações. A$D$ são exemplos de diferentes preparações em siri azul, $E$ - preparação com lagosta, $F$ - experimento com rede híbrida (preparação siri) em que o neurônio LP foi substituído por um neurônio modelo artificial preparado para imitar o comportamento original do LP. Acima de cada gráfico estão representadas a média da fase e duração dos bursts do LP (retângulo superior) e PD (retângulo inferior) com respeito ao período pilórico (traço grosso na horizontal). As barras nas laterais dos retângulos representam os desvios padrões dessas grandezas. Os números contidos no retângulos correspondem às médias e desvios padrões do número de spikes por burst dos neurônios. Os pequenos retângulos cinzas na vertical representam as porções do burst $\left(l_{L P}\right.$ e $\left.l_{P D}\right)$ que correspondem ao pico máximo de $I M M_{\text {rel }}$. As setas indicam o sentido do fluxo de informação do LP para o $P D$. 
NA através da sinapse artificial. O NA foi preparado para imitar a duração e número de spikes por burst do LP original. A fase, também similar à do LP original, é determinada como um intervalo de tempo fixo que entre o início da hiperpolarização pós-burst do PD e o primeiro spike do próximo burst do NA.

As preparações usadas nos experimentos com circuitos híbridos apresentaram variabilidade com relação ao período pilórico (de $0.62 \mathrm{~s} \pm 0.03 \mathrm{~s}$ a $0.83 \mathrm{~s}$ $\pm 0.05 \mathrm{~s}$ ), número de spikes por burst do neurônio PD ( de $7.4 \pm 0.7$ a $15 \pm$ 2) e número de spikes por burst do NA que imita o LP original (de $4 \pm 1$ a $8.0 \pm 0.8)$. Essas flutuações são comparáveis às observadas nos experimentos com o circuito intacto. Além disso, os valores de entropias obtidos ao longo do burst para ambos os tipos de NA estão no intervalo $[2,2 ; 4,5]$ bits nos experimentos com os circuitos híbridos, muito similar aos obtidos para o LP real nos experimentos com o circuito intacto.

Os experimentos com circuitos híbridos apresentaram valores de $I M M_{\text {rel }}$ qualitativamente semelhantes aos encontrados para o circuito intacto: os picos de $I M M_{r e l}$ se encontram no início de ambos neurônios de estímulo e resposta (Fig. 4.4). De um total de 16 experimentos realizados, 15 (94\%) apresentaram um máximo absoluto no início do NA (estatisticamente significante em todos os casos). A entropia do NA é tipicamente alta e $I M M_{r e l}$ tem valores muito proeminentes, indicando que os PSIBs do PD podem refletir variações do neurônio pre sináptico, mesmo se a sinapse é artificial.

Assim, os instantes de disparo no burst do NA são absolutamente descorrelacionados de qualquer atividade do circuito, sendo que a única influência que NA recebe do PD é sobre a fase de hiperpolarização do PD que determina quando o NA é permitido disparar o primeiro spike. Dessa forma, é impossível que qualquer neurônio do CPG influencie os PSIBs do NA. Esses resultados não só mostram que um neurônio artificial é capaz de transmitir informação 
ao PD da mesma forma que o LP faria, como também sugere que o mecanismo de codificação de informação observado na rede intacta pode se dar através de uma única sinapse.

\subsection{IMM RELATIVA AO ESTÍMULO}

Até esse ponto no manuscrito, a $I M M_{r e l}$ corresponde à $I M M_{\infty}$ normalizada pela entropia da resposta: a análise visa mostrar quanto o neurônio de resposta é dedicado a codificar o estímulo. Mas isso não responde o quanto do sinal de estímulo é efetivamente codificado na resposta, para isso é necessário conhecer $I M M / H(S)$. Imaginando um cenário em que $H(S)$ é alta e $H(R)$ baixa, mesmo que o neurônio de resposta esteja muito dedicado a codificar informação, apenas uma pequena parte do estímulo será aproveitada para esse fim, sendo que o restante da capacidade informacional $H(S)$ poderia ser devida a ruído ou estar dedicada a expressar outro tipo de informação que não chega ao neurônio de resposta.

A entropia do LP tipicamente apresenta alguma oscilação ao longo do burst e varia de 2,3 a 4,6 bits em diferentes preparações. A Fig. 4.5 A mostra a $I M M$ calculada para $\mathrm{LP} \rightarrow \mathrm{PD}$ relativa à entropia do LP para três experimentos no circuito intacto. Nesses casos, pode-se observar que os valores são bastante significativos e que os picos absolutos estão em regiões semelhantes dos gráficos. De fato, a análise de 11 de 16 experimentos (69\%) apresentaram pico de $I M M / H(S)$ na primeira metade do burst do LP com a primeira metade do burst do PD. Além disso, para todos os 16 casos os valores são bastante expressivos: de 4 a $25 \%$ (todos significantes) da informação contida nos padrões de disparo do LP estão codificadas nos PSIBs do PD.

A Fig. $4.5 \mathrm{~B}$ mostra a $I M M$ calculada para $\mathrm{NA} \rightarrow \mathrm{PD}$ relativa à entropia do 

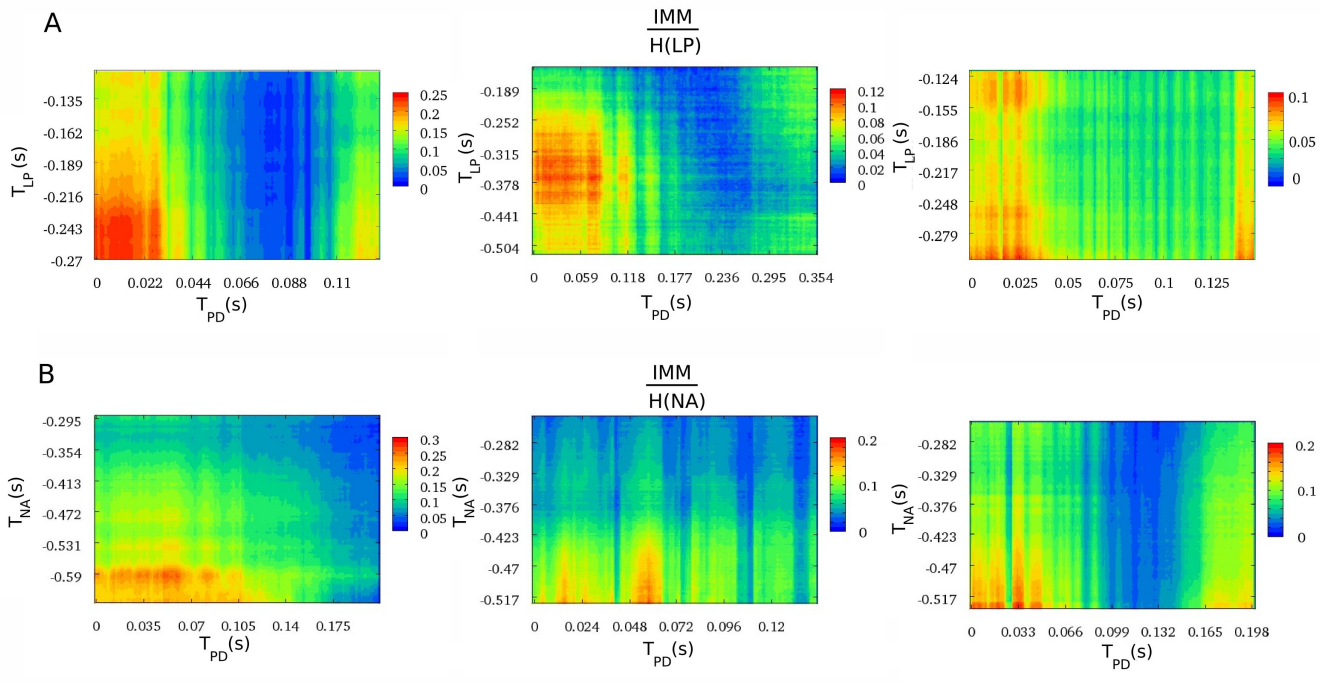

Fig. 4.5 - IMM normalizada pela entropia do estímulo A-Circuito intacto: $I M M_{\infty} / H_{\infty}(L P)$, fluxo de informação no sentido $L P \rightarrow P D$. B-Circuito híbrido: $I M M_{\infty} / H_{\infty}(N A)$, fluxo de informação no sentido $N A \rightarrow P D$.

NA para três experimentos com o circuito híbrido. Como o comportamento do NA é ajustado para se assemelhar ao do LP original, os valores de entropia para o neurônio artificial também se encontram em uma faixa parecida de valores de $[2.2,4.5]$ bits em diferentes preparações. Da mesma forma que nos resultados para o circuito intacto, pode-se observar que os valores de $I M M / H(N A)$ são bastante significativos e que os picos absolutos estão em regiões semelhantes dos gráficos: 14 de 16 experimentos (88\%) apresentaram pico de $I M M / H(S)$ na primeira metade do burst do NA com a primeira metade do burst do PD e para todos os experimentos os valores máximos variaram de 4 a $30 \%$ de $H(S)$ (todos significantes). Isso significa que mesmo os PSIBs gerados artificialmente têm um grau de "aproveitamento" bastante expressivo.

Em princípio, a $I M M_{\text {rel }}$ pode se referir tanto a $I M M / H(R)$ quanto a $I M M / H(S)$ mas, neste manuscrito, a não ser que se especifique o contrário, a expressão $I M M_{\text {rel }}$ sempre diz respeito à informação relativa à entropia de resposta. 


\subsection{REFERÊNCIAS TEMPORAIS E SENTIDO DO FLUXO DE INFORMAÇÃO}

\subsubsection{REFERÊNCIAS DEPENDENTES E INDEPENDENTES}

Nossa técnica se baseia na análise de séries de trens de disparos (processos puntuais), assumindo que estímulo e resposta sejam determinados a priori. Em uma situação em que a estimulação é controlada, o início de cada estímulo é determinado pelo experimentador que impõe uma referência de tempo própria. Nosso caso é diferente pois lidamos com os neurônios conectados por mútua inibição: o neurônio LP só dispara na fase de hiperpolarização do PD e vice e versa. Como existe flutuação no período pilórico e na fase de disparo entre LP e PD, o início do trem de estímulos depende do final do trem de resposta anterior, assim, essas flutuações devem ser levadas em conta quando se escolhe a referência de tempo para determinar os instantes de disparo.

Nos resultados das seções anteriores, apresentamos $I M M_{\text {rel }}$ de LP para PD calculada com a referência temporal no primeiro spike do PD (representada na Fig. 3.2 da seção de métodos). Essa escolha se deve principalmente ao fato do PD ser o marcapasso da rede, definindo o período pilórico. Portanto, qualquer atraso ou adiantamento no instante do início do burst do PD deve afetar o início do burst de cada um dos neurônios, inclusive do LP. Dessa forma, quando calculamos a $I M M_{r e l}$, os padrões de disparo que encontramos no LP refletem não apenas flutuações nos tempos de disparo dentro do burst, mas também nas variações do início do burst do LP com relação ao burst anterior do PD.

Da mesma forma, se colocamos a referência no primeiro spike do burst de estímulos, os tempos de disparo do burst de resposta são influenciados pela flutuação do início da resposta com relação ao final do estímulo. De 16 experimentos, $11(69 \%)$ das séries apresentaram 2 picos de $I M M_{\text {rel }} \mathrm{LP} \rightarrow \mathrm{PD}$ 
correspondendo ao início e final do burst do PD com o final do burst do LP (Fig. 4.6 B). Os dois picos são sempre bem definidos: o pico global é no máximo $20 \%$ maior que o outro pico local e essas regiões são separadas por um vale em que a $I M M_{r e l}$ é muitas vezes quase nula, ou menos de $30 \%$ do valor do pico.

Para eliminar a influência das flutuações da fase nos padrões de disparo, ao invés de usar apenas uma referência de tempo, podemos simplesmente usar duas referências independentes: para cada par de bursts, colocamos uma referência de tempo no primeiro spike do burst de estímulo e outra no primeiro spike do burst de resposta. Assim, ao calcular $I M M_{\text {rel }}$, estamos considerando apenas as flutuações intraburst dos tempos de disparo. Se período pilórico e fase não apresentassem nenhuma flutuação, os resultados da análise com referências dependentes e independentes seriam absolutamente idênticos: para cada escolha de referência os tempos de spikes iriam diferir apenas com relação a uma constante, sem alterar as distribuições ou PSIBs.

Na verdade, em todos os casos, a $I M M_{\text {rel }}$ de LP para PD para referências dependentes é maior do que a $I M M_{\text {rel }}$ para independentes: de 1 a $19 \%$ da capacidade informacional do PD é dedicada a codificar a relação de fase entre LP e PD (Fig. 4.6 C). Se por um lado esse resultado mostra a importância da fase no fluxo de informação, por outro, também revela que os padrões formados unicamente pelos tempos de disparo intraburst são responsáveis tanto pelo conteúdo informacional dos estímulos quanto pela codificação na resposta. E mais, podemos dizer que isso corresponde à maior parte da informação codificada, ou seja, o conteúdo informacional dos PSIBs é mais importante que o da fase em todos os casos. Do total de 16 experimentos, 11 (69\%) apresentaram um pico de $I M M_{\text {rel }}$ (absoluto ou local) no início de burst do PD com o início do burst do LP para referências independentes, regiões muito próximas dos picos para $I M M_{r e l}$ com referência no PD. 
Acima de cada diagrama da Fig. 4.6 encontra-se a representação dos bursts de LP e PD. O tamanho do retângulo representa a duração média dos bursts de cada neurônio e sua posição é determinada pela relação de fase entre ambos neurônios. As referências de tempo estão representadas como linhas vermelhas verticais: em $\mathrm{A}$ e $\mathrm{B}$ há apenas uma linha no início do burst de resposta e estímulo respectivamente e em C há duas linhas verticais no início do burst de cada um dos neurônios. É importante notar que em A o início e final do burst do neurônio de estímulo (no qual a referência não está colocada) estão associados a uma incerteza relativamente grande (em torno de $20 \%$ da duração do burst). O mesmo vale para o neurônio de resposta em B.

Os retângulos cinza representam a região de cada burst que corresponde à duração da palavra para a qual a $I M M_{\text {rel }}$ é máxima. Por essa representação, é mais fácil observar que, para $I M M_{r e l}$ de LP $\rightarrow \mathrm{PD}$, as regiões dos bursts do LP e PD que correspondem ao pico são muito similares quando a referência é colocada na resposta (A) ou usando referências independentes(C).

\subsubsection{FluXo DE INFORMAÇÃO PD $\rightarrow$ LP}

A capacidade do PD de codificar informação nos PSIBs é um ponto central de nossos resultados pois, por ser o marcapasso, sua atividade repercute no comportamento de todo o CPG. No entanto, uma vez que mostramos que o LP é capaz de enviar informação ao PD, será que pode existir fluxo de informação no sentido contrário?

Analisamos as mesmas séries temporais de LP e PD no circuito intacto (resultados da seção anterior), mas desta vez, separando pares de bursts de modo que o burst do PD precedesse o do LP. Nesta análise também usamos a referência de tempo no primeiro spike do burst do neurônio de resposta, neste caso, o LP. Para todos os 16 experimentos, os gráficos de $I M M_{\text {rel }}$ apresenta- 
ram picos de 5 a 35\%, todos significantes e de todos os diagramas, 11 (69\%) apresentaram dois picos bem definidos no início e no final do PD com o início do LP (Fig. 4.6 D).

Todavia, as análises de PD $\rightarrow$ LP com referência no estímulo (PD) ou com referências independentes (Fig. 4.6 E e F), apesar de possuírem picos com valores significantes em todos os casos, não apresentaram nenhuma regularidade com relação às posições dos picos nos diagramas.

Os gráficos deixam claro que, independentemente da escolha de referência temporal e do sentido do fluxo de informação $(\mathrm{LP} \rightarrow \mathrm{PD}$ ou $\mathrm{PD} \rightarrow \mathrm{LP})$, a disposição dos valores de $I M M_{r e l}$ ao longo dos bursts é sempre anisotrópica: existem algumas ilhas bem definidas em que a $I M M_{r e l}$ é mais pronunciada e outras regiões em que é nula ou quase nula.

Para os experimentos com o circuito híbrido, todas as séries apresentaram $I M M_{r e l}$ nula no sentido PD $\rightarrow \mathrm{NA}$, o que é esperado uma vez que os PSIBs do NA são completamente independentes da atividade do PD.

\subsubsection{REAPROVEITAMENTO DA INFORMAÇÃO}

No corpo celular o sinal é propagado passivamente pela difusão iônica cujo efeito é atenuado exponencialmente com o tempo. Se a informação recebida pelo PD fosse codificada de maneira linear, esperaríamos que os estímulos inibidores PIPSs (potenciais inibidores pós-sinápticos) resultantes do início do disparo do LP teriam peso menor que os últimos PIPS na integração do sinal pelo PD, ou seja, é natural pensar que quando o PD dispara, ele devesse ser mais responsivo aos estímulos pré-sinápticos mais recentes do último burst do LP.

Podemos pensar em uma sequência de três bursts $(\mathrm{LP} \rightarrow \mathrm{PD} \rightarrow \mathrm{LP})$ : se o neurônio de resposta se "lembrasse" apenas dos estímulos mais recentes, então 

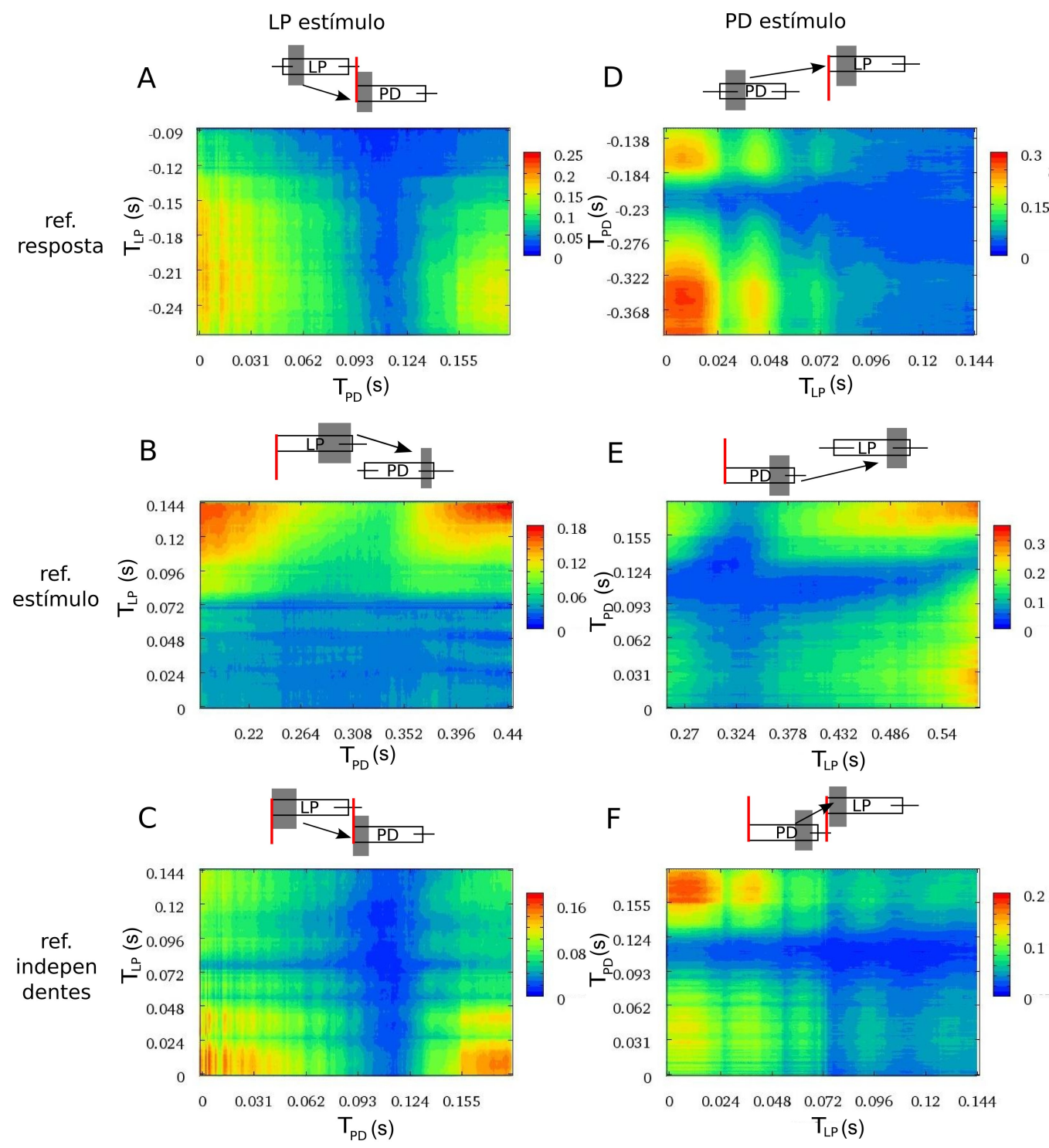

Fig. 4.6 - Resultados de $I M M_{\text {rel }}$ para $L P \rightarrow P D$ e $P D \rightarrow L P$ com diferentes referências temporais para um mesmo experimento. $A$. $L P \rightarrow P D$ referência no $P D \boldsymbol{B}$. $L P \rightarrow P D$ referência no $L P C$. $L P \rightarrow P D$ referências independentes $\boldsymbol{D}$. $P D \rightarrow L P$ referência no $L P \boldsymbol{E} . P D \rightarrow L P$ referência no $P D \boldsymbol{F} . P D \rightarrow L P$ referências independentes. Acima de cada diagrama estão representados os bursts de LP e PD. Os retângulos horizontais correspondem à duração média de cada burst. Em cada caso, as linhas vermelhas verticais representam as referências temporais adotadas e os retângulos cinza na vertical representam a porção do burst associada ao pico de $I M M_{\text {rel }}$. 
a informação seria expressa apenas no final do bursts de estímulo com relação ao início do burst de resposta. Nesse cenário, a informação expressa no PD sobre o burst anterior do LP não poderia ser propagada até o burst seguinte do LP.

Porém, os gráficos da $I M M_{\text {rel }}$ mostram que a informação não é processada de maneira intuitiva, ou previsível como a sugerida no parágrafo anterior. A Fig. 4.7 ajuda a entender o fluxo de informação de um neurônio para outro, mostrando de maneira esquematizada as regiões dos bursts responsáveis pelos picos de $\mathrm{IMM}_{\text {rel }}$ nos casos A e D da Fig. 4.6, sendo que as regiões vermelhas e azuis representadas no esquema correspondem às regiões cinza do burst do PD e LP respectivamente.

A Fig. 4.6 A mostra que os PSIBs do início do PD expressam informação do início do burst anterior do LP e em D podemos ver que esses mesmos PSIBs estão codificados no início do burst seguinte do LP. Desse modo, os PSIBs do LP podem codificar até 7,5\% da atividade do início de LP anterior (o que também é válido para o PD). Assim, o mecanismo de codificação de informação nos PSIBs serve como uma "memória de curto prazo"i.e. permite que haja reaproveitamento da informação.

\subsection{INFORMAÇÃO DO NEURÔNIO MOTOR LP É ENCONTRADA EM UM NERVO QUE PROJETA EM ÁREAS SENSORIAIS DO CÉREBRO}

Até agora, mostramos que os PSIBs do neurônio motor LP são codificados nos PSIBs do PD, mas seria possível que essa informação fosse codificada também por outro neurônio do STNS? Se isso for possível, qual seria sua função?

Para investigar essas questões, realizamos experimentos registrando a ati- 


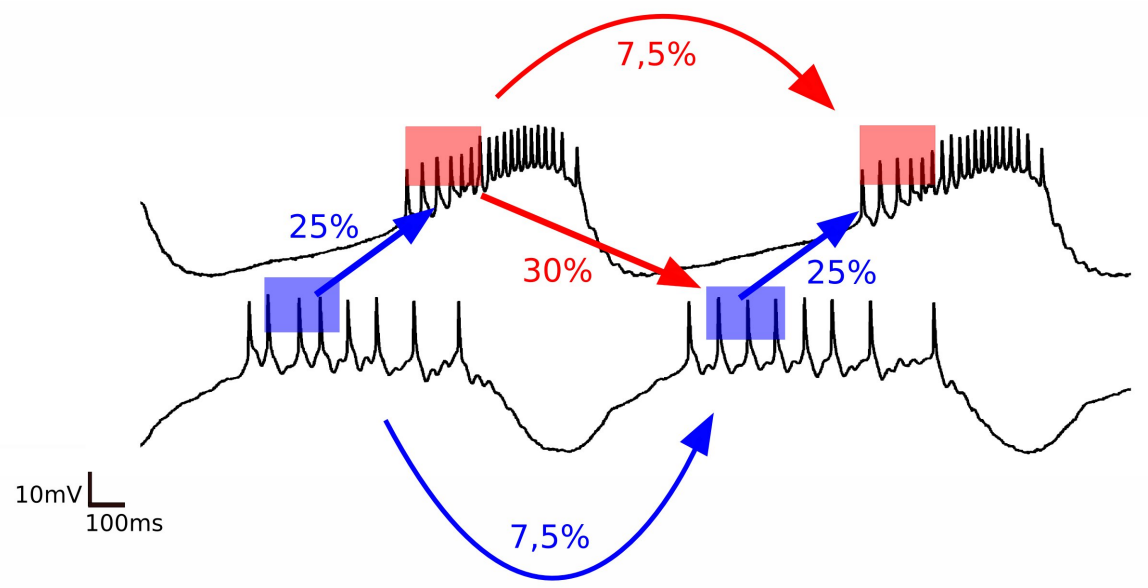

Fig. 4.7 - Informação expressa no início do LP é codificada em 30\% nos PSIBs do burst seguinte do LP. Em seguida, esses mesmos PSIBs são codificados em $25 \%$ nos PSIBs do início do burst seguinte do LP. Assim, existe uma via de reaproveitamento de informação início LP $\rightarrow$ início PD $\rightarrow$ início LP

vidade extracelular do nervo ivn e do neurônio LP usando a mesma técnica de análise para computar $I M M_{r e l}$ entre os sinais do burst do LP e de um trecho correspondente do ivn no intervalo de [-2;2] s usando o primeiro spike do LP como referência temporal. Os PSIBs correspondentes aos spikes do ivn que ocorrem antes do burst do LP são considerados estímulo enquanto que os PSIBs do LP são considerados resposta. Da mesma maneira, os PSIBs do ivn são considerados resposta se correspondem a spikes após o burst do LP e os PSIBs do LP são tidos como estímulo.

De fato, parte dos PSIBs do LP é codificada pelas unidades ativas do ivn. A região de máxima $I M M_{r e l}$ é posicionada na região positiva de $T_{i v n}$, significando que a informação flui do LP para o ivn (Fig. 4.8). O nervo leva aproximadamente 0,6 s para expressar informação vinda do LP. Como a velocidade de condução no ivn é da ordem de m/s (Moulins et al., 1979; Russel e Hartline, 1984), e o STG está apenas a alguns centímetros do eletrodo, a velocidade de condução no sinal pelo axônio não justica o atraso na informação observada. Esse resultado sugere que o atraso medido está relacionado com a maneira 
como a informação é codificada/processada, sinapse por sinapse, do LP até chegar ao ivn. Apesar das conexões sinápticas entre LP e as unidades ativas do ivn serem completamente desconhecidas, podemos especular a respeito da via de transmissão de informação dizendo, por exemplo, que essa informação é recebida por alguma unidade ativa do ivn através de uma sinapse inibitória.

Os valores de $I M M_{r e l}$ mais proeminentes chegam a $12,5 \%$ e correspondem a uma região próxima ao início do LP. Em sete de dez preparações diferentes em siris azuis, os pico de $I M M_{r e l}$ aparecem na parte positiva do gráfico com relação ao eixo $T_{i v n}$, ou seja, nesses casos, o pico corresponde ao fluxo de informação do LP para o ivn. Os valores de $I M M_{\text {rel }}$ nos picos variaram de 2.5 a $28 \%$ (todos estatisticamente significantes). As outras três séries temporais restantes não apresentaram valores significantes de $I M M_{r e l}$ em nenhuma região do gráfico e correspondem a séries em que as unidades do ivn de frequência mais alta não estavam ativas.

\subsection{Número De Bits e ALFABeto}

O método de maximização da entropia permite escolher a janela que contém PSIBs com maior capacidade informacional para um determinado número de bits $n$, mas, se escolhêssemos um valor diferente de $n$, seria possível obter conjuntos de PSIBs com capacidade informacional ainda maior? Se sim, como obter o melhor $n$ ?

Na seção de métodos, propusemos um critério que se baseia em determinar a taxa de produção de informação $d_{i, n}=H_{i, n} / L_{i, n}=H_{i, n} /\left(n \cdot B_{i, n}\right)$ para cada ponteiro $i$ variando ao longo do burst. A Fig. 4.9 mostra um exemplo da relação entre $d$ e o número de bits para qualquer $i$ e $n$ variando entre 2 e 10 para uma série de $\mathrm{PD}$. Nesse caso, $\mathrm{n}=5$ maximiza a taxa de produção de 


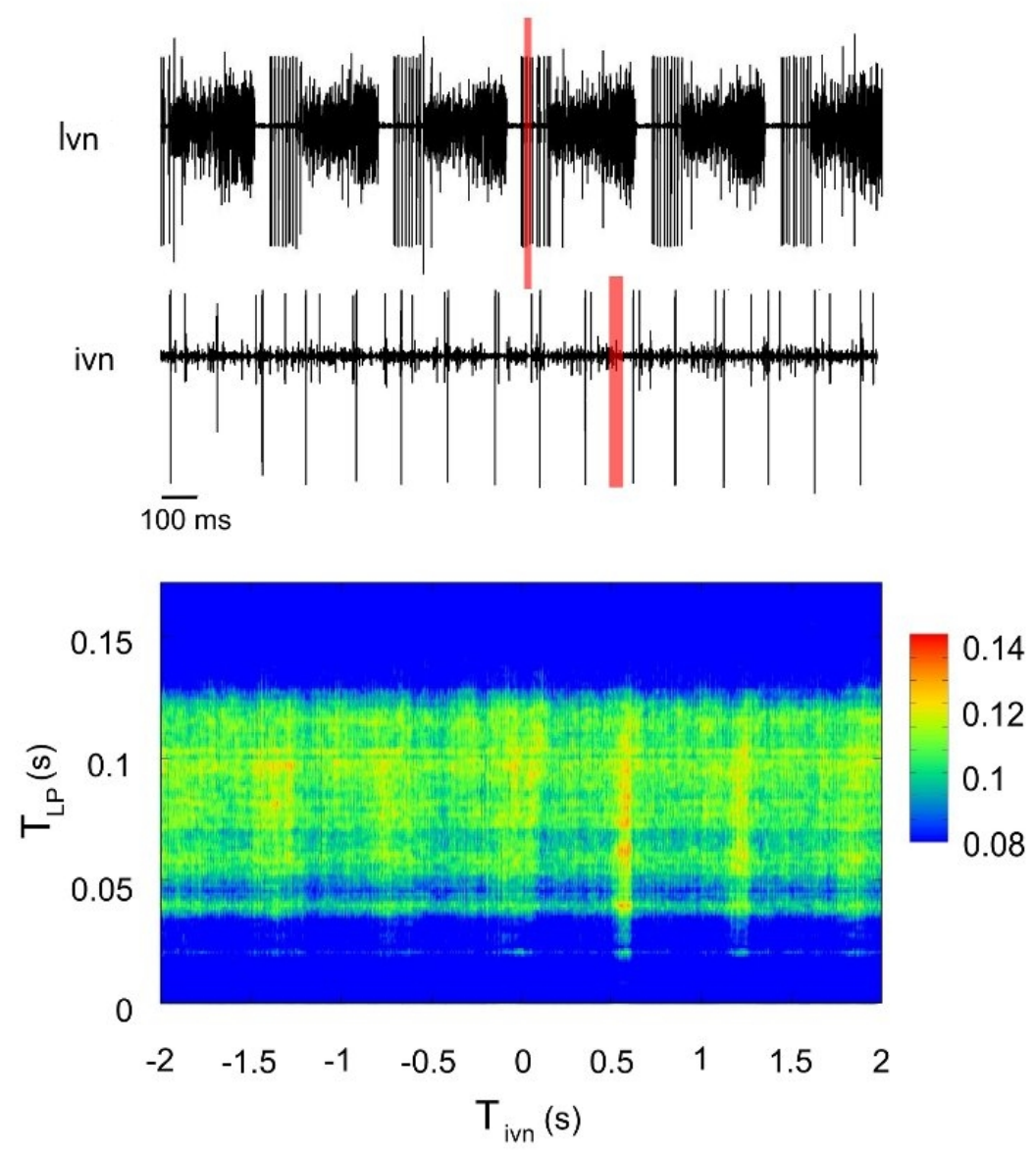

Fig. 4.8 - IM $M_{\text {rel }}$ entre $L P$ e ivn em função de $T_{L P}$ e $T_{i v n}$. O traço superior é o sinal extracelular obtido do nervo lvn onde podemos claramente ver e detectar os spikes do LP (unidades de maior amplitude). O traço inferior é o sinal extracelular do nervo ivn, onde há diversas unidades ativas, inclusive algumas de alta frequência, da ordem de grandeza da frequência da atividade em spikes do LP. Pode-se ver pelo mapa de IM $M_{\text {rel }}$ um pico bem definido indicando que a informação sobre os PSIBs do LP demora 0.6s para chegar ao ivn. Os retângulos em vermelho mostram as porções do burst $L P$ e do trecho do ivn $\left(l_{L P}\right.$ e $\left.l_{\text {ivn }}\right)$ que correspondem ao pico máximo de $I M M_{\text {rel }}$. 


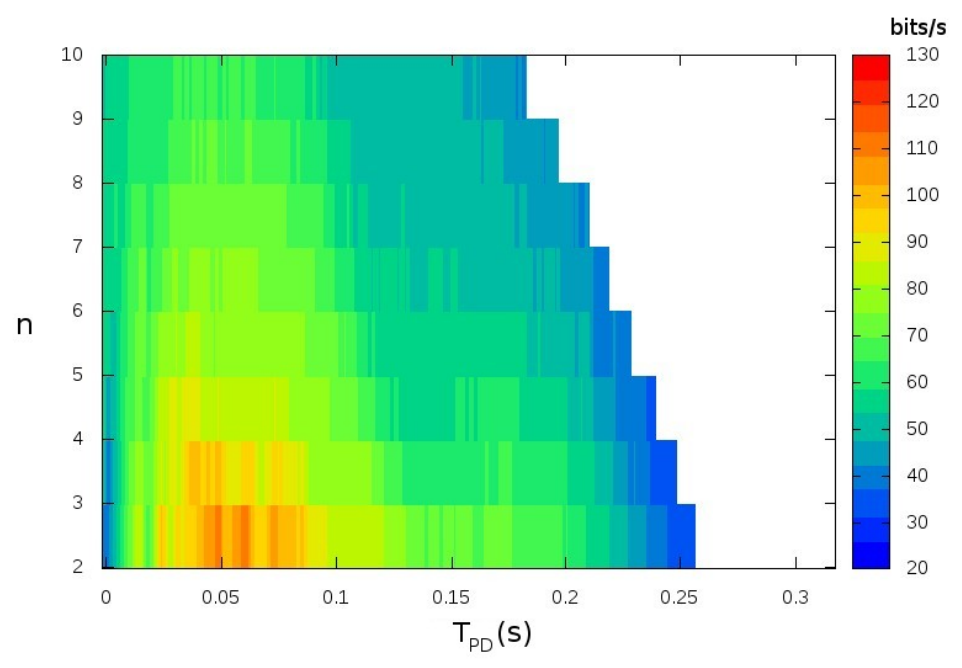

Fig. 4.9 - Taxa de produção de informação em bits/s. $d_{i, n}=H_{i, n} /\left(L_{i, n}\right)$ ao longo do burst do neurônio PD para bits variando de 2 a 10.

informação, portanto se trabalhássemos com $n>5$ que estaríamos incluindo mais spikes na estatística que não acrescentam informação proporcionalmente ao tamanho da janela.

Existe ainda um outro critério que diz respeito à limitação estatística. Como o tamanho da matriz de probabilidades conjuntas cresce com $2^{2 n}$, existe uma limitação prática na escolha de $n$, determinada pela amostragem de dados experimentais (em nosso caso, esse limite está em torno de 8 bits).

Como no exemplo da Fig. 4.9, na maioria dos casos das séries analisadas nesse trabalho, o maior número de bits que maximiza $d$ para qualquer região do burst de estímulo ou resposta é igual ou menor que 5. Portanto $n=5$ parece uma boa escolha segundo ambos critérios apresentados. 


\subsection{Estudo DA VARIAÇÃo DA ENTROPia COM O NÚMERO DE Bits}

Uma vez escolhido o número de bits $n$, o algoritmo determina qual duração da janela $L$ produz o conjunto de PSIBs de maior conteúdo informacional, mas podemos ainda questionar se a relação é recíproca, ou seja, se $n$ é o número de bits que melhor caracteriza o conjunto de eventos nessa janela.

Para isso estudamos a relação da entropia com o número de bits para $L$ fixo. Utilizamos o algoritmo para escolher $L_{i}$ que maximiza a entropia para determinado $n=N$ para uma posição $i$ no burst. Em seguida, calculamos a entropia dos PSIBs formados quando dividimos $L_{i}$ em $n \neq N$ bins. Repetimos esse procedimento para vários valores de $n$ e para todos os valores de $i$.

A Fig. 4.10 mostra a entropia relativa $H / n$ média ao longo do burst em função de $n$ para análise para uma série temporal onde utilizamos $n=5$. Nesse exemplo, vemos que de fato, a entropia relativa tem seu máximo também em 5 bits.

Assim, mostramos que a escolha de $L$ e $n$ mantém uma relação de reciprocidade: $L$ é a janela que melhor caracteriza o sistema para bits $n$, da mesma forma $n$ é o melhor número de bits para caracterizar o sistema para a janela L. Essa relação é unívoca para os dados analisados.

\subsection{O ALFABETO}

Até esse ponto no manuscrito, foi demonstrada a capacidade informacional dos PSIBs, mas ainda não foi explicado como são esses padrões. A figura 4.11 mostra o histograma de ocorrências de todas as 32 palavras possíveis para todas as janelas dentro da duração do burst escolhidas pelo programa para uma série temporal do neurônio PD. A ordem em que as palavras aparecem no histograma foi escolhida especialmente para que palavras próximas correspon- 


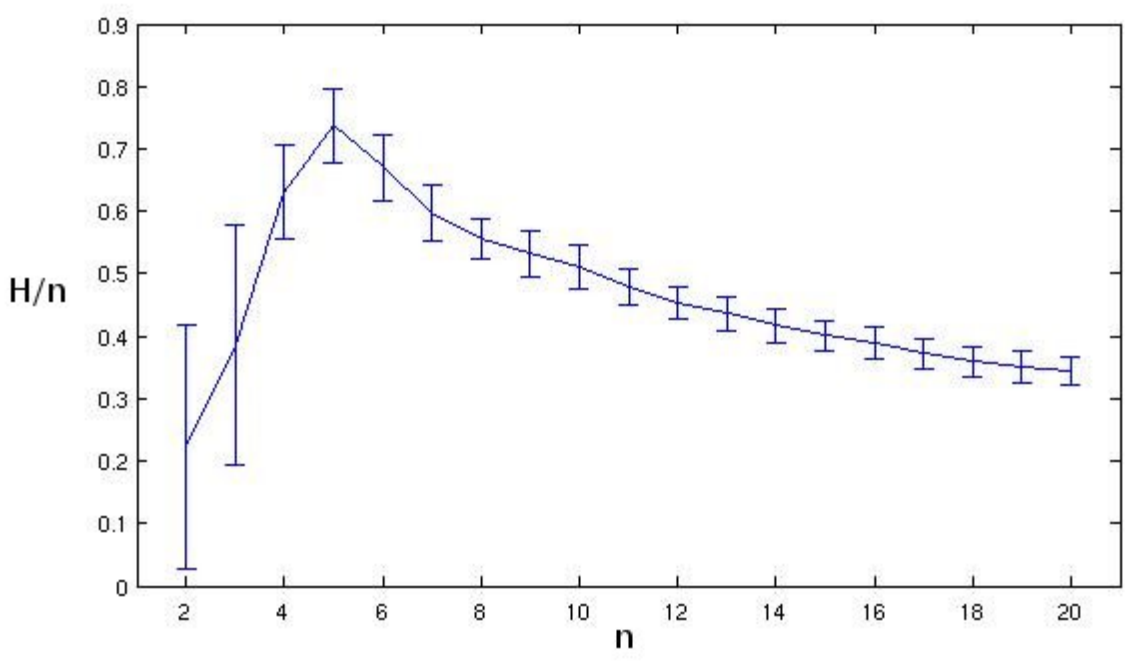

Fig. 4.10 - Gráfico da entropia relativa $H / n$ com o número de bits da palavra n. A duração da janela é fixa e foi escolhida para maximizar a entropia para 5 bits.

dam a sequências de spikes parecidas, tanto quanto ao número como quanto à proximidade de ocorrência dos spikes.

As palavras estão primeiramente agrupadas por números de ocorrências de spikes, ou seja, pelo número de '1's. A primeira palavra não tem nenhum '1', da segunda à sexta têm um '1', e assim por diante. Dentro destes grupos de '1's, as palavras estão agrupadas por afinidade obedecendo a ordem Gray.

O código Gray também é chamado de código binário refletido ("reflected binary code") por poder ser gerado através de um algoritmo recursivo de reflexão dos bits seguido da adição de ' 0 ' à frente dos bits originais e de ' 1 ' à frente dos bits refletidos. Isso resulta em um código em que dois números consecutivos diferem por apenas um bit. Por exemplo, no código Gray, o número 11000 aparece seguido de 01000, enquanto que no código binário existem 16 números entre o segundo e o primeiro.

Em princípio, o algoritmo da maximização da entropia não impõe restrição alguma sobre como deve ser a distribuição das palavras, de modo que, por exemplo, se os ISI's respeitassem uma distribuição de Poisson a distribuição das 


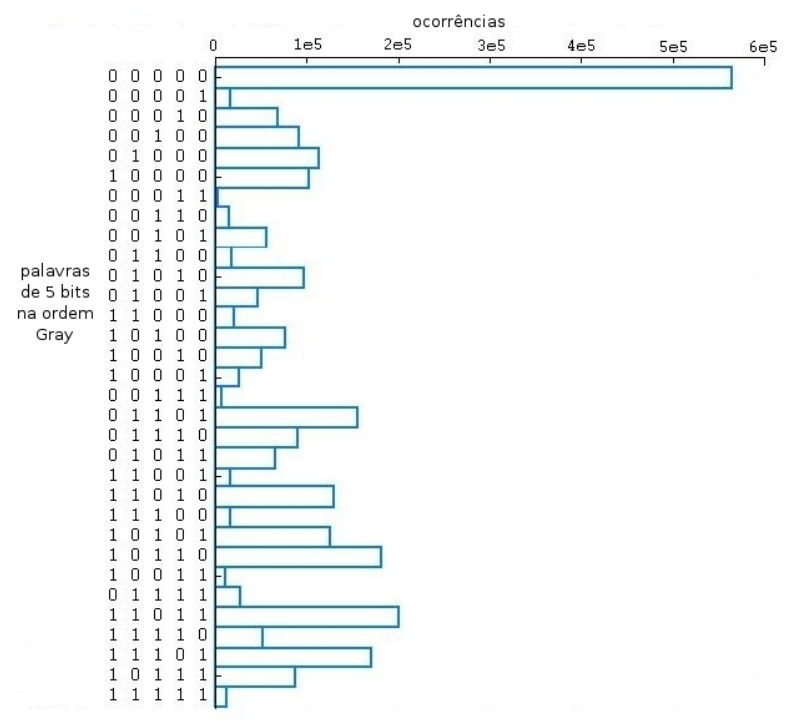

Fig. 4.11 - Histograma da ocorrência de palavras em todos os trechos do burst do PD. As palavras estão ordenadas em grupos pelo número de ocorrências de spikes e dentro destes grupos estão ordenadas pela ordem Gray.

palavras seria uniforme. No entanto, o histograma mostra que a distribuição das palavras não é uniforme e se dá de maneira não intuitiva. Existem palavras muito próximas com número de ocorrências bem diferente. Por exemplo, as palavras '10110' e '10011' diferem apenas pelo deslocamento de um dígito entretanto a primeira é 16 vezes mais frequente que a segunda.

Este é um resultado interessante, pois ainda que não seja possível compreender o código utilizado pelo neurônio apenas olhando para a distribuição das palavras, o conhecimento do alfabeto nos permitirá no futuro testar os efeitos das diferentes palavras na transmissão de informação de um neurônio para outro.

\subsection{CONDUtÂNCIAS LENTAS E CODIFICAÇÃO DE INFORMAÇÃO}

Para estudar quais as propriedades dinâmicas envolvidas no mecanismo de codificação encontrado, utilizamos uma técnica de congelamento de con- 

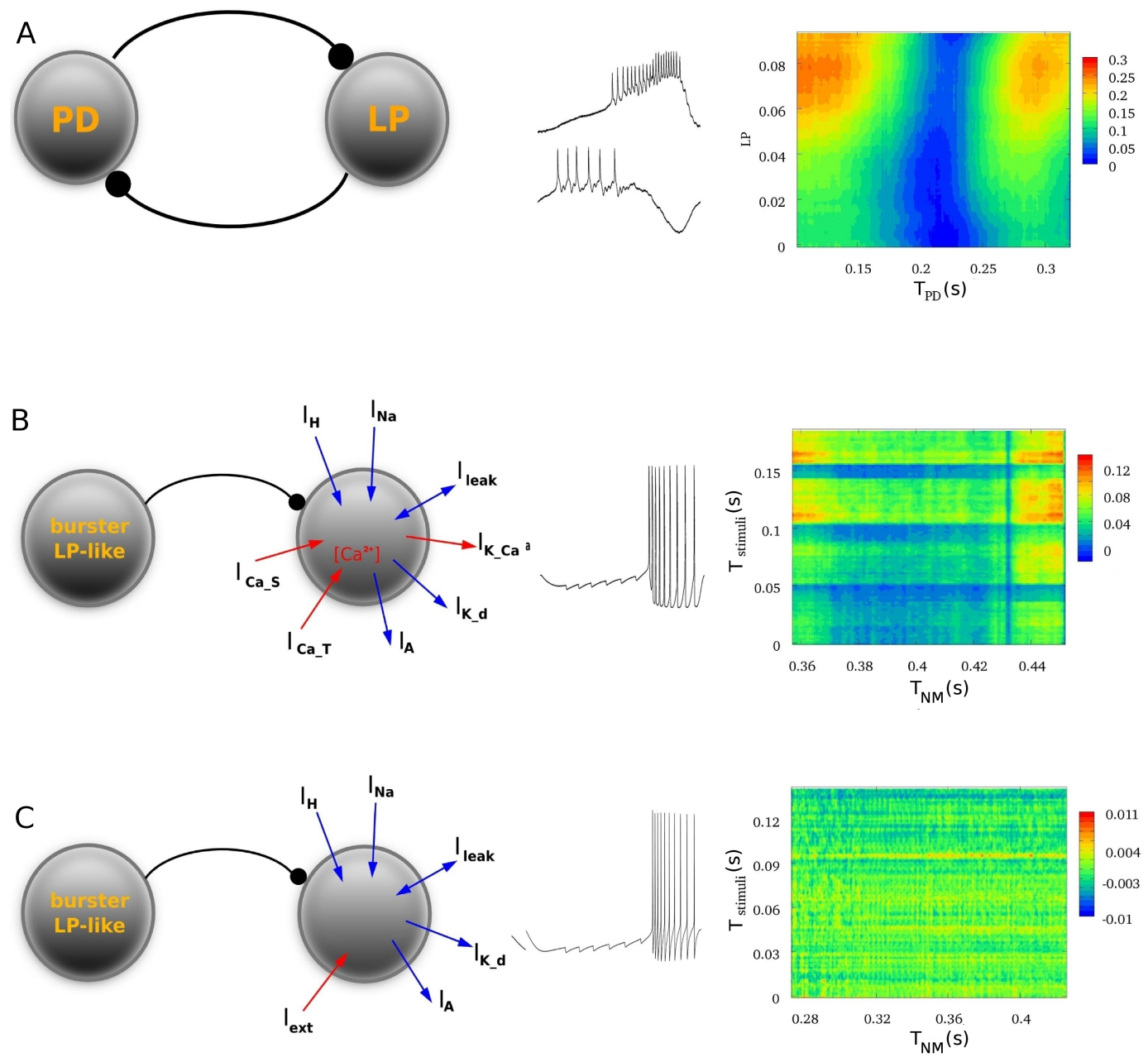

Fig. 4.12 - A - Exemplo de resultados da $I M M_{\text {rel }}$ para $L P \rightarrow P D$ com referência no $P D$ e exemplo do traço intracelular para ambos neurônios. $B$ - Neurônio modelo (NM) para marcapasso de condutâncias tipo HH. Instantes de perturbações aparecem como potenciais inibitórios no traço do potencial de membrana precedendo o burst do neurônio modelo. Diagrama de $I M M_{\text {rel }}$ apresenta picos contundentes em posições similares às do diagrama em A. C - Neurônio modelo sujeito ao mesmo tipo de perturbação, mas com condutâncias dependentes de cálcio e concentração de cálcio intracelular "congeladas". O gráfico de IM $M_{\text {rel }}$ não apresenta valores significantes. 
dutâncias ("conductance clamp" descrito na seção 2.6) para investigar o papel das condutâncias dependentes de cálcio nos tempos de disparo intrabust.

Realizamos simulações computacionais utilizando um modelo de marcapasso para o PD (Turrigiano et al. 1995, Prinz et al., 2003) sujeito a trens de potenciais inibitórios na fase hiperpolarizada e aplicamos o mesmo método de análise usado nos dados experimentais. Alguns parâmetros do modelo foram ajustados de modo a obtermos um comportamento similar à relação LP-PD observada experimentalmente. O tempo médio entre perturbações e a entropia dos padrões nos trens de perturbações são ajustados para que se assemelhem aos produzidos pelo LP real. Foram gravadas as séries temporais dos instantes das perturbações e dos instantes de disparo do neurônio modelo para 1000 bursts.

Primeiramente, realizamos uma simulação do modelo com todas as condutâncias dinâmicas sem estimulação, gravando séries temporais do potencial de membrana e de com todas as variáveis dinâmicas $m_{i}$ e $h_{i}$ de cada condutância dependente de cálcio a ser congelada $\left(\mathrm{I}_{C a_{-} S}, \mathrm{I}_{C a_{-} T}\right.$ e $\left.I_{K_{-} C a}\right)$, bem como da concentração de cálcio intracelular (Fig. 4.12 B).(Ver Apêndice). Em seguida, realizamos outra simulação também do modelo com todas as condutâncias, desta vez respondendo espontaneamente a trens de IPSPs provocados na fase hiperpolarizada.

Analizamos essa série temporal usando o mesmo método aplicado aos dados experimentais, sendo que desta vez os bursts de estímulos correspondem aos trens de IPSPs e os bursts de resposta correspondem à resposta do neurônio modelo subsequentes ao estímulo. Podemos ver que o gráfico de $I M M_{\text {rel }}$ apresenta dois picos contundentes correspondendo ao final do trem de estimulação com o início e final do burst do neurônio modelo, regiões muito similares às encontradas no caso da série temporal real (Fig. $4.12 \mathrm{~A})$. 
Em seguida, a simulação é repetida submetendo o neurônio modelo a trens de IPSPs similares ao caso anterior, no entanto neste caso as condutâncias lentas estão congeladas, ou seja $m_{i}(t)$ e $h_{i}(t)$ correspondem às séries temporais previamente registradas. Neste caso, o comportamento do neurônio modelo é visualmente muito similar ao observado na situação anterior, no entanto, o gráfico de $I M M_{r e l}$ demonstra que os padrões de perturbações não afetam os PSIBs do neurônio modelo.

A análise informacional revelou que os picos desaparecem do diagrama e que $I M M_{r e l}$ não apresenta regiões com valores significantes, o que indica que a dinâmica das correntes lentas dependentes de cálcio é importante para o mecanismo de codificação de informação observado experimentalmente (Rodrigues et al., 2010).

Na dissertação de mestrado de Rafael Viegas (Viegas, 2011), estão descritos experimentos de "conductance clamp" em neurônios do STG. Seu protocolo consiste em introduzir uma condutância lenta do tipo Hodgking-Huxley (HH) em uma célula sujeita a IPSPs utilizando "dynamic clamp" e em seguida submeter o mesmo neurônio a perturbações parecidas, porém utilizando os valores de condutância previamente gravados na ausência de estímulos. Seus resultados mostraram que usando condutância do tipo HH os PSIBs do neurônio respondem ao trem de perturbação de modo muito similar ao descrito para LP/PD no circuito intacto: o diagrama de $I M M_{r e l}$ também apresenta um pico no início do trem de estímulos com o início do burst de resposta (como os resultados apresentados na seção 4.2 desse trabalho). Quando a condutância é substituída pela condutância gravada, os valores de $I M M_{r e l}$ caem drasticamente e o pico desaparece.

Esses resultados indicam que as condutâncias lentas devem ter um papel importante no mecanismo de codificação de informação que encontramos e 
podem servir de motivação para investigações futuras. 


\section{Discussão}

Centros geradores de padrões motores têm sido intensivamente estudados nas últimas quatro décadas, tendo contribuído muito para a compreensão da fisiologia e da dinâmica de redes neurais neste período. O estudo da neurodinâmica tem evoluído concomitantemente com o desenvolvimento de novas técnicas de análise dedicadas. Por exemplo, curvas de resposta de fase (PRC, Oprisan et al., 2004; Galán et al., 2005; Ermentrout et al., 2007; Schleimer and Stemmler, 2009) contribuíram para a compreensão de sincronização em CPGs (Ayers e Selverston, 1984, Canavier e Achuthan, 2010) considerando neurônios como osciladores periódicos. Análises de PRC consideram apenas as flutuações na fase de bursts de neurônios interagindo no CPG, desconsiderando qualquer oscilação nos ISI intraburst.

As flutuações nos instantes de disparo intraburst desses neurônios não despertam muito interesse em geral por não afetarem a contração muscular. No entanto, mapas de retorno de ISIs intraburst (Segundo et al., 1998) de neurônios de CPG revelaram padrões sutis sensíveis a alterações fisiologicamente relevantes no circuito (Campos et al., 2007; Szücs et al., 2003, 2005). Szücs et al. (Szücs et al., 2003) mostraram que a assinatura do mapa de primeiro retorno do neurônio PD é modificada quando a sinapse entre LP e PD é artificialmente modificada, o que significa que os PSIBs do PD são sensíveis à atividade do LP.

Neste trabalho investigamos mais a fundo as relações entre padrões de 
disparos desses dois neurônios, não apenas considerando relações de primeira ordem entre ISIs, mas também olhando para uma grande variedade de PSIBs usando uma ferramenta baseada em teoria da informação. Para isso desenvolvemos um método de análise para inferir o fluxo de informação de um neurônio motor a outro e também de um neurônio motor a um nervo que projeta no cérebro.

A ferramenta que desenvolvemos é distinta em essência de outros métodos normalmente utilizados na análise informacional de sinais neurais. Tipicamente, o estudo de codificação de informação em trens de spikes requer a identificação de padrões normalmente definidos a priori do experimento em termos de ocorrências de bursts ou certas sequências de spikes ou ISIs que podem ser associadas a alguma característica específica do estímulo (Eyerabide and Samengo, 2010; Tiesinga et al., 2008; Kreuz et al. , 2011; Kumar et al. 2010; Butts et al., 2007).

Ao lidar com sistemas sensoriais, o experimentador pode observar quais características do estímulo são importantes (ex. certo odor ou frequência sonora) e baseado no conhecimento prévio do que está sendo codificado, pode identificar padrões interessantes na resposta que estejam possivelmente relacionados àquelas características. No entanto, para investigar fluxo de informação entre dois neurônios bursters motores, é necessário adotar uma abordagem diferente. No nosso caso, ambos os sinais de estímulo e resposta são sequências de spikes ocorrendo nos bursts de cada neurônio, então não existe um critério simples para determinar quais características do estímulo são mais importantes de serem codificadas pela resposta.

Por isso, ao invés de procurarmos o código utilizado pelo neurônio, utilizamos um conceito mais geral de informação tentando ao mesmo tempo fazer o menor número possível de hipóteses a respeito do código em si. Apesar 
deste método ter sido desenvolvido com o propósito de responder questões específicas, também é potencialmente útil a neurocientistas interessados em código neural devido ao seu poder de revelar informação oculta em padrões de spikes, e poderia ainda contribuir para a análise informacional de séries temporais de outros tipos de processos puntuais.

Mostramos que o neurônio PD dedica boa parte de sua capacidade total de codificação para expressar informação sobre os PSIBs do LP. Um fato ainda mais interessante é que normalmente a região de máxima $I M M_{r e l}$ corresponde ao começo dos bursts de ambos neurônios.

As variações amplas nos valores de $I M M_{r e l}$ são claramente independentes das flutuações nos valores das entropias ao longo dos bursts de ambos neurônios. Se pensarmos no neurônio PD como um simples integrador de entradas sinápticas recebidas na fase hiperpolarizada, então a dinâmica exibida durante a despolarização deveria depender linearmente dos estímulos. Observando que as entropias de ambos neurônios flutuam suavemente ao longo dos bursts, variações abruptas só podem aparecer nos gráficos de $I M M_{r e l}$ se a informação for representada na resposta de maneira não-linear, o que está em acordo com trabalhos anteriores (Chacron et al., 2004).

Nossos resultados de $I M M_{\text {rel }}$ são consistentes com estudos anteriores de PRC que descreveram o efeito de pulsos inibitórios na fase do PD utilizando o começo de seu burst como referência de tempo (Oprizan et al., 2004): o início de um burst do LP (que normalmente inclui o primeiro spike do LP) é fortemente correlacionado com o início do burst seguinte do PD. No entanto, nossa análise considera não apenas variações na fase relativa entre LP e PD, mas também na estrutura temporal dos disparos. Se o PD fosse sensível apenas a variações na fase, então a posição esperada do pico de $I M M_{r e l}$ seria pequena incluindo apenas o primeiro spike do LP e não os spikes subsequentes. Além 
disso, quando a informação da fase é completamente removida (referências independentes) o pico mais pronunciado ainda se mantem no início de ambos os bursts com valores bastante expressivos, indicando que não apenas a fase, mas também a estrutura temporal dos spikes contribui para a informação expressa no burst seguinte do PD.

A análise de dados do circuito intacto revelou que os PSIBs do PD são afetados pelos PSIBs do LP, no entanto, não podemos excluir a possibilidade da influência de um elemento externo sobre esses neurônios. Para esclarecer essa questão, realizamos experimentos com o circuito híbrido e mostramos que a resposta do PD a um neurônio artificial é bastante similar à resposta ao LP natural na rede intacta. O neurônio modelo imita o LP na média da duração do burst, fase e número de spikes por burst, mas os tempos de disparo são determinados por parâmetros do modelo definidos a priori. Portanto, a $I M M_{\text {rel }}$ medida reflete como a variabilidade dos PSIBs do PD neste caso é afetada pela variação espontânea dos tempos de disparo do neurônio artificial, isento da influência de qualquer elemento da rede. Como o efeito observado na rede intacta (onde existem outros neurônios estimulando LP e PD simultaneamente) também aparece na rede híbrida (relação unidirecional) podemos alegar que uma única sinapse é suficiente para suportar o mecanismo de codificação de informação encontrado.

Além de mostrarmos que o PD pode expressar informação sobre os PSIBs do LP, também encontramos fluxo de informação no sentido inverso. Os neurônios LP e PD são responsáveis pela contração de músculos antagonistas que, por esse motivo, são acoplados por sinapses inibitórias, operando em antifase. Por isso, pode-se definir com clareza o que é o sinal de estímulo, que consiste no trem de disparos (burst) do neurônio pré sináptico, e o sinal de resposta, que corresponde ao trem de disparos do neurônio pós sináptico 
subsequente ao estímulo.

Inferindo a informação que o neurônio pós-sináptico expressa sobre a atividade do pré-sináptico e sabendo que estão conectados por mútua inibição, pode-se entender a relação de mútua influência entre esses neurônios e investigar se a informação é reaproveitada de um ciclo a outro do mesmo neurônio $(L P \rightarrow P D \rightarrow L P)$. De fato, a anisotropia que emerge dos gráficos de $I M M_{r e l}$ permite o reaproveitamento da informação (os PSIBs de um burst do LP são indiretamente codificados nos PSIBs burst seguinte do LP através do burst intermediário do PD), o qual pode ser entendido como um tipo de memória de curto prazo (de outra forma também pode ser vista como uma informação ressonante na rede).

Em neurônios motores de CPGs de crustáceos, a atividade em bursts é associada com coordenação muscular, mas a escala de tempo dos ISI não pode ser associada diretamente ao controle motor. Morris e Hooper (Morris e Hooper, 1997; Hooper et al., 2007) mostraram que a contração do músculo cpv1b, controlado pelo neurônio PD através de uma sinapse graduada (Graubard et al., 1980), é determinada pelo número de spikes de tal forma que variações sutis na frequência não afetam a taxa de contração. Por isso, a contração muscular deve ser independente de qualquer informação codificada nos PSIBs. Por outro lado, em um outro sistema muscular análogo, o músculo acessório fechador da rádula em Aplysia opera entre os regimes rápido e lento, respondendo de forma não-linear a diferentes padrões de disparo (Zhurov and Brezina, 2006). Por isso, apesar de não ser o caso do CPG pilórico, é possível haver um sistema neuromuscular com propriedades não lineares no qual a codificação de informação em PSIBs possa estar diretamente envolvida no controle motor.

Se a informação expressa através de PSIBs não é importante para contração muscular no sistema pilórico, teria ela alguma importância fisiológica? Para 
abordar essa questão, procuramos por informação transmitida do STG para um nervo que conecta o STNS ao cérebro. De fato, a atividade do nervo ivn codifica informação dos PSIBs do LP. Nesta análise, a referência de tempo é colocada no primeiro spike do LP, portanto, qualquer informação contida nos PSIBs se deve unicamente às variações nos tempos de disparo intraburst independentes de qualquer relação de fase com outros neurônios pilóricos.

Estudos anteriores em lagostim (Böhm, et al., 2001) mostraram que existem neurônios do STNS localizados nos OG e CoGs que enviam fibras através do ivn. Arborizações desses neurônios espalham-se por dentro do protocérebro e outras áreas, principalmente da primeira e segunda antena, levando a comunicação com centros de processamento importantes no cérebro. Como o STNS é bastante invariante entre espécies, é razoável supor que também no siri o ivn pode ser uma via que leva informação do $\mathrm{CPG}$ pilórico a áreas sensoriais do cérebro. Apesar de não podermos afirmar, baseado nos resultados de medidas de $I M M_{r e l}$, que a informação enviada é de fato utilizada para alterar o comportamento, é consistente assumir que essa via encontrada permite que informação sobre o sistema pilórico seja disponibilizada ao cérebro.

Outro resultado importante é que $I M M_{\text {rel }}$ é qualitativamente muito similar em diferentes preparações. O CPG pilórico pode apresentar um vasto repertório de ritmos em um mesmo animal e em diferentes espécimes devido à variabilidade no aparato de excitabilidade celular, força sináptica e concentração basal de neuromoduladores. Todos os animais usados nesse estudo foram coletados já adultos de seu habitat natural, ou seja, devem apresentar um ritmo gastro-pilórico funcional e a variabilidade de ritmos encontrada pode ser considerada bem representativa do repertório dinâmico encontrado na natureza (Goaillard et al., 2009). Nosso estudo revelou um fenômeno de fluxo de informação que é onipresente em diferentes espécimes de duas espécies distin- 
tas a despeito de diferenças bruscas no período pilórico, número de spikes por burst ou relações de fase entre LP e PD encontradas em cada preparação.

No CPG pilórico do STG, as propriedades de excitabilidade dos neurônios e de conectividade da rede agem em conjunto para gerar padrões que, apesar de autônomos, estão sujeitos à ação de centros de modulação que ajustam o comportamento dos neurônios em burst de acordo com a necessidade do animal (Selverston et al., 2000). Além da natureza não-linear intrínseca dos neurônios pilóricos existe ainda o efeito extremamente complexo dos neuromoduladores que atuam desde a escala celular até a sistêmica e em diversas escalas de tempo e, apesar dos moduladores serem muito bem conhecidos, pouco se compreende de fato sobre os mecanismos neuromodulação.

Neste cenário podemos propor uma possível função para o mecanismo de codificação de informação encontrado. Em princípio, essa informação poderia ser aproveitada para auxiliar no controle do funcionamento do STG de maneira mais rápida do que a informação que chega ao cérebro via retroalimentação sensorial (neurônios mecanoceptores sensíveis a estiramento que enviam informação ao cérebro e a gânglios superiores sobre a contração muscular) .

Estudos recentes (tanto em experimentos quanto em simulações) mostraram que circuitos com diferentes propriedades celulares e sinápticas podem apresentar atividade semelhante com relação a período de burst e fase, o que significa que devem ser funcionalmente equivalentes (Grashow et al., 2010; Goaillard et al., 2009; Marder and Prinz, 2002). Foi proposto que esse fenômeno pode ser parte de mecanismos intrincados responsáveis pela manutenção da homeostase. Em nosso trabalho, mostramos que um mecanismo tão sutil como a transmissão de informação contida em PSIBs é conservado apesar das diferenças nas propriedades das redes e mesmo em circuitos com diferentes funcionalidades, que pode ser evidência de um outro nível de regulação homeostática. 
Estudos em sistemas sensoriais têm mostrado que neurônios podem usar padrões temporais de spikes e frequência de disparo para codificar diferentes sinais simultaneamente (Bair and Koch, 1996; Panzeri et al., 2010; Middleton et al., 2011) e em nosso trabalho mostramos que neurônios pilóricos também podem executar essa tarefa. Nossos resultados expandem a visão do papel atribuído aos neurônios motores de CPGs, mostrando que são capazes de expressar informação em duas escalas de tempo distintas: uma no padrão de burst que diz respeito ao fenômeno mais conspícuo que é a contração motora, e outra na microestrutura dos padrões de disparo relacionada ao detalhamento temporal do estímulo pré-sináptico. Assim, esses neurônios normalmente vistos apenas como executores da função motora, também podem ter um papel na regulação do comportamento da rede diretamente ou através do sistema nervoso central.

Nosso trabalho sugere que uma abordagem não ortodoxa ao estudo de um sistema bem descrito mas não completamente conhecido, pode revelar fenômenos insuspeitos que não seriam encontrados através do estudo da propriedades mais conspícuas da rede. Tradicionalmente, a análise da dinâmica de CPGs têm sido um caminho direto ao entendimento de como o sistema nervoso controla o comportamento em outros sistemas nervosos em diversas espécies de invertebrados e vertebrados (Clarac and Perlstein, 2007, Marder and Bucher, 2007), dessa forma, esperamos que este trabalho possa contribuir para futuros avanços nessa área bem como trazer novas perspectivas ao estudo do código neural em outros sistemas. 


\section{Conclusões}

Centros geradores de padrões motores CPGs têm sido intensivamente estudados nas últimas quatro décadas e, apesar de terem sido inicialmente tratados como redes simples, hoje sabe-se que são extremamente complexas com propriedades dinâmicas e vias neuromodulatórias ainda não são completamente compreendidas.

Encontramos evidências de que neurônios motores são capazes de codificar, através de uma única sinapse, informação detalhada a respeito do comportamento do neurônio pré-sinaptico. Tal informação está contida na microestrutura dos padrões de disparo que inclui a variação sutil dos tempos de spikes intraburst. A informação é codificada de maneira não-linear ao longo do burst de ambos neurônios, e as porções dos bursts de estímulo e resposta que correspondem ao pico de informação mútua são surpreendentemente conservadas entre diferentes animais, indicando que é um mecanismo geral.

Os resultados de experimentos com redes híbridas corroboram os obtidos para o circuito intacto, o que nos permite alegar que o mecanismo de codificação encontrado deve se dar através de uma única sinapse. Além disso, a informação contida nos padrões de disparo do neurônio LP é codificada por neurônios nos gânglios superiores cujos axônios arborizam em áreas sensoriais do cérebro do animal, o que poderia, em princípio, auxiliar nos mecanismos de regulação do próprio CPG.

O método de análise que desenvolvemos para inferir informação mútua 
é distinto de outros comumente utilizados porque tentamos fazer o menor número de hipóteses possível a respeito do código neural. Nosso método pode ser útil a outros neurocientistas interessados no código neural em outros sistemas devido ao seu poder de revelar informação oculta em padrões de spikes, ou poderia ainda encontrar outras aplicações na análise informacional de séries temporais de outros tipos processos puntuais.

Nossos resultados expandem a visão do papel atribuído aos neurônios motores de CPGs que são capazes de expressar informação em duas escalas de tempo distintas: uma no padrão de burst, relativo ao fenômeno mais conspícuo que é a contração motora, e outra na microestrutura dos padrões de disparo relacionada a variações sutis na atividade do neurônio pré-sináptico. Tradicionalmente, a análise da dinâmica de CPGs têm sido um caminho direto ao entendimento de como o sistema nervoso controla o comportamento em diversas espécies de invertebrados e vertebrados e, assim como diversos fenômenos primeiramente observados no CPG pilórico foram mais tarde encontrados em outros sistemas, esperamos que nosso trabalho também possa contribuir para futuros avanços na compreensão do código neural. 


\section{REFERÊNCIAS}

Adrian ED e Zotterman Y (1926) The impulses produced by sensory nerve endings: Part II: The response of a single end organ. Journal of Physiology 61: $151-71$

Ayers J, Selverston AI (1984) Synaptic perturbation and entrainment of gastric mill rhythm of the spiny lobster. J Neurophysiol 51: 113-25

Bair W, Koch C (1996) Temporal precision of spike trains in extrastriate cortex of the behaving macaque monkey. Neural Comput 8:1185-1202.

Böhm H, Dybek E, Heizel HG (2001) Anatomy and in vivo activity of neurons connecting the crustacean stomatogastric nervous system to the brain. J Comp Physiol A 187:392-403.

Borst A, Theunissen FE (1999) Information theory and neural coding. Nature Neurosci 2:947-957.

Brocard F, Tazerart S, Vinay L (2010) Do pacemakers drive the central pattern generator for locomotion in mammals? Neuroscientist 16:139-155.

Butts DA, Weng C, Jin J, Yeh CI, Lesica NA, Alonso JM, Stanley GB (2007) Temporal precision in the neural code and the timescales of natural vision. 
Nature 449:92-U67.

Campos D, Aguirre C, Serrano E, Rodriguez FB, de Polavieja GG, Varona P (2007) Temporal structure in the bursting activity of the leech heartbeat CPG neurons. Neurocomputing 70:1792-1796.

Canavier CC, Achuthan S (2010) Pulse coupled oscillators and the phase resetting curve. Math Biosci 226:77-96.

Carelli PV (2008) Modelagem estocástica de neurônios e sua interação em tempo real com neurônios biológicos. Tese de doutorado. Universidade de São Paulo

Carelli PV, Reyes MB, Sartorelli JC, Pinto RD (2005) Whole cell stochastic model reproduces the irregularities found in the membrane potential of bursting neurons. J Neurophysiol 94:1169-1179.

Chacron MJ, Longtin A, Maler L (2004) To burst or not to burst? J Comput Neurosci 17:127-136.

Clarac F, Pearlstein E (2007) Invertebrate preparations and their contribution to neurobiology in the second half of the 20th century. Brain Res Rev 54:113161.

Cleland T e Selverston AI (1995) Inhibitory glutamate receptors in of central pattern generator neurons in the lobster stomatogastric ganglion. J. Neurosci. 15:6631-6639, 1995.

Dayan P, Abbot LF (2001) Theoretical Neuroscience: Computational and 
Mathematical Modelling of Neural Systems. Cambridge MA: MIT Press

Destexhe A, Bal T (2009) Dynamic Clamp: from principles to applications. Springer

Ermentrout GB, Galán RF, Urban NN (2007) Relating neural dynamics to neural coding. Phys Rev Lett 99:248103.

Esteves IM, Fernandes NM, Koberle R (2011) How to take turns: the fly's way to encode and decode rotational information arXiv:1103.0451 [q-bio.NC]

Eyherabide HG, Rokem A, Herz AVM, Samengo I (2008) Burst firing is a neural code in an insect auditory system. Front Comput Neurosci 2:3-7.

Eyherabide HG, Samengo I (2010) Time and category information in patternbased codes . Front Comput Neurosci 4:1-20.

Fanselow EE, Sameshima K, Baccala LA, Nicolelis MA (2001) Thalamic bursting in rats during different awake behavioral states. Proc. Nat. Acad. Sci. 98:15330-5.

Galán RF, Ermentrout GB, Urban NN (2005) Efficient estimation of phaseresetting curves in real neurons and its significance for neural-network modeling. Phys Rev Lett 94:158101.

Goaillard JM, Taylor AL, Schulz DJ, Marder E (2009) Functional consequences of animal-to-animal variation in circuit parameters. Nat Neurosci 12:14241430.

Graham Brown T (1914) On the nature of the fundamental activity of the nervous centres; together with an analysis of the conditioning of rhythmic 
activity in progression, and a theory of the evolution of function in the nervous system. J Physiol Lond 48:18-46.

Grashow R, Brookings T, Marder E (2010) Compensation for Variable Intrinsic Neuronal Excitability by Circuit-Synaptic Interactions. J Neurosci 30:91459156.

Graubard K, Raper JA, Hartline DK (1980) Graded synaptic transmission between spiking neurons. P Natl Acad Sci USA 6: 3733-3735

Gutierrez GJ, Grashow RG (2009) Cancer borealis Stomatogastric Nervous System Dissection. J Vis Exp. 25. http://www.jove.com/details.php?id=1207

Hell JW, Ehlers MD (2008) Structural and organization of the synapse. New York NY: Springer.

Hille B (2001) Ion Channels of Excitable Membranes. Sunderland MA: Sinauer Associates.

Hooper SL (1998) Transduction of temporal patterns by single neurons. Nat Neurosci 1:720-726.

Hooper SL, Guschlbauer C, von Uckermann G, Büschges A (2007) Different motor neuron spike patterns produce contractions with very similar rises in graded slow muscles. J Neurophysiol 97:1428-1444.

Hooper SL, Weaver AL (2000) Motor neuron activity is often insufficient to predict motor response. Curr. Opin. Neurobiol. 10: 676-82.

Hubel DH, Wiesel TN (1965) Binocular interaction in striate cortex of kittens 
reared with artificial squint. J. Neurophysiol. 28:1041-59

Izhikevich EM (2007) Dynamical Systems in Neuroscience. Cambridge MA: MIT Press.

Johnston D, Wu SMS (1995) Foundations of Cellular Neurophysiology. Cambridge MA: MIT Press.

Kayser C, Montemurro MA, Logothetis NK, Panzeri S (2009) Spike-phase coding boosts and stabilizes information carried by spatial and temporal spike patterns. Neuron 61:597-608.

Koch C (1999) Biophysics of Computation: Information Processing in Single Neurons. New York NY:Oxford University Press.

Kreuz T, Chicharro D, Greschner M, Andrzejak RG (2011) Time-resolved and time-scale adaptive measures of spike train synchrony. J Neurosci Methods 195:92-106.

Kumar A, Rotter S, Aertsen A (2010) Spiking activity propagation in neuronal networks: reconciling different perspectives on neural coding Nat Rev Neurosci 11:615-627.

Latorre R, Rodriguez FB, Varona P (2006) Neural Signatures: Multiple Coding in Spiking Bursting Cells Biol Cybern 95:169-183.

Lundstrom BN, Fairhall AL, Maravall M (2010) Multiple Timescale Encoding of Slowly Varying Whisker Stimulus Envelope in Cortical and Thalamic Neurons In Vivo. J. Neurosci. 30:5071-5077.

MacKay DJC (2003) Information theory, inference, and learning algorithms. 
Cambridge, UK: Cambridge UP.

Marder E, Bucher D (2007) Understanding Circuit Dynamics Using the Stomatogastric Nervous System of Lobsters and Crabs. Annu Rev Physiol 69:291316.

Marder E, Prinz, AA (2002) Modeling stability in neuron and network function: the role of activity in homeostasis. Bioessays 24:1145-1154.

Marin B, Baroni F, Varona P, Pinto RD (2009) Temporal structure of bursting patterns as representation of input history. Eighteenth Annual Computational Neuroscience Meeting, Berlin. BMC Neuroscience, 2009. v. 10.

Maynard, DM (1966) Integration in Crustacean ganglia. Symp. Soc. Exp. Biol. 20:111-149

Maynard, DM e Selverston, AI (1975) Organisation of the stomatogastric ganglion of the spiny lobster: IV. The pyloric system. J. Comp. Physiol. 100:161182.

Middleton JW, Yu N, Longtin A, Maler L (2011) Routing the Flow of Sensory Signals Using Plastic Responses to Bursts and Isolated Spikes: Experiment and Theory J Neurosci 31(7):2461-2473 .

Morris LG, Hooper SL (1997) Muscle response to changing neuronal input in the lobster (Panulirus interruptus) stomatogastric system: spike number versus spike frequency-dependent domains. J Neurosci 17:5956-5971.

Moulins, M, Vedel JP, Nagy F (1979) Complex motor neurone in crustacea: three axonal spike initiating zones in three different ganglia. Neurosci Lett 
$13: 231-236$.

Nelken I, Chechik G, Mrsic-Flogel TD, King AJ, Schnupp JWH (2005) Encoding stimulus information by spike numbers and mean response time in primary auditory cortex. J. Comput. Neurosci. 19,:199-221.

Nowotny T, Szücs A, Pinto RD, Selverston AI (2006) StdpC: A modern dynamic clamp. J Neurosci Methods 158:287-299.

Nusbaum MP, Beenhakker MP (2002) A small-systems approach to motor pattern generation. Nature 417:343-350.

Oprisan SA, Prinz AA, Canavier CC (2004) Phase resetting and phase locking in hybrid circuits of one model and one biological neuron. Biophys J 87:22832298.

Paninski, L (2003) Estimation of entropy and mutual information. Neural Comput 6:1191-1253

Panzeri S, Brunel N, Logothetis NK, Kayser C (2010) Sensory neural codes using multiplexed temporal scales. Trends Neurosci 33:111-120.

Panzeri S, Treves A (1996) Analytical estimates of limited sampling biases in different information measures. Network: Computation in Neural Systems $7: 87-107$

Pinto RD, Elson RC, Szücs A, Rabinovich MI, Selverston AI, Abarbanel HDI (2001) Extended dynamic clamp: controlling up to four neurons using a single desktop computer and interface. J Neurosci Methods 108:39-48.

Prinz AA, Billimoria CB, Marder E (2003) Alternative to Hand-Tuning Con- 
ductance Based Models: Construction and Analysis of Databases of Model Neurons. J. Neurophysiol. 6:3998-4015

Prinz AA, Bucher D, Marder E (2004) Similar network activity from disparate circuit parameters. Nat Neurosci 7:1345-1352

Purves et al.(2004) Neuroscience. $3^{a}$ edição. Sunderland MA: Sinauer Associates

Reinagel P, Godwin D, Sherman SM, Koch C (1999) Encoding of visual information by LGN bursts. J Neurophysiol 81:2558-2569.

Rieke FM, Warland D, de Ruyter van Steveninck R, Bialek W (1997) Spikes: Exploring the Neural Code. Cambridge, MA:MIT Press

Rodrigues LB, Marin B, Pinto RD (2010) The role of specific ionic conductances in information coding in motor neurons. Neuroscience Meeting Planner. San Diego, CA: Society for Neuroscience. Online.

Roulston M (1999) Estimating the errors on measured entropy and mutual information, Physica D 125:285-294

Rullen, R. V. e Thorpe, S. J. (2001). Rate Coding Versus Temporal Order Coding: What the Retinal Ganglion Cells Tell the Visual Cortex. Neural Computation, 13(6):1255-1283

Russel, DF, and Hartline, DK (1984) Synaptic regulation of cellular properties and burst oscillations of neurons in gastric mill system of spiny lobsters, panulirus interruptus. J. Neurophysiol. 52: 54-73.

Sabourin P, Pollack GS (2009) Behaviorally relevant burst coding in primary 
sensory neurons. J Neurophysiol 102:1086-1091.

Segundo JP, Sugihara G, Dixon P, Stiber M, Bersier LF (1998) The spike trains of inhibited pacemaker neurons seen through the magnifying glass of nonlinear analyses. Neuroscience 87:741-766.

Selverston AI (2010) Invertebrate central pattern generator circuits, Philos Trans R Soc Lond B Biol Sci 365:2329-2345.

Selverston AI e Mulloney B (1974) Organisation of the stomatogastric ganglion of the spiny lobster: II. Neurons driving the medial tooth. J. Comp. Physiol. 91:33-51.

Selverston AI, Rabinovich MI, Abarbanel HDI, Elson R, Szücs A, Pinto RD, Huerta R, Varona P (2000) Reliable circuits form irregular neurons: a dynamical approach to understanding central pattern generators. J Physiol 94:357-74.

Selverston AI, Russell DF, Miller JP (1976) The stomatogastric nervous system: structure and function of a small neural network. Prog Neurobiol 7:215290.

Schleimer JH, Stemmler M (2009) Coding of information in limit cycle oscillators. Phys Rev Lett 103, 248105.

Shannon CE (1948) A mathematical theory of communication. Bell Systems Tech J 27:379-423.

Shadlen MN, Newsome WT (1994) Noise, neural codes and cortical organization. Curr. Opin. Neurobiol. 4:569-579.

Sharp AA, O’Neil MB, Abbott LF e Marder E (1993) Dynamic Clamp: Computer- 
Generated Conductances in Real Neurons. J Neurophysiol. 69:992-995.

Sherman, SM (2001) Tonic and burst firing: dual modes of thalamocortical relay. Trends Neurosci 24:122-126.

Sherman SM, Guillery RW (2002) The role of the thalamus in the flow of information to the cortex. Philos. Trans. R. Soc. Lond. B Biol. Sci. 357:16951708.

Sherrington C (1907) The Integrative Action of the Nervous System. J. Nervous and Mental Disease 12:801-802

Softky WR, Koch C (1993) The highly irregular firing of cortical cells inconsistent with temporal integration of random EPSPs. J. Neurosci. 13:334-350.

Stein W (2009) Modulation of stomatogastric rhythms . J Comp Physiol A 195:989-1009

Steriade M, McCormick DA, Sejnowski TJ (1993) Thalamocortical oscillations in the sleeping and aroused brain. Science 262: 679-685.

van Steveninck RRD, Lewen GD, Strong SP, Köberle R, Bialek W (1997) Reproducibility and Variability in Neural Spike Trains. Science 275:1805-1808.

Swensen AM, Marder E (2001) Modulators with convergent cellular actions elicit distinct circuit output. Journal of Neuroscience 11:4050-4058

Szücs A, Pinto RD, Rabinovich MI, Abarbanel HDI, Selverston, AI (2003) Synaptic modulation of the interspike interval signatures of bursting pyloric 
neurons. J Neurophysiol 89:1363-1377.

Szücs A, Abarbanel HDI, Rabinovich MI, Selverston AI (2005) Dopamine modulation of spike dynamics in bursting neurons. Eur J Neurosci 21:763-772.

Taylor AL, Goaillard JM, Marder E (2009) How multiple conductances determine electrophysiological properties in a multicompartment model. J Neurosci $29: 5573-5586$

Theiler J, Eubank S, Longtin A, Galdrikian B, Farmer JD (1992) Testing for nonlinearity in time series: the method of surrogate data. Physica D 58: 77-94.

Tiesinga P, Fellous JM, Sejnowski TJ (2008) Regulation of spike timing in visual cortical circuits. Nat Rev Neurosci 9:97-109.

Tobin A, Bierman HS (2009) Homarus americanus Stomatogastric Nervous System Dissection. J Vis Exp. 27. http://www.jove.com/details.php?id=1171

Tolhurst DJ, Movshon JA, Dean, AF (1983) The statistical reliability of signals in single neurons in cat and monkey visual cortex. Vision Res. 23:775-785.

Turrigiano G, LeMasson G, Marder E (1995) Selective regulation of current densities underlies spontaneous changes in the activity of cultured neurons. J. Neurosci 5: 3640-3652 Viegas RG (2011) Dissecação dinâmica de condutânicas iônicas em tempo real. Dissertação de mestrado. Universidade de São Paulo

Zhurov Y, Brezina V (2006) Variability of motor neuron spike timing maintains and shapes contractions of the accessory radula closer muscle of Aplysia. J Neurosci 26:7056-7070 


\section{APÊNDICE}

\section{Fisiologia DE MEMBRAnAs E MODELOS DE NEURÔNIOS}

Este apêndice apresenta muito superficialmente conceitos básicos (mas nada triviais) com o intuito de introduzir o leitor aos assuntos abordados neste manuscrito e normalizar a nomenclatura e simbologias adotadas nesse texto. Aos que ainda não foram introduzidos à fisiologia de membranas e neurociência computacional e têm interesse em adquirir um conhecimento mais sólido, aconselha-se consulta das referências citadas neste manuscrito ou de outros textos de neurociência como: Hille, 2001, que é a referência canônica de canais iônicos; Kandel et al., 2000, texto básico, clássico e abrangente sobre neurociência; Johnston e Wu, 1995, também explica neurofisiologia com certa abordagem quantitativa bastante interessante; Izhikeich, 2007, texto elegante e acessível que explica excitabilidade neural a partir de conceitos de sistemas dinâmicos; Koch, 1999 e Dayan e Abbot, 2004, sobre neurociência computacional.

Neurônios são células excitáveis que comunicam-se entre si através de sinapses, formando redes complexas capazes de processar informação.

Os principais componentes da maquinaria de excitabilidade celular consistem na membrana que separa o meio intra do extracelular, nos diversos tipos de canais iônicos dependentes (ou não) de voltagem e nos mecanismos de manutenção do gradiente de concentrações iônicas entre o meio intra e extracelular. 
Os canais iônicos são proteínas que atravessam a membrana celular permitindo a passagem de um tipo (ou tipos) de íons $\left(\mathrm{Na}^{+}, \mathrm{K}^{+}, \mathrm{Ca}^{2+}, \mathrm{Cl}^{-}\right.$, como na 7.1), que contém múltiplas subunidades com sensores de voltagem e possuem sítios de ativação e inativação em alguns casos. O potencial de membrana de repouso é fruto da separação de cargas entre o meio intra (mais negativo) e extra celular e determinado pela diferença de concentração iônica e pela permeabilidade da membrana a cada tipo de íon. O influxo e efluxo de cargas positivas (íons $\mathrm{Na}^{+}$e $\mathrm{K}^{+}$) deve ser balanceado de modo que esse potencial se mantenha constante quando a célula se encontra quiescente. Para contrabalancear o fluxo passivo de íons, o controle do gradiente iônico se dá através do transporte ativo de íons através da membrana com custo energético através da $\mathrm{Na}^{+} / \mathrm{K}^{+}$ATPase (também conhecida como bomba de sódio e potássio) contra o gradiente eletroquímico.

A membrana plasmática consiste em uma camada fosfolipídica finíssima ( $5 \mathrm{~nm}$ ) que separa as cargas entre o meio intra e extracelular, funcionando como um capacitor. Valores típicos da capacitância e do potencial de membrana estão em torno de $1 \mu \mathrm{F} / \mathrm{cm}^{2}$ e $\mathrm{V}_{m}=-65 \mathrm{mV}$, respectivamente.

Conhecendo essas propriedades, podemos associa-las a um circuito elétrico equivalente. A corrente total que atravessa um pedaço da membrana (contendo canais como na Fig. 7.1 B) é:

$$
I=C_{m} \dot{V}+I_{N a}+I_{K}+I_{C a}+I_{C l}
$$

em que $C_{m}$ é a capacitância da membrana, $\mathrm{V}$ é o potencial de membrana e $I_{i}$ são as correntes iônicas do tipo $i$.

A dinâmica de abertura e fechamento dos canais iônicos é regida pelas probabilidades de transição entre os estados fechado e aberto e, apesar da 
natureza estocástica dessas transições, a corrente iônica total gerada por uma população de canais de um mesmo tipo pode ser bem aproximada ${ }^{1}$ por

$$
I_{i}=g_{i} \cdot p \cdot\left(V-E_{i}\right)
$$

em que $E_{i}$ é o potencial de reversão para os íons que atravessam o canal tipo $i$ (Ver eqs. de Nernst e Goldman em Hille, 2001) e

$$
g_{i}=\bar{g}_{i} p
$$

onde $\bar{g}_{i}$ é a condutância máxima quando todos os canais estão abertos e $p$ é a proporção de canais abertos.

Assim, da eq. 7.1 temos que,

$$
C_{m} \dot{V}=I+g_{N a}\left(V-E_{N a}\right)+g_{K}\left(V-E_{K}\right)+g_{C a}\left(V-E_{C a}\right)+g_{C l}\left(V-E_{C l}\right) .
$$

ou ainda, generalizando,

$$
C_{m} \dot{V}=\sum_{i} g_{i}\left(V-E_{i}\right)
$$

A população $p$ de canais abertos depende da cinética de ativação $m$ e inativação $h$

$$
p=m^{a} h^{b}
$$

onde os expoentes $a$ e $b$ correspondem ao número de partículas de ativação e inativação ${ }^{2}$ respectivamente. As dinâmicas de ativação e inativação podem

\footnotetext{
${ }^{1}$ Ver Carelli et al., 2005 para outra abordagem com modelos estocásticos)

${ }^{2}$ Hodgkin e Huxley falaram em partículas de ativação e inativação em seus trabalhos originais sem conhecimento da biofísica dos canais de membrana: os expoentes a e b eram determinados através de ajuste estatístico desses parâmetros. Posteriormente, com o advento da biologia molecular, o conceito de "partículas" de ativação e inativação encontrou
} 
A

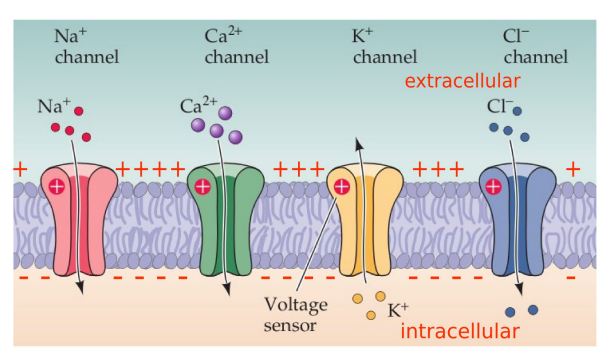

C

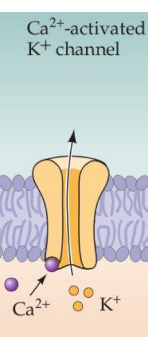

D

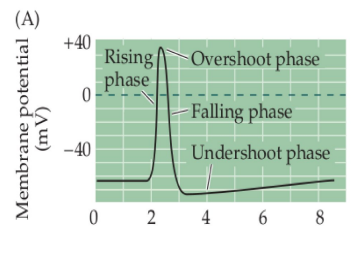

B

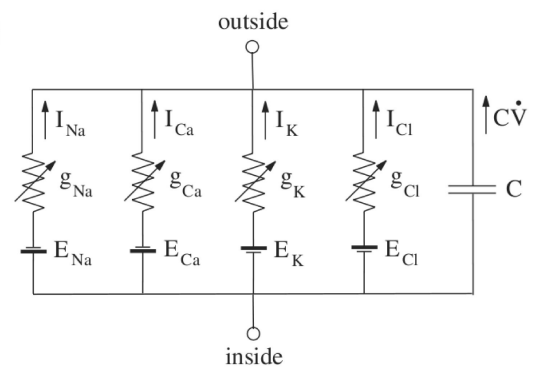

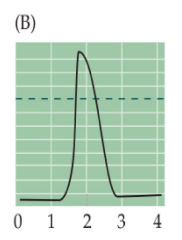
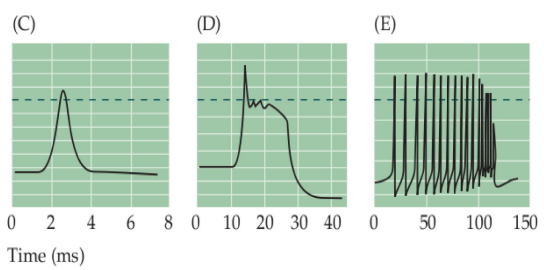

Fig. 7.1 - A- Canais seletivos a íons sódio, potássio, cálcio e cloro sensíveis a voltagem. B-Circuito elétrico equivalente. C-Canal para potássio dependente de cálcio. D- Diversos modos de excitabilidade, de potenciais de ação individuais a atividade em burst (Figuras adaptadas de Purves et al., 2004)

ser escritas como equações diferenciais de primeira ordem,

$$
\begin{gathered}
\dot{m}=\left(m_{\infty}(V)-m\right) / \tau_{m}(V) \\
\dot{h}=\left(h_{\infty}(V)-h\right) / \tau_{h}(V)
\end{gathered}
$$

onde $m_{\infty}(V)$ (ou $h_{\infty}(V)$ ) é a probabilidade de subunidade encontrar-se no estado aberto para dado potencial de membrana em um tempo infinito e $\tau_{m}$ (ou $\tau_{h}$ ) é o tempo de relaxação.

Existe uma grande variedade de canais iônicos com propriedades bastante distintas, o que permite com que neurônios apresentem um vasto repertório dinâmico. A capacidade de uma célula disparar potenciais de ação (PA, Fig. 7.1 D, esquerda) tem um papel importante na comunicação neural. Com apenas

um certo paralelo com as subunidades dos canais de membrana responsáveis pela abertura/fechamento/inativação desses mesmos canais 
A

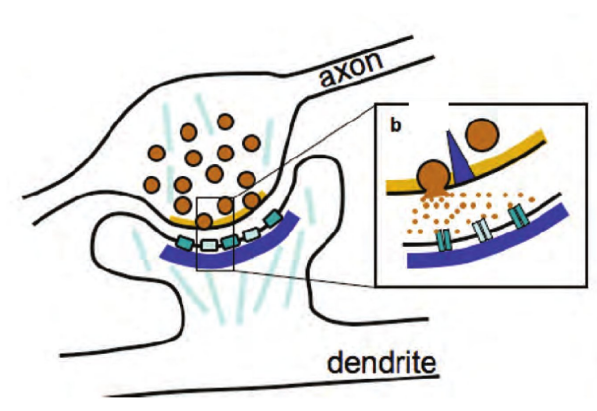

B

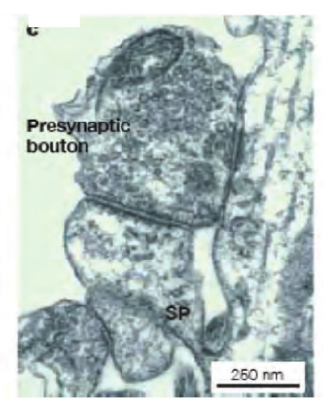

C

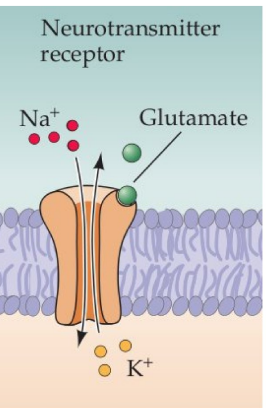

Fig. 7.2 - A-Mecanismo de liberação de neurotransmissor em sinapses químicas. $B$-Eletromicrografia de uma sinapse excitatória. C-Representação de um receptor de glutamato.(Figuras adaptadas de Purves et al., 2004 e Hell et al., 2008)

uma condutância de sódio e outra de potássio (ambas rápidas) a célula é capaz de passar por uma despolarização instantânea ( $\mathrm{V}$ fica mais positivo) seguida de uma hiperpolarização (V fica mais negativo) também abrupta.

Normalmente tido como um evento estereotipado, o tipo de PA disparado pode, na realidade, variar muito entre diferentes células e mesmo para uma mesma célula quando submetida a condições de estimulação diferentes (Fig. 7.1 D). Além da variedade de comportamentos que emergem de células com condutâncias rápidas parecidas, existe ainda o efeito de condutâncias lentas que traz uma riqueza à dinâmica neural ainda maior. Um exemplo é o canal para potássio dependente de cálcio (Fig. 7.1 C) que além de sensível a voltagem depende também da concentração de cálcio intracelular (que também deve entrar como variável dinâmica no modelo) e exerce um papel importante em células em atividade em rajadas (bursts, Fig. 7.1 D, direita).

Nas redes neurais, a comunicação entre neurônios se dá através de sinapses elétricas ou químicas. As sinapses químicas são junções celulares assimétricas por onde um neurônio (pré-sinaptico) libera vesículas contendo neurotransmissores de acordo com sua atividade elétrica (Fig. 7.2 A). Uma vez liberados 
na fenda sináptica (Fig. 7.2 B), os neurotransmissores se ligam a receptores específicos localizados na membrana celular do outro neurônio (pós-sináptico), provocando a abertura de canais iônicos (Fig. 7.2 C) que pode, no caso de uma sinapse excitatória, causar momentanemente a despolarização da membrana (potencial excitatório pós-sinaptico) ou hiperpolarização (potencial inibitório pós-sinaptico) se a sinapse for inibitória. Essa dinâmica pode ser traduzida no modelo inserindo-se uma condutância sináptica $g_{\text {syn }}$ (Ver seção de redes híbridas nos métodos experimentais). 


\title{
Single Synapse Information Coding in Intraburst Spike Patterns of Central Pattern Generator Motor Neurons
}

\author{
Ludmila Brochini, ${ }^{1,2}$ Pedro V. Carelli, ${ }^{2,3}$ and Reynaldo D. Pinto ${ }^{1}$ \\ ${ }^{1}$ Department of Physics and Informatics, Institute of Physics of São Carlos, University of São Paulo, São Carlos 13566-590, Brazil, ${ }^{2}$ Department of General \\ Physics, Institute of Physics, University of São Paulo, São Paulo 05508-090, Brazil, and ³Department of Physics, Federal University of Pernambuco, Recife \\ 50670-901, Brazil
}

Burst firing is ubiquitous in nervous systems and has been intensively studied in central pattern generators (CPGs). Previous works have described subtle intraburst spike patterns (IBSPs) that, despite being traditionally neglected for their lack of relation to CPG motor function, were shown to be cell-type specific and sensitive to CPG connectivity. Here we address this matter by investigating how a bursting motor neuron expresses information about other neurons in the network. We performed experiments on the crustacean stomatogastric pyloric CPG, both in control conditions and interacting in real-time with computer model neurons. The sensitivity of postsynaptic to presynaptic IBSPs was inferred by computing their average mutual information along each neuron burst. We found that details of input patterns are nonlinearly and inhomogeneously coded through a single synapse into the fine IBSPs structure of the postsynaptic neuron following burst. In this way, motor neurons are able to use different time scales to convey two types of information simultaneously: muscle contraction (related to bursting rhythm) and the behavior of other CPG neurons (at a much shorter timescale by using IBSPs as information carriers). Moreover, the analysis revealed that the coding mechanism described takes part in a previously unsuspected information pathway from a CPG motor neuron to a nerve that projects to sensory brain areas, thus providing evidence of the general physiological role of information coding through IBSPs in the regulation of neuronal firing patterns in remote circuits by the CNS.

\section{Introduction}

Burst coding is a phenomenon far from being completely understood, and is just a part of a central issue in neuroscience related to the understanding of the neural code in a broad sense. Burst firing is an important excitability property related to motor control in central pattern generators (CPGs) (Brocard et al., 2010 Selverston, 2010), to sensory information processing in visual and auditory centers (Reinagel et al., 1999; Eyherabide et al., 2008; Sabourin and Pollack, 2009), and is known to enhance signal detection in thalamocortical circuits (Steriade et al., 1993; Sherman, 2001).

Many studies have brought burst coding (Eyherabide and Samengo, 2010) to increased attention, especially for one of its

\footnotetext{
Received March 22, 2011; revised June 14, 2011; accepted July 8, 2011.

Author contributions: R.D.P. designed research; L.B., P.V.C., and R.D.P. performed research; L.B., P.V.C., and R.D.P. analyzed data; L.B. and R.D.P. wrote the paper.

This work was supported by the Brazilian agencies Fundaçăo de Amparo à Pesquisa do Estado de Săo Paulo
The This work was supported by the Brazilian agencies Fundação de Amparo à Pesquisa do Estado de Săo Paulo
(www.fapesp.br), Conselho Nacional de Desenvolvimento Cientifico e Tecnológico (www.cnpq.br), Coordenacão de Aperfeiçoamento de Pessoal de Nível Superior (www.capes.gov.br), and by the Instituto Nacional de Ciência e Tecnologia Interfaces Cérebro-Máquina INCeMaq. We thank R. Köberle, B. Marin, and M. Copelli for discussions; A. . Selverston from University of California San Diego, where the lobster data were acquired, for his hospitality and comments on a preliminary version of the manuscript, and also the anonymous referees for their comments and comments on a preliminary version of the manuscript
suggestions, all very useful in improving this paper. The authors declare no competing financial interest.

Correspondence should be addressed to Dr. Reynaldo D. Pinto, Lab. Neurodinâmica/Neurobiofísica, Dept. Física Informática - FFl Instituto de Física de São Carlos - IESC/USP, Gaixa Postal 369, São Carlos-SP 13560-970 Brat. E-mail: reynaldo@ifsc.usp.br.

D01:10.1523/NNEUROSCI.1568-11.2011

Copyright $\odot 2011$ the authors $\quad 0270-6474 / 11 / 3112297-10 \$ 15.00 / 0$
}

most prominent features: bursting is an effective way for a system to code different types of information using (at least) two distinct timescales, one related to the bursting period and another to the intraburst spiking timescale (Kayser et al., 2009; Panzeri et al., 2010).

CPGs, such as those found in the crustacean stomatogastric nervous system (STNS), have been traditionally used to analyze how complex dynamics emerge in small circuits (Marder and Bucher, 2007). Bursting activity of pyloric CPG motor neurons of the stomatogastric ganglion (STG) is clearly associated with muscle contraction that is insensitive to small changes in intraburst spike timing (Morris and Hooper, 1997). Despite not expressing obvious motor information, intraburst spike patterns (IBSPs) presented by CPG neurons are characteristic of each neuron and change according to network connectivity (Szücs et al., 2003). Thus, in addition to motor information expressed in bursting, CPG neurons also have potential to express other kinds of information through IBSPs (Latorre et al., 2006). We investigated this matter by analyzing experimental data through an information theoretical tool that we developed specifically to compute information expressed within IBSPs.

We performed experiments on a pair of neurons of the blue crab STG pyloric CPG: the pyloric dilator (PD) neuron, which belongs to the pacemaker group, and the lateral pyloric (LP) neuron. These neurons are coupled with mutual inhibition and operate in antiphase (Selverston et al., 1976). Since the pacemaker receives the strongest feedback from the circuit through the inhibitory synapse from LP to PD, we choose to address the 
information flow in that direction. We found that the PD neuron is able to dynamically express information received from the previous LP burst. This is not only observed in the intact network, but also when PD is coupled to an artificial neuron that mimics LP activity.

Moreover, the information expressed in the IBSPs is inhomogeneous along the burst, revealing the ability of a single motor neuron to nonlinearly encode information through a single synapse. We also found that the informational content of IBSPs of the LP neuron not only affects PD dynamics, but also appears in the activity of the inferior ventricular nerve (ivn), a nerve that connects the STNS to the brain and has been shown to project into sensory areas of the brain in other crustacean species (Böhm et al., 2001). Our findings suggest that this nonlinear coding capability through spike patterns (Tiesinga et al., 2008) of motor neurons could be useful to higher levels of motor control mechanisms.

\section{Materials and Methods}

Animals. We experimented mostly on adult blue crabs (Callinectes sapi$d u s$ ) of either sex from the southern coast of São Paulo state. A few experiments were done with California spiny lobsters (Panulirus interruptus), also of either sex, at the Institute for Nonlinear Science-University of California San Diego. All procedures followed the ethical principles suggested by the Society for Neuroscience and were approved by the Committee on Ethics in Animal Experimentation of the Federal University of São Carlos.

Preparations. Dissection and preparation procedures were similar to those traditionally used in spiny lobsters or crab STNS preparations (Selverston et al., 1976). The STNS was removed from the crab stomach and pinned in a silicone elastomer-lined (Sylgard 184; Dow Corning) dish, filled with crustacean normal saline (in mM: $479 \mathrm{NaCl}, 13 \mathrm{KCl}, 14$ $\mathrm{CaCl} 2,6 \mathrm{MgSO}_{4} 4 \mathrm{Na} 2 \mathrm{SO} 4,5 \mathrm{HEPES}$, and 5 TES; $\mathrm{pH}$ 7.4).

In addition to the STG, we removed the commissural ganglia (CoGs) and the oesophageal ganglia (OG), their connecting and motor nerves, and the ivn nerve, cutting it as close to the brain as possible (Fig. $1 \mathrm{~A}$ ). During all experiments, preparations were superfused with saline and maintained either at $23 \pm 1{ }^{\circ} \mathrm{C}$ (crabs) or $16 \pm 1^{\circ} \mathrm{C}$ (lobsters).

Electrophysiology. Extracellular signals were recorded from the lateral ventral motor nerve (lvn) and the ivn with stainless steel electrodes. Nerve signals were amplified by an A-M 1700 differential AC amplifier (A-M Systems).

Neurons were impaled with sharp glass microelectrodes (filled with 3 M K-acetate $+0.1 \mathrm{M} \mathrm{KCl}$; resistance $\sim 30 \mathrm{M} \Omega$ ) and intracellular signals were amplified using Neuroprobe 1600 amplifiers (A-M Systems).

Intracellular and extracellular signals were digitized at a $10 \mathrm{kHz}$ sample rate by a Digidata 1322 ADC interface (Molecular Devices) using a dedicated acquisition software (Axoscope9; Molecular Devices). Neurons were identified by their characteristic bursting phase and by comparing their intracellular spike timings to the impulses recorded from their respective motor nerves.

A simplified version of the pyloric CPG consists of the pacemaker group, composed of the anterior burster interneuron (the only neuron in the pyloric CPG known to project to the anterior ganglia), two PD neurons, and the LP neuron, the only motor neuron from which PD receives presynaptic inputs (Fig. $1 B$ ).

Hybrid circuit experiments. We used the dynamic clamp method to simulate an inhibitory synaptic connection between a computer model artificial neuron (AN) and the PD neuron (Fig. 1C). A Digidata 1200B
B

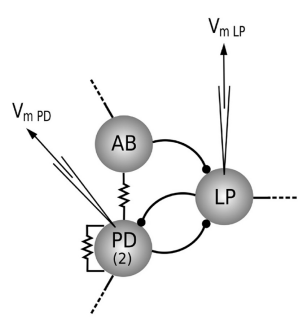

C

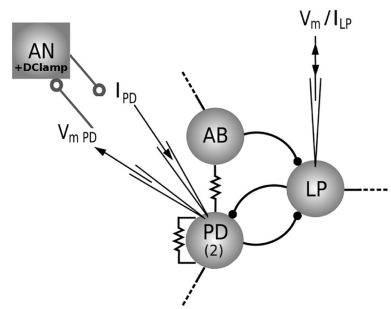

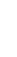

dures. $A$, Representation of the whole stomatogastric nervous system in the Petri dish: the two commissural ganglia (COGS) and the $\mathrm{OG}$ are kept in the preparation to provide neuromodulation to the STG. In a set of experiments, extracellular signals are recorded from the lvn, which contains $L P$ spikes, and from the ivn, which connects the STNS to the brain. $\boldsymbol{B}$, scheme of the intact pyloric CPG. The pacemaker group is composed of two PD motor neurons that are connected to the according to a model of synaptic chemical inhibition. One PD neuron is impaled with two electrodes: one to record the membrane

data acquisition interface (Molecular Devices) was used to implement a protocol based on previous homemade implementations of the dynamic clamp (Pinto et al., 2001; Nowotny et al., 2006). In the original dynamic clamp protocol, a computer simulates synapses between neurons by monitoring their membrane potentials and generating the currents to be injected. The currents are calculated from equations modeling the voltage- and time-dependent synaptic conductances. We modified the protocol to simultaneously compute the membrane potential of AN from a mathematical model and simulate a synapse from AN to a biological neuron. Such a modification allowed the delivery of inhibitory currents to the PD neuron according to the behavior of a presynaptic AN membrane potential computed in real time.

Our AN neuron was either a real-time implementation of a whole-cell stochastic model of LP (stochastic AN) or simply a sequence of random spikes (random AN). Both were set to resemble the original LP mean behavior and its variability, as detailed below.

The stochastic AN is based on a stochastic LP model that was previously developed to reproduce the irregular behavior of biological LP neurons, which is absent in the Hodgkin-Huxley deterministic model (Carelli et al., 2005). Due to its stochastic nature, the model naturally presented spike timing variability from burst to burst. In our implementation of the stochastic LP model in the dynamic clamp, we were able to tune the stochastic AN to mimic the original LP variability in each preparation by changing the values of the following maximum conductances ( $G i$, range in $\mathrm{mS} / \mathrm{cm}^{2}$ in parenthesis): slow calcium $\left(3.0<G_{-} \mathrm{Ca}_{\mathrm{s}}<4.0\right)$, transient calcium $\left(0.9<G_{-} \mathrm{Ca}_{\mathrm{t}}<1.1\right)$, and calcium-dependent potassium $\left(3.5<G_{-} \mathrm{K}_{[\mathrm{Ca}]}<4.5\right)$. The tuning of these parameters was done by visual comparison between the membrane potential traces of the original LP and of the stochastic AN. All other parameters were kept the same as described in the original reference (Carelli et al., 2005). The dynamic clamp synapse from PD to the stochastic AN was set to shutdown AN when PD starts a burst A typical value of this conductance was $G_{-} \operatorname{syn}_{\mathrm{PD} \rightarrow \mathrm{AN}}=200 \mathrm{mS}$.

The random $\mathrm{AN}$ burst sequences were obtained from statistics during 5-10 min on the original PD/LP bursting behavior at each preparation regarding time of first and last spikes of $\mathrm{LP}$ after PD hyperpolarization $\left(\mathrm{LP}_{\text {start }} / \mathrm{LP}_{\text {end }}\right)$, maximum and minimum number of spikes in a LP burst ( $\left.\max \_s p k / m i n \_s p k\right)$, and minimum interspike interval of LP (min_ISI). Values of these parameters varied widely among different preparations according to the pyloric rhythm natural variability. An example of a set is $\max \_s p k=6, \min \_s p k=4, \min \_I S I=15 \mathrm{~ms}, \mathrm{LP}_{\text {start }}=50 \mathrm{~ms}, \mathrm{LP}_{\text {end }}=$ $400 \mathrm{~ms}$. Next, we generated a long sequence of bursts in which, for each burst, we chose from flat random distributions, as follows: $n$ spk, the number of spikes of that burst ( $\left.\min \_s p k \leq n \_s p k \leq \max \_s p k\right)$; the time 
of the first spike, $t_{1}$, in the range $\left[\mathrm{LP}_{\text {start }}, \mathrm{LP}_{\text {start }}+\left(\mathrm{LP}_{\text {end }}-\mathrm{LP}_{\text {start }}\right) / n \_s p k\right]$; and the random sequence of spikes, with each $t_{\mathrm{i}}$ randomly chosen in the range $\left[t_{\mathrm{i}}+\min \_I S I, t_{\mathrm{i}}+\right.$ min_ISI $+\left(\mathrm{LP}_{\mathrm{end}}-t_{\mathrm{i}}-\min \_I S I\right) /\left(N \_s p k-\right.$ $i)$ ], where $1 \leq \bar{i} \leq\left(n \_\right.$spk -1$)$. This sequence of random bursts was stored in a file to be used by the dynamic clamp to implement the random AN in real time. During the experiments with the random AN, the dynamic clamp detected each PD hyperpolarization and generated the artificial membrane potential according to the previously stored sequence of random bursts.

The synaptic strength from AN to the PD was adjusted in the dynamic clamp until inhibitory postsynaptic potentials, with amplitude similar to those produced by the activity of the original LP, were found in the PD trace [typical values of conductance used were in the range $(50 \mathrm{mS} \leq$ $G_{-}$syn $_{\mathrm{AN} \rightarrow \text { PD }} \leq 200 \mathrm{mS}$ )]. Values of AN spikes per burst ranged from $4 \pm 1$ to $8.0 \pm 0.8$ in different experiments, corresponding to $10-25 \%$ of variation from burst to burst.

The experiments consisted of impaling the LP neuron with a single electrode and one PD neuron with two electrodes, one for current injection and the other for membrane potential recording. We simultaneously recorded PD and biological LP neurons with no artificial stimulation for $\sim 30$ min. After that, we hyperpolarized the biological LP with a current of $\sim-10 \mathrm{nA}$, and then connected the AN to the PD neuron by the artificial dynamic-clamp synapse, recording both PD and AN membrane potential as well as the current delivered to $\mathrm{PD}$ for $\sim 30 \mathrm{~min}$.

$L P$ and ivn recordings. In the last set of experiments, we recorded long time series $(\sim 30 \mathrm{~min}$ to $2 \mathrm{~h})$ of lvn and ivn extracellular signals (Fig. 1A). LP spikes could be easily identified in the lvn trace because of their large amplitude and characteristic phase. The length of the ivn nerve is typically $\sim 8 \mathrm{~mm}$ (from the OG to the brain in blue crabs) and the extracellular electrode recording ivn activity was positioned $\sim 4$ $\mathrm{mm}$ far from the OG.

Analysis method. Studying the information conveyed by spike trains requires the identification of patterns that are usually defined before the analysis in terms of burst occurrences or certain spike/ISI sequences that can be associated with some specific stimulus features (Butts et al., 2007; Tiesinga et al., 2008; Eyherabide and Samengo, 2010; Kumar et al., 2010; Kreuz et al., 2011).

When dealing with sensory systems, an experimenter can readily infer what stimulus features are important (i.e., certain odor or sound frequency) and, based on previous knowledge of what is being coded, identify interesting patterns in the response spike train. However, studying information flow between two bursting neurons requires a different approach. In this case, both stimulus and response signals are sequences of spikes occurring in each neurons burst, so there is no simple criterion to determine which stimulus characteristics are important to be coded by the response neuron. Since we cannot adopt a relevance criterion, we use entropy to estimate which stimulus features are most informative.

We developed a method to extract all ISI patterns that occurred in a large number of sequential pairs of stimulus and response bursts. Then we computed the average mutual information to estimate how much the response IBSPs express information about stimulus IBSPs. This way we infer information flow between neurons while making the least number of assumptions about the code itself.

Information theory. Information theory presents powerful concepts that can be applied to the study of neural coding (Shannon, 1948; Bors and Theunissen, 1999). If a specific event, $x$, occurs with probability $p(x)$ the informational content of $x$ (in bits) is defined as

$$
i(x)=\log _{2} \frac{1}{p(x)} .
$$

For a series of discrete events, $x$, belonging to a set $X=\left(x_{1}, x_{2}, \ldots, x_{n}\right)$, the entropy of $X$, related to the degree of variability of the set, is defined as

$$
H(X)=-\sum_{x} p(x) \log _{2} p(x)
$$

A neuron is able to express information about stimuli if the variability of its response is somehow correlated to stimuli changes. The mutual infor- mation $i$ between a stimulus $s$ belonging to a set $S$ and a response $r$ belonging to a set $R$ is defined as

$$
i(s, r)=\log _{2}\left(\frac{p(s, r)}{p(s) p(r)}\right),
$$

where $p(s, r)$ is the joint probability of finding the stimulus $s$ and the response $r$. The average mutual information (AMI) is a measure of the mutual information of all possible pairs of (stimulus, response) defined by $S$ and $R$ :

$$
\operatorname{AMI}(S, R)=\sum_{s, r} p(s, r) i(s, r)
$$

Algorithm. The two simultaneously recorded membrane potential time series of the stimulus (LP) and response (PD) neurons were treated using a simple algorithm that detects spikes (using derivative and amplitude threshold), providing a spike timing time series for each neuron. Burst occurrences were identified as any spike sequence between two large ISIs $(\geq 0.2 \mathrm{~s})$. Only stationary series with respect to the mean and standard deviations of number of spikes per burst, period, and burst duration of each neuron were considered for further analysis. After finding all bursts, pairs of stimulus (LP) and response (PD) bursts were collected by imposing that the LP burst must precede the PD burst. This constraint guaranteed a causality relation, allowing us to claim that information flows from the stimulus to the response neuron, despite the symmetry $(S-R)$ of AMI measure.

Since the bursting period has some intrinsic variability, it is necessary to choose a time reference for each pair of stimulus and response bursts. We set the first PD spike as time reference (Fig. $2 A$ ). The same choice is often used in other techniques applied to pyloric neurons time series analysis (Ayers and Selverston, 1984; Canavier and Achuthan, 2010). The PD neuron is part of the pacemaker group, which strongly inhibits all other motor neurons, dictating the pyloric rhythm. Thus, the PD burst onset is important to determine when LP is allowed to fire. One consequence of this choice is that burst-to-burst natural fluctuations of the interval between the onsets of LP and PD will be reflected in the LP firing patterns extracted during the analysis. However, this choice is neither obvious nor unique, and all choices have different consequences. Other choices of the time reference can be used to explore complementary properties of information coding in the system. For example, they can be used to investigate how the interval between the onsets of LP and PD influences the results. Other parameters such as the start $\left(s_{\mathrm{LP}}\right)$ and end $\left(e_{\mathrm{LP}}\right)$ of LP burst and the end of PD burst $\left(e_{\mathrm{PD}}\right)$, are obtained from statistics over the whole series.

A string of zeros is associated with each burst of stimulus/response (each bit of the string has a time bin $b_{0}=\Delta t$, where $\Delta t=0.1 \mathrm{~ms}$ is the resolution of the data acquisition). When a spike is detected in a burst the corresponding bit of the string is set to 1 . Two pointers $i$ and $j$ are used to represent the displacement along the duration of the bursts, corresponding to the $i$ th and $j$ th bit of the stimulus and response strings, respectively.

For a pair of pointers $(i, j)$, two sets of $n$ bits words are extracted: a stimulus set $S_{i}^{1}=\left(W_{\mathrm{LP}, i, 1}^{1}, W_{\mathrm{LP}, i, 2}^{1}, \ldots, W^{1}{ }_{\mathrm{LP}, i, N}\right)$ and a response set $R_{j}^{1}=\left(W^{1}{ }_{\mathrm{PD} j, 1}, W^{1}{ }_{\mathrm{PD}, j, 2,}, \ldots, W^{1}{ }_{\mathrm{PD}, j,}\right)$ (Fig. $\left.2 A\right)$, where $N$ is the total number of bursts in the time series. The word $W^{1}{ }_{L P, i, 1}$ corresponds to the sequence of $n$ bits starting at the $i$ th bit of the LP string of the first pair of bursts. Analogously, the following word, $W^{1}{ }_{\mathrm{LP}, i, 2}$, is an $n$ bits word starting at the $i$ th bit of the LP string of the second pair of bursts, and so on. The same logic applies to words of the response set.

The stimulus entropy $H\left(S_{i}^{1}\right)$ is computed based on the probability of occurrence of every possible word in the set $S_{i}^{1}$. The same is done to compute the response entropy $H\left(R_{j}^{1}\right)$ for the pointer $j$.

The following steps consisted in repeating the procedure of word extraction to calculate entropies for words with larger bins (Fig. $2 A$ ). This is achieved by using a resampling parameter $k$, so that the new bin is $b=$ $k \Delta t$. The word $W_{\mathrm{LP}, i, m}^{k}$ is also an $n$ bits word starting at the pointer $i$ of the LP $m$ th burst string, except that each bit is set to 1 if a spike occurs within the new bins. This procedure produces stimulus sets $S_{i}^{k}=\left(W_{L P, i, 1}^{k}\right.$, $\left.W_{\mathrm{LP}, i, 2}^{k}, \ldots, W_{\mathrm{LP}, i, N}^{k}\right)$ as function of $k$. Analogously, for a certain $j$ 
A

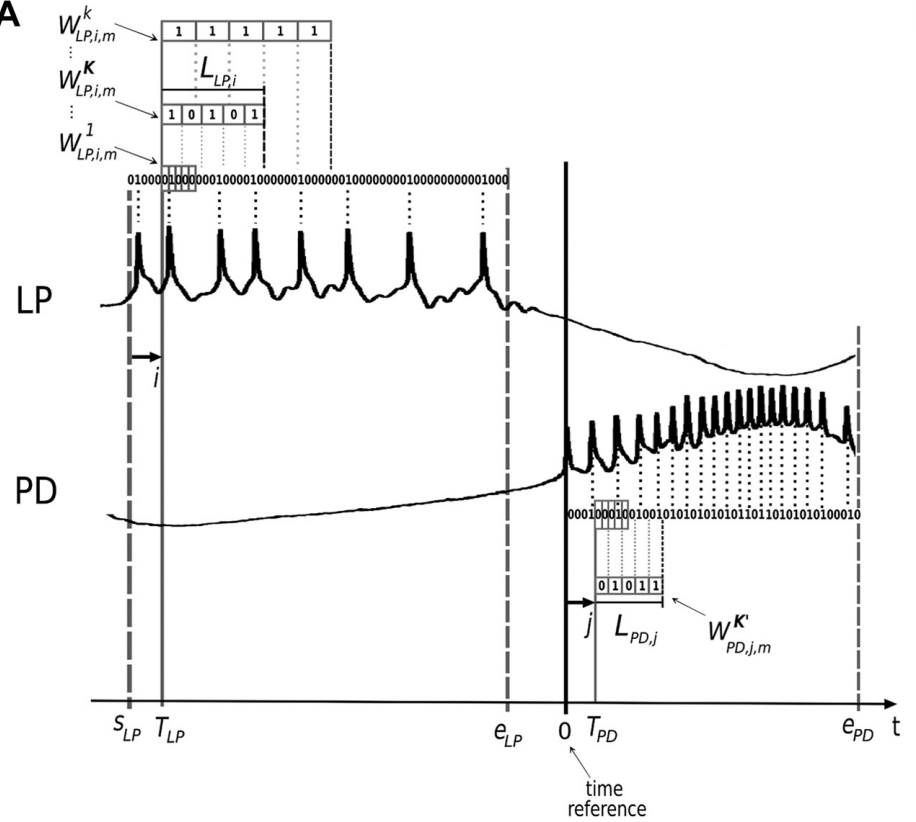

B

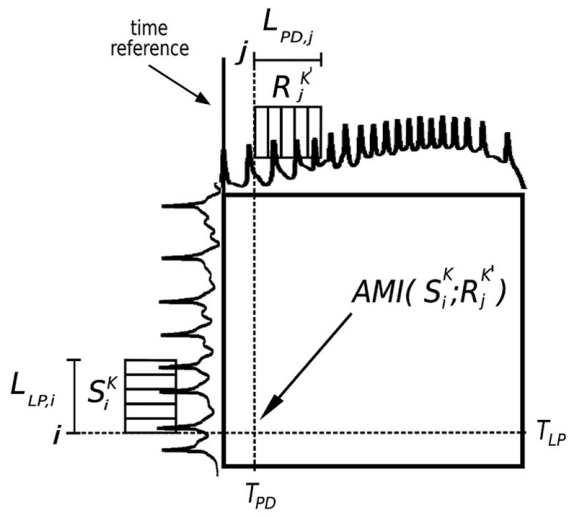

Figure 2. Entropy maximization and AMI representation. $A$, lllustration of the $m$ th pair of stimulus (LP) burst followed by the response (PD) burst. Time series are resampled into two binary strings in which a bit is set to one or zero according to spike occurrence, depicted above LP or below PD neuron trace, respectively. The time reference (thick vertical line) is set at the first spike of the PD burst for each pair of bursts. The start and end of $L P\left(s_{1 P}\right.$ and $e_{L P}$, respectively) and the end of PD $\left(e_{P D}\right)$ bursts are chosen according to statistics over the whole time series. Five bits words are formed beginning at the string bit pointed by $i$ or $j$. The first stimulus word $W^{1}{ }_{\mathrm{LP}, i, m}$ is composed of the sequence of five bits starting at the i pointer position. The resampling parameter $k$ is used to select words of larger bins $\left(W_{\mathrm{LP}, i, m,}^{1} W_{\mathrm{LP}, i, m}^{2} \ldots, W_{\mathrm{LP}, i, m^{K}}^{K} \ldots\right)$; this way, the words represent a larger portion of the burst. Note that for very small $k$, the words have almost all bits equal to zero and for very large

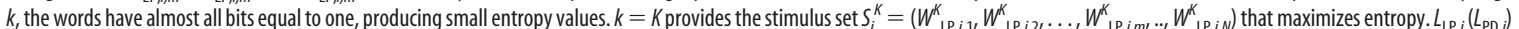
is the word duration associated with the stimulus (response) set. It measures the portion of the burst that $S_{i}^{K}\left(\right.$ or $\left.R_{i}^{K \prime}\right)$ represents and can vary along the burst. $B$, Schematic representation of AMI graphs: AMI $\left(S_{i}^{K}, R_{j}^{K^{\prime}}\right)$ is computed for all possible pairs of pointers $(i, j)$ according to the procedure described in $\boldsymbol{A}$.

pointer of the response strings, we computed a response set $R^{k}=\left(W^{k}\right.$ $\left.{ }_{\mathrm{PD}, j, 1}, W_{\mathrm{PD}, j, 2}^{k}, \ldots, W_{\mathrm{PD}, j, N}^{k}\right)$ for every possible $k$ value. From the probabilities of each word in the sets $S_{i}^{k}$ and $R_{j}^{k \prime}$, we compute stimulus $H\left(S_{i}^{k}\right)$ and response $H\left(R_{j}^{k^{\prime}}\right)$ entropies.

The sets used to calculate AMI were chosen by looking for the value of $k\left(k^{\prime}\right)$ that correspond to the set $S_{i}^{k}\left(R_{j}^{k \prime}\right)$ with the maximum value of entropy $H\left(S_{i}^{k}\right)\left[H\left(R_{j}^{k \prime}\right)\right]$. Considering $K$ and $K^{\prime}$, the values of $k$ and $k^{\prime}$ that respectively maximize the entropy of $S_{i}^{k}$ and $R_{j}^{k \prime}$, we compute $\operatorname{AMI}\left(S_{i}{ }^{K}\right.$, $R_{j}^{K^{\prime}}$ ) based on the joint probabilities of occurrence of all possible pairs of words $\left(W^{K}{ }_{\mathrm{LP}, i, m}, W^{K,}{ }_{\mathrm{PD}, j, m}\right)$. AMI was calculated for all possible pointer values $(i, j)$, leading to a matrix of AMI values (Fig. $2 B$ ).

In the analysis of LP/ivn time series, a slightly modified protocol had to be used, since the ivn nerve does not present burst activity. First, all LP and ivn spikes were detected and LP bursts separated. Each pair of stimulus and response consisted in one LP burst and the ivn spikes within the interval of $[-2: 2] s$ with respect to the first spike of each LP burst.

Then we calculated entropies and AMI values following the same steps previously described. In the AMI matrix obtained for LP/ivn, those regions with positive ivn time index correspond to information flow from LP to ivn and those with negative ivn time index correspond to information flow from ivn to LP.

Analysis. To ease the interpretation of our results, instead of bin size we used the word duration $L_{\mathrm{LP}, i}=n \cdot K \cdot \Delta t$, which is associated with the pointer $i$ of the LP string for which $K$ maximizes the entropy. In the graphs, we used $l$, which is $L$ normalized by the burst duration. Also, instead of dealing with pointers, we used an equivalent but more intuitive timescale: $t_{\mathrm{LP}}$ is proportional to $i$ and $t_{\mathrm{PD}}$ is proportional to $j$. In the results section, $t$ will be referred to as "time index."

All analyses were made with fixed $n=5$, chosen by using a criterion of information gain over time. For each neuron and for $n$ ranging from 2 to 12 bits, we calculated $H_{i}(n) / L_{i}(n)$ along the burst. Typically, the values of $n$ maximizing information gain over time for any index were $<5$ bits, so $n=5$ seemed to be the best choice (data not shown).

Since data were acquired at $10 \mathrm{kHz}$, the maximum resolution is $0.1 \mathrm{~ms}$. The analysis starts at the beginning of the burst $(i=1)$, with $k=1\left(b_{0}=\right.$ $0.1 \mathrm{~ms}$ ). Because this bin is too small, these words will be mostly populated by zeros and will form a set with low entropy. The value of $k$ is increased unit by unit until it reaches a maximum value (typically $>500$ ) that corresponds to a word duration equal to the burst duration. In this case, the bin is too large, resulting in a set of low entropy because the words will be mostly populated by ones. The values of $K$, which maximize the entropy of a neuron in a given position of the burst, are strongly dependent on the bursting frequency and average spike number/burst in that specific preparation. In addition to the great variations of the values obtained for $K(50-200)$, they typically correspond to word lengths of $\sim 20-30 \%$ of the total burst duration.

In addition to computing entropies and mutual information, we applied the method of surrogates (Theiler et al., 1992) based on randomly scrambling all stimuli of the stimulus/response bursts pairs to break the causal relation within pairs. The AMI of the surrogate set $\mathrm{AMI}_{\text {sur }}\left(S_{i}{ }^{K}\right.$ $R_{j}^{K^{\prime}}$ ) is computed using joint probabilities of occurrence of all possible pairs of words $\left(W_{\mathrm{LP}, i, R}^{K}, W_{\mathrm{PD}, j, m}^{K}\right)$, where $R$ is an index of the scrambled order of burst occurrences. Therefore, $\mathrm{AMI}_{\text {sur }}$ results must be due to statistical properties of IBSPs across the whole time series, disregarding causality.

To determine whether the results were statistically significant, we computed significance as sig $=\left(\mathrm{AMI}_{\mathrm{rel}}-<\mathrm{AMI}_{\text {surr }}>\right) / \sigma_{\text {surr }}$, where $<\mathrm{AMI}_{\text {surr }}>$ is the mean and $\sigma_{\text {surr }}$ is the standard deviation of $\mathrm{AMI}_{\text {sur }}$ results calculated for 20 surrogate datasets. All results reported in this manuscript were considered statistically significant if $\operatorname{sig}>7$.

Instead of just computing AMI, we normalized it by the entropy of the response, which we called relative mutual information $\mathrm{AMI}_{\mathrm{rel}}=\mathrm{AMI} /$ 


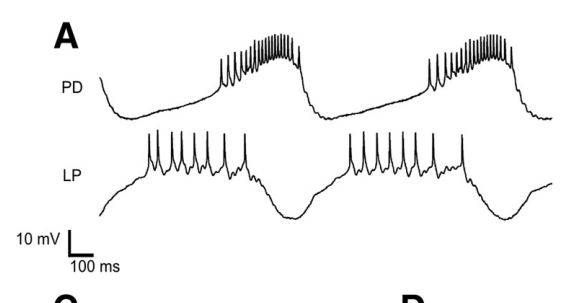

C

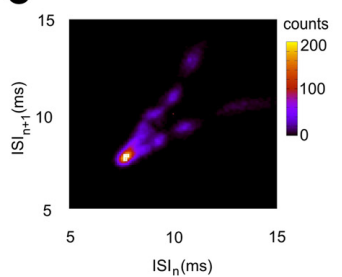

D
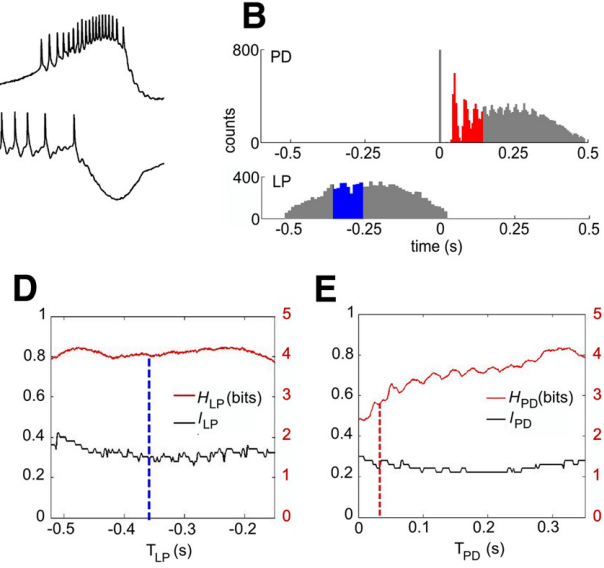

E

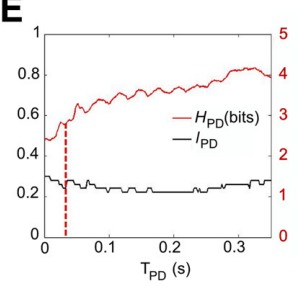

Figure 3. Time series, spike distributions, ISI signature, and entropies. A, Sample of LP and PD neurons time series presenting a typical antiphasic periodic bursting behavior. Spike rate of PD neuron is not uniform along the PD burst: from the beginning to the middle of the burst ISIs get progressively smaller and from the middle to the end of the burst, ISIs get progressively larger. B, Spike distributions of PD and LP using the first spike of each PD burst as time reference. The first spikes of PD occur in a well defined sequence that becomes less reliable along the burst. The distribution portion corresponding to the set of words of maximum loca entropy for $T_{P D}=0.03 \mathrm{~s}$ is shown in red. Because of the time reference chosen, the distribution of $L P$ spikes is much less precise. The distribution portion corresponding to the set of words of maximum local entropy for $T_{\mathrm{LP}}=-0.36 \mathrm{~s}$ is shown in blue. C, Intraburst ISI first return map showing clusters organized in a V-shape signature, characteristic of the PD. The clusters apparently present no inner structured pattern. $D$, Entropy $H_{1 P}$ (in bits, right $y$-axis) and / (dimensionless, left $y$-axis); word duration is normalized by the $\mathrm{LP}$ burst duration. The blue dashed line is an example where $T_{\mathrm{LP}}=-0.36 \mathrm{~s}$ corresponds to $H_{\mathrm{LP}}=4.0$ bits and the set of words that maximizes entropy has a word duration $I_{L P}=0.3$ ( $30 \%$ of $L P$ burst). $E$, Same as $D$ but for PD bursts. The red dashed line indicates $T_{\mathrm{PD}}=0.03 \mathrm{~s}$ that corresponds to $H_{\mathrm{PD}}=2.8$ bits and the set of words that maximized the entropy has a word duration $I_{\mathrm{PD}}=0.22$ ( $22 \%$ of the PD burst). $H_{\mathrm{LP}}$ is approximately four bits along all LP burst while $H_{\mathrm{PD}}$ increases from 2.5 to four bits along the PD burst. The entropies are smooth but not homogeneously distributed along the bursts. I is also smooth for each neuron but there is no simple relation between $H$ and $I$.

$H(R)$. It represents how much of the response neuron coding capability is dedicated to encode information about the stimulus.

Analysis programs were developed using $\mathrm{C}++$ language and ran in free open source Ubuntu Linux 9.04 (Canonical) based AMD64 3200 $\mathrm{MHz}$ PCs or similar.

\section{Results}

In intracellular experiments made with the intact STG (Fig. $1 A, B$ ), we identified and impaled PD and LP neurons with microelectrodes and recorded long stationary time series of their antiphasic activity (Fig. $3 A$ ) for further analysis. Recording times varied from $30 \mathrm{~min}$ to $2 \mathrm{~h}$, containing $1200-6000$ pairs of bursts depending on pyloric rhythm. In a second set of experiments, we interfaced the PD neuron to a computer model neuron in real time while the real LP was maintained hyperpolarized (Fig. 1C). Finally, we performed experiments recording the extracellular activity at the lvn and at the ivn that connects the OG to the brain (Fig. 1A).

\section{PD neuron is sensitive to previous IBSPs of the presynaptic} LP neuron

In this section, we show a detailed analysis of data obtained in a single typical experiment. First, we calculated the spike distribution for all pairs of the PD burst preceded by an LP burst using the first PD spike as time reference (Fig. 3B). The first few spikes of the PD neuron presented a pattern consisting of a sequence of ISIs occurring in a reproducible manner with well defined means and deviations. The latter portion of the distribution shows that spike times are progressively less precise along the burst. The LP spike distribution presents no clear pattern because the natural fluctuations of the beginning of LP burst with respect to the first spike of the next PD contribute with additional variability to LP spike timing.

The use of more sophisticated tools allows one to distinguish other firing structures in a neuron burst. Previous studies revealed interesting patterns that can be seen in subsequent intraburst ISIs return maps of CPG neurons in crayfish (Segundo et al., 1998), lobster (Szücs et al., 2003), and leech (Campos et al., 2007), but cannot be recognized just by looking at spike distributions.

Some of these return map patterns have been referred to as ISI signatures of the neurons (Szücs et al., 2003; Latorre et al., 2006; Campos et al., 2007) because they are very similar for the same neuron type among preparations and distinct for different neuron types. In our experiments, we found that a blue crab PD neuron ISI signature has a typical structure of clusters organized in a V shape (Fig. 3C), which is similar to the one found for the lobster PD neuron.

The V-shaped pattern of ISI first return maps could be seen as a consequence of a well known progressive increase followed by a decrease of spiking frequency along the PD burst (Fig. 3A). Thus, the first return maps reveal a pattern that can be visually identified in the PD neuron membrane potential trace. However, both branches of the V-shaped signature clearly present clusters, a feature of the ISI first return map that would not be identified by simple visual inspection of the intracellular trace. The clusters' positions in the signature are sensitive to changes in the circuit connectivity (Szücs et al., 2003, 2005) and each cluster seems to have no inner structure. The ISI first return map of the blue crab LP neuron (data not shown) also resembles the LP signature found in the lobster (Szücs et al., 2003). It consists of a single comet-shaped cluster formed by apparently noisy deceleration of ISIs.

If we looked into the apparently noisy clusters of each neuron signatures, would we find even more structured patterns and could they be somehow correlated? We developed an information theoretical analysis tool that allowed us to unveil such fine patterns along the burst and to infer information coding capacity of these neurons.

In information theory (Shannon, 1948; Borst and Theunissen, 1999), the entropy $(H)$ is a measure of variability and determines the maximum amount of information in a system. In our case, $H$ is a measure of IBSPs variability along the burst (Fig. $3 D, E$ ).

Starting at the same given position within all bursts, which defines our time index $(T)$, we choose a word of duration $L$ and divide it into five bins. We build a set of words by assigning a bit one or zero according to the occurrence of a spike within each bin and then calculate the entropy of the set. After computing the entropy for different values of $L$, we find $L_{\max }$ as the one that maximizes the entropy as a function of $T$ (Fig. $2 A$ ), ensuring that IBSPs have the greatest variability. We chose $L$ to be a variable 
rather than a constant, as is usual in informational analysis, to allow a possibly inhomogeneous coding of information along the burst duration.

Both neurons present high entropy values $\left(H_{\mathrm{LP}}, H_{\mathrm{PD}}\right)$ along their bursts, close to the maximum possible value of five bits (Fig. $3 D, E$ ). Entropy is clearly inhomogeneous throughout the PD burst and there is also some entropy fluctuation along the LP neuron burst. The parameter $l_{\mathrm{LP}}\left(l_{\mathrm{PD}}\right)$, which is $L_{\max }$ normalized by the burst duration, presents small variations that are independent of those found in $H_{\mathrm{LP}}\left(H_{\mathrm{PD}}\right)$. This fact justifies allowing different values of $L$ along the bursts.

From the values of $T$ and $L$, it is possible to find which spikes contribute to entropy maximization. For instance, the word duration maximizing entropy for the time index $T_{\mathrm{PD}}=0.03 \mathrm{~s}$ is $L_{\max , \mathrm{PD}}=0.11 \mathrm{~s}$, and the corresponding normalized value is $l_{\mathrm{PD}}$ $=0.22$ (Fig. $3 E)$. The spikes that lie within the [0.03:0.14] s interval of the PD histogram (Fig. 3B), where the second, third, and fourth spikes can be visually discriminated, code up to $H_{\mathrm{PD}}=2.8$ bits of information in their IBSPs (Fig. 3E).

To infer how much PD and LP IBSPs variabilities are correlated along bursts, we computed their AMI and represented it in a 2D color map (Fig. $2 B$ ). In a typical experiment, AMI (Fig. $4 A$ ) is not uniform along PD and LP bursts, and its maximum value of 0.66 bits (Fig. $4 \mathrm{~A}$ ) corresponds to the first half of LP burst, starting at $T_{\mathrm{LP}}=-0.36 \mathrm{~s}$ (Fig. $3 \mathrm{~B}$, blue region), with the beginning of the PD burst at $T_{\mathrm{PD}}=0.03 \mathrm{~s}$ (Fig. $3 \mathrm{~B}$, red region). The AMI peak represents a twofold increase with respect to the background values, in contrast to the entropies that do not present such abrupt behavior (Fig. 3D,E).

AMI is symmetric with respect to stimulus and response (de Ruyter van Steveninck et al., 1997; Borst and Theunissen, 1999; MacKay, 2003). Therefore, it does not imply causality. To overcome this limitation, our method establishes a precedence relation of LP burst with respect to the following PD burst. Additionally, we calculate AMI for surrogate data (Theiler et al., 1992) where the order of LP bursts is scrambled, thus disrupting causality. AMI for the surrogate data $\left(\mathrm{AMI}_{\text {surr }}\right)$ (Fig. $\left.4 \mathrm{~B}\right)$ drops to only $10 \%$ of the original values. This means that the conspicuous AMI values of the original series are due to the causal relation (stimulus-response) between the LP IBSPs and the subsequent PD IBSPs. The AMI values are statistically significant (see Materials and Methods, above) at the peak and surrounding regions. By normalizing AMI to the response neuron entropy $\mathrm{AMI}_{\text {rel }}=$ $\mathrm{AMI} / H_{\mathrm{PD}}$, it is possible to infer how much $\mathrm{PD}$ is dedicated to code LP IBSPs. The peak of AMI $\mathrm{Al}_{\text {rel }}$ indicates that up to $25 \%$ of PD IBSPs can be predicted once LP IBSPs are known (Fig. 4C). Hence, $\mathrm{AMI}_{\text {rel }}$ takes into account fluctuations in response entropy, allowing direct comparison of $\mathrm{AMI}_{\mathrm{rel}}$ results along $\mathrm{PD}$ burst. Clearly, the position of maximum values of the $\mathrm{AMI}_{\mathrm{rel}}$ matrix indicates that information is mainly transmitted from the first half of the LP burst to the beginning of the PD burst.

The analysis of the information flow in the opposite direction, from a PD burst to the next LP burst (data not shown), produced statistically significant peaks in different regions of the AMI diagram, indicating that the sensitivity to presynaptic IBSPs is also a property of other bursting neurons and not only of the PD neuron.
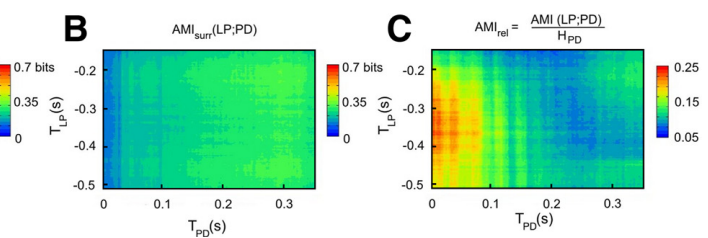

$\mathrm{T}_{\mathrm{PD}}(\mathrm{s})$

Figure 4. Average mutual information. $A$, Matrix of local AMI values calculated for $L P$ and PD in bits. $T_{L P}$ and $T_{\mathrm{PD}}$ (in seconds) are the time indexes that vary along the neurons bursts. As the first spike of $P D$ is used as time reference, $T_{\mathrm{PD}}$ is always positive and $T_{L P}$ 列 relation between $L P$ and PD: the PD neuron changes its IBSPs according to the input previously received from LP. C, AMI $\mathrm{rel}_{\text {l }}=$

\section{Information flow from LP to PD is ubiquitous}

It is widely known that pyloric neurons can present similar behavior in different preparations despite variations of their intrinsic excitability properties (Marder and Prinz, 2002; Goaillard et al., 2009). Is it possible for pyloric neurons of different animals to share a common information coding mechanism?

To address this question, we applied the same analysis to several LP/PD time series from experiments with Callinectes sapidus and Panulirus interruptus. We collected data from several crab preparations until having approximately a threefold natural variation of some important pyloric features, such as the pyloric period (from $0.44 \pm 0.03 \mathrm{~s}$ to $1.3 \pm 0.7 \mathrm{~s}$ ) and number of spikes per burst of the LP neuron (from $4.4 \pm 0.5$ to $15 \pm 3$ ) and of the PD neuron (from $7.5 \pm 0.5$ to $20 \pm 1$ ). Despite such wide differences in pyloric general behavior, the results of $\mathrm{AMI}_{\text {rel }}$ were qualitatively very similar for different preparations.

Despite some differences in the overall conformation of $\mathrm{AMI}_{\text {rel }}$ hot spots along diagrams for different preparations, there are strong similarities in the position of $\mathrm{AMI}_{\text {rel }}$ peaks (Fig. 5). To observe the peak position more accurately, it is necessary to consider what portion of the burst corresponds to the maximum value of $\mathrm{AMI}_{\text {rel. }}$. The maximum values of $\mathrm{AMI}_{\text {rel }}$ can vary in each case, but for most preparations the position of the global peak is close to the beginning of both stimulus (LP) and response (PD) bursts. In Figure 5, above the $\mathrm{AMI}_{\mathrm{rel}}$ graphs, the upper box represents the LP burst duration normalized to the pyloric period and the lower box represents the PD burst duration. The shaded regions in each pair of boxes represent the burst portions that correspond to the $\mathrm{AMI}_{\text {rel }}$ global peak. In this representation, it is clear that the peak of $\mathrm{AMI}_{\text {rel }}$ corresponds to the beginning (first few spikes) of LP and PD bursts in all six cases. From a total 16 time series from different crab (Fig. 5A-D) and lobster (Fig. $5 E$ ) preparations analyzed, $14(87.5 \%)$ have their absolute or local maximum at the beginning of LP and 13 (81\%) have absolute or local maximum at the beginning of LP with the beginning of PD. In all cases, $\mathrm{AMI}_{\text {rel }}$ peaks are statistically significant.

\section{A hybrid circuit where PD is connected to a model neuron through a single synapse presents similar results to those obtained for the intact circuit}

The results presented so far indicate an information flow mechanism shared among different animals, but the question of whether such information flows through a single synapse or follows an indirect pathway using other connectivities across the STNS remains unanswered.

We investigated this matter by doing several experiments in which the PD neuron interacted with an AN in real time, while the LP neuron was kept hyperpolarized to a quiescent state. In 

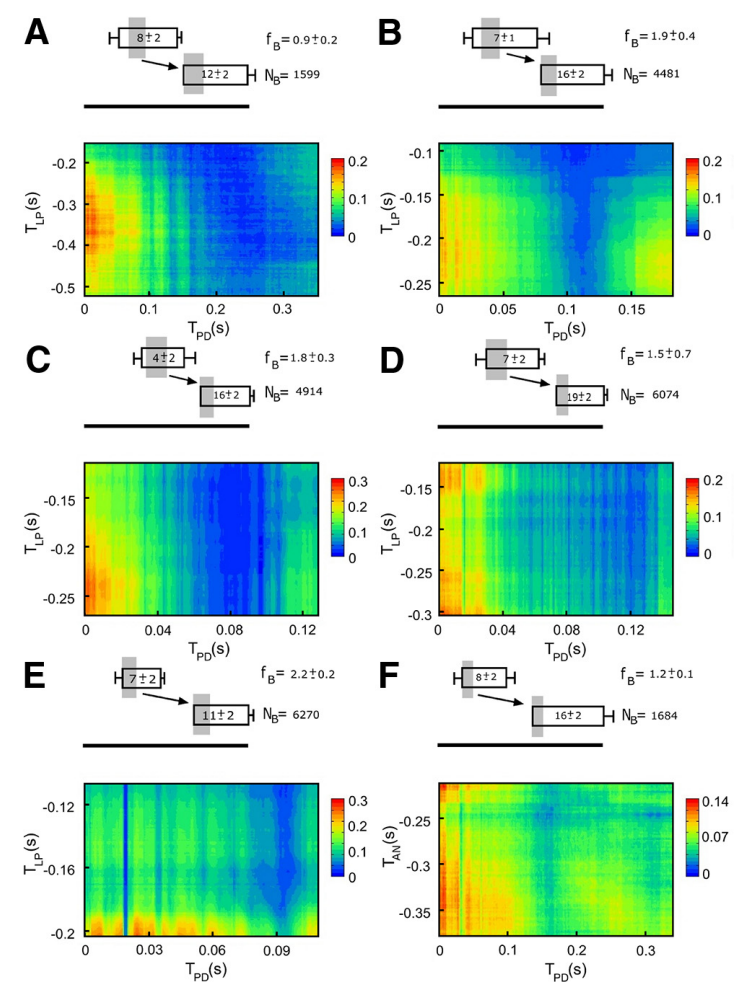

Figure 5. $\quad A M I_{\text {rel }}$ results in different preparations for experiments with $L P$ and $P D$ neurons. $\boldsymbol{A}-\boldsymbol{D}$, Preparations with the intact circuit of Callinectes sapidus. $\boldsymbol{E}$, Preparations with the intact circuit of Panullirus interruptus. $\boldsymbol{F}$, A hybrid circuit in which the LP neuron was replaced by an AN (prepared to mimic the original LP) and connected to PD through an artificial inhibitory synapse. Above each graph is a representation of the LP (upper box) and PD (lower box) average bursting duration and phases (time reference in the first spike of the PD bursts). The lateral bars represent SDs. The size of rectangles were normalized to the bursting period (horizontal bar with the same length for all maps). Bursting frequency ( $f_{\mathrm{B}}$ in Hertz) and the number of pairs of bursts $\left(N_{\mathrm{B}}\right)$ used in the analysis are also indicated in each case. The average number of spikes/burst of each neuron is indicated inside each rectangle. Gray shading represents the portions of the bursts that correspond to the maximum peak of $\mathrm{AMI}_{\text {rel, }}$ and the arrow points the direction of information flow from $L P$ to $P D$. AMI re peaks correspond to the beginning of both $L P$ and $P D$ bursts in all cases. Results are similar for different animals (with different LP and PD bursting phases, average spike numbers, and pyloric frequencies) and even among different species and are reproduced in hybrid circuit experiments.

this hybrid circuit, interaction was provided by a single inhibitory artificial synapse from AN to PD, implemented through a dynamic clamp protocol (Pinto et al., 2001; Nowotny et al., 2006). The AN was implemented either as a random spike generator or as a conductance-based model with additional stochastic dynamics (Carelli et al., 2005) and it was prepared to mimic the bursting phase and the average number of spikes/burst found in the original LP. The PD hyperpolarization onset determined when AN was allowed to burst and it was the only influence the biological circuit had over the AN. This way it was impossible for any CPG neuron to influence AN's IBSPs.

The preparations used in the hybrid experiments showed variability regarding to the pyloric period (from $0.62 \pm 0.03 \mathrm{~s}$ to $0.83 \pm 0.05 \mathrm{~s}$ ), number of spikes per burst of the PD neuron (from $7.4 \pm 0.7$ to $15 \pm 2$ ), and number of spikes per burst of the AN that mimicked the original LP (from $4 \pm 1$ to $8.0 \pm 0.8$ ). These fluctuations are comparable to those observed in intact

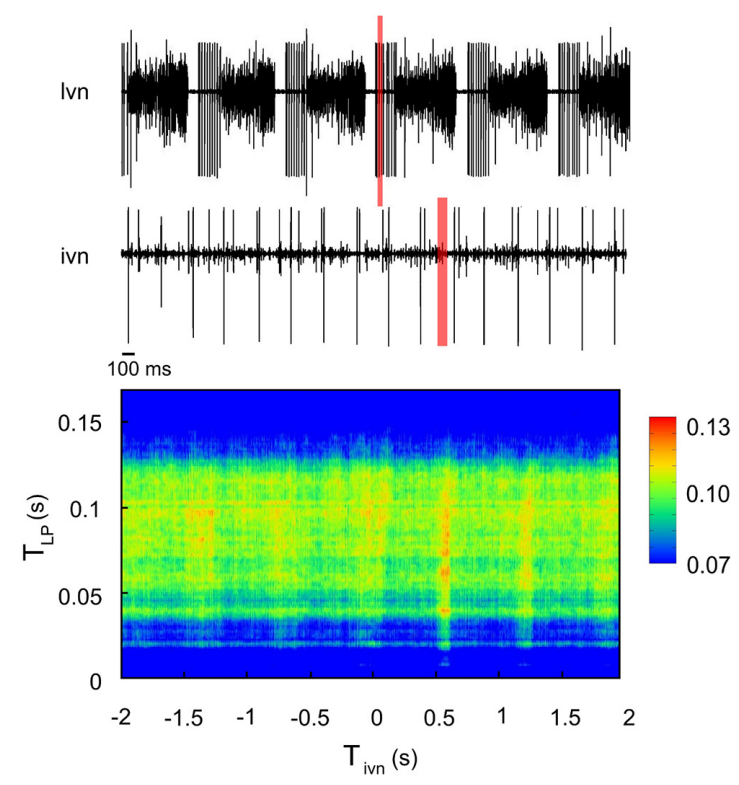

Figure 6. $\quad A M I_{\text {rel }}$ between $L P$ neuron and ivn as a function of $T_{L \mathrm{P}}$ and $T_{\mathrm{ivn}}$. The upper trace is the extracellular signal obtained from the lvn; we can clearly see and detect the LP spikes (big units). The lower trace is the extracellular signal recorded from the ivn. The peak of AMI ${ }_{\text {rel }}$ lies at $T_{\text {ivn }} \sim 0.6 \mathrm{~s}$. The red shaded rectangles represent portions of the LP and ivn signals that correspond to the $\mathrm{AMI}_{\text {rel }}$ peak.

circuit experiments. Moreover, of a maximum value of five bits, the entropy values obtained along the bursts of both random and stochastic AN were in the range of $[2.2,4.5]$ bits in different experiments, very similar to the range of $[2.3,4.6]$ bits obtained for the real LP in intact circuit experiments. Our hybrid circuit experiments presented $\mathrm{AMI}_{\mathrm{rel}}$ results qualitatively similar to those found for the intact circuit: the peak of $\mathrm{AMI}_{\text {rel }}$ lies at the beginning of both stimulus and response neuron bursts (Fig. $5 F$ ). From a total of 16 experiments performed, 15 (94\%) had an absolute maximum at the beginning of AN with the beginning of PD (statistically significant in all cases). Since AN entropy is typically high and $\mathrm{AMI}_{\text {rel }}$ also has very prominent values, the $\mathrm{PD}$ neuron IBSPs can reflect IBPSs variations of a presynaptic neuron, even if it they are completely artificially generated.

\section{Information from the LP motor neuron is found in a nerve} with fibers that project into sensory areas of the brain

Could the LP neuron be able to transmit information contained in its IBSPs to STNS neurons other than the PD neuron? If so, what could this information be used for?

We addressed this question by looking for information flow between the LP neuron and the ivn nerve that connects the OG to the brain (Böhm et al., 2001), using the same analysis technique for computing $\mathrm{AMI}_{\mathrm{rel}}$. Since the ivn signal is tonic, some adjustments were necessary as the original method was designed to separate the time series in pairs of bursts. Using the first spike of each LP burst as time reference, we collected all LP bursts with their corresponding portions of the ivn signal in the range of $[-2: 2] \mathrm{s}$ with respect to the local time reference.

We computed AMI $\mathrm{I}_{\text {rel }}$ between LP burst and ivn IBSPs (Fig. 6). The IBSPs corresponding to ivn spikes occurring before the LP burst were considered stimuli and the LP IBSPs were taken as 
responses. Conversely, if ivn IBSPs happened after LP IBSPs, LP was considered stimulus signal and ivn the response.

We found that part of the LP IBSPs is actually coded by ivn active units. The maximum $\mathrm{AMI}_{\text {rel }}$ region lies at a positive value of $T_{\mathrm{ivn}}$, meaning information flows from LP to ivn (Fig. 6). The nerve takes approximately one pyloric cycle to express information received from the LP, $\sim 0.6 \mathrm{~s}$ after the LP burst. Since conduction velocity in the ivn is likely to be of the order of meters per second (for the superior oesophageal nerve, see Moulins et al., 1979; for the stomatogastric nerve, see Russell and Hartline, 1984), and the STG is only a few centimeters apart fror the ivn electrode, the nerve conduction velocity does not justify the delay found. This result suggests that the delay found is related to the way information is processed/coded, synapse by synapse, from the LP until it reaches the ivn. The most prominent values of $\mathrm{AMI}_{\mathrm{rel}}$ correspond to a region near the beginning of the LP burst reaching a value of $12.5 \%$. Three of 10 different crab preparations showed no significant $\mathrm{AMI}_{\text {rel }}$ values in any region of the graph. Nevertheless, the other seven cases $(70 \%)$ presented an information flow from LP to ivn, with $\mathrm{AMI}_{\text {rel }}$ peaks ranging from $2.5 \%$ to $28.0 \%$ (all statistically significant).

\section{Discussion}

The study of complex burst dynamics is improving concomitantly with the development of dedicated analysis tools. For instance, phase response curves (PRCs) (Ayers and Selverston, 1984; Canavier and Achuthan, 2010) have greatly contributed to our understanding of synchronization in CPGs, considering neurons as periodic oscillators (Oprisan et al., 2004; Galán et al., 2005; Ermentrout et al., 2007; Schleimer and Stemmler, 2009). PRC methods target the phase shifts produced in periodic bursts by interacting neurons, disregarding any oscillations of intraburst ISIs. In fact, a few neurons' burst onsets and terminations dictate the constriction and dilation rhythm of pyloric muscles, so little attention has been traditionally paid to intraburst ISIs due to their lack of influence on motor activity.

Nevertheless, return maps of intraburst ISIs (Segundo et al., 1998) of CPG neurons reveal fine patterns that are sensitive to physiologically meaningful alterations of the circuit (Szücs et al., 2003, 2005; Campos et al., 2007). The shapes in first return maps were called neural signatures due to their reproducibility, typical of each neuron type. We found that the blue crab PD neuron has a very similar signature to the one previously reported for the lobster PD neuron (Szücs et al., 2003). This previous work described changes in the lobster PD neuron signature when the LP to PD synapse is artificially modified, meaning that PD's IBSPs are sensitive to LP activity or connectivity.

In the present work, we thoroughly investigated such relations, not only considering first-order ISI patterns, but also looking at a wide range of IBSPs using an information theoretical analysis tool. Although the method was developed to find and measure informational content of IBSPs, it may also have other applications due to its power to reveal hidden information in spike patterns.

In fact, we found that $\mathrm{PD}$ is able to express informational content of LP IBSPs that reaches significant amounts of its coding capacity. An even more interesting phenomenon is that usually the region of maximum $\mathrm{AMI}_{\mathrm{rel}}$ corresponds to the beginning of both LP and PD bursts. Moreover, this result is robust in different preparations and even across different species.

Furthermore, wide variations in $\mathrm{AMI}_{\mathrm{rel}}$ values were clearly not directly dependent on entropy variations of both neurons. If we think of the PD neuron as a simple integrator of synaptic inputs received in the hyperpolarization phase, then the dynamics observed during the depolarization phase should depend linearly on the inputs. If we observe that both entropies vary smoothly along the bursts, singular peaks can only be found in the $\mathrm{AMI}_{\text {rel }}$ graphs if the input information is coded into output through a nonlinear transfer function, which is in agreement with the predictions of previous work (Chacron et al., 2004).

PRC studies have described the effect of inhibitory pulses on PD phase by using its burst onset as time reference (Oprisan et al., 2004). The $\mathrm{AMI}_{\text {rel }}$ results are also consistent with those findings: the beginning of a LP burst (which usually comprises the first LP spike) is strongly correlated with the very beginning of the following PD burst. However, our analysis considers not only variations in PD phase relative to LP onset, but also the detailed spike timing within LP burst. If the PD neuron were only sensitive to phase variations, then the expected position of the $\mathrm{AMI}_{\text {rel }}$ peak would be at the very beginning of LP, and the peak region should be quite small, comprising only the first LP spike and not the subsequent ones. Our results reveal that not only phase, but also slight variations in ISI of a series of spikes are important to account for information expressed in the PD following burst.

Our results revealed correlations between LP and PD IBSPs in the intact circuit. However, they do not rule out the possible influence of a third element in both neurons activity. To clarify this issue, we showed that the PD response to an artificial neuron is quite similar to its response to LP in the intact network. The model neuron mimics, on average, the LP bursting phase and duration and its spike distribution is also similar to the original neuron. This way, spike timing is dictated only by parameters set before the experiment, based on statistics of the LP behavior. Therefore, PD's IBSPs variability in this case can only be affected by the AN spontaneous IBSPs variability. These results allow us to claim that the variations of the patterns of AN are reflected in the IBSPs of PD and that a single synapse is sufficient to account for the IBSP information coding mechanism found.

In crustacean CPG motor neurons, bursting is associated with coordination of muscle contraction, but intraburst ISI timescale cannot be directly associated with motor control. Morris and Hooper (Morris and Hooper, 1997; Hooper et al., 2007) showed that the cpvib muscle contraction, controlled by the PD neuron through a graded synapse, is determined by spike number in such a way that small variations in frequency do not affect its contraction slope. Therefore, muscle contraction must be independent of information encoded in IBSPs. In contrast, in a different neuromuscular system (Zhurov and Brezina, 2006), the accessory radula closer muscle of Aplysia operates between the fast and slow regimens, presenting nonlinear contraction responses to different spike timings. The authors argue that such properties contribute to maintaining robust muscle contraction patterns in vivo. Therefore, although it is not the case for the pyloric $\mathrm{PD}$ neuron and cpv1b muscle (Morris and Hooper, 1997), in a system with nonlinear muscle properties, the IBSP information coding shown here could be directly involved in a mechanism of motor regulation.

If information expressed through IBSPs is not important for muscle contraction, does it have any relevance to the system at all? To address this question, we looked for information transmitted to another nerve that connects the STNS to the brain. In fact, ivn expresses information from LP IBSPs. In this analysis, the time reference is at the first spike of LP bursts; therefore, all information contained in IBSPs is only due to intraburst spike timing variability and not related to phase or pyloric period. 
A previous study in crayfish (Böhm et al., 2001) showed that there are STNS neurons located within the OGs and CoGs that send fibers through the ivn. Arborizations of these neurons spread inside the protocerebrum and other areas, mainly the neuropils of the first and second antennae, leading to communication with important processing centers in the brain. As the STNS is known to be quite functionally invariant across species, ivn is a good candidate for a pathway that delivers information from the pyloric circuit to sensory areas of the brain. Although it is not possible to ensure, based only on information theoretical results, that the information conveyed would actually be used to affect behavior, it is consistent to assume that the pathway described makes information about pyloric neurons behavior available to the brain.

In the pyloric CPG of the STG, the intrinsic bursting capabilities of neurons interplay with synaptic connectivity, providing an autonomous way to generate output pattern. However, the CPG is controlled by higher centers and through sensory feedback that together regulate the bursting pattern (Selverston et al. 2000). Although neuromodulators, synapses, and cellular machinery of the STNS have been extensively studied, there is still no broad understanding of how the CPG is regulated. We propose the coding mechanism found as an alternate feedback pathway to help modulatory control.

Another important finding is that $\mathrm{AMI}_{\text {rel }}$ results are qualitatively similar across different preparations. The pyloric CPG can present a vast repertoire of rhythms in a single animal and across different specimens due to intrinsic variability in cellular excitability machinery, synaptic strength, and baseline neuromodulator concentrations. All animals used in our experiments were collected from their natural habitat, so we may consider the variability of pyloric activity observed to be representative of the dynamical repertoire that would be found in the natural environment (Goaillard et al., 2009). Our results revealed an information flow phenomenon that is ubiquitous among different preparations and for different species, despite striking differences in pyloric period, number of spikes per burst, or phase relations between LP and PD across different animals.

Recent experimental and theoretical works have shown that circuits with different cellular and network properties can present similar activity regarding bursting period and phase, meaning that they must be functionally equivalent (Marder and Prinz, 2002; Goaillard et al., 2009; Grashow et al., 2010). It has been proposed that such a remarkable phenomenon can be part of intricate mechanisms responsible for homeostasis maintenance. We showed that a subtle phenomenon, such as information transmission through IBSPs, is conserved despite differences in network properties, and even in circuits with functionally different activities. Thus, it could be considered evidence of another level of homeostatic regulation. We are currently investigating what ionic mechanisms might be responsible for the observed phenomena.

Previous studies have shown that sensory neurons can use temporal spike patterns and firing rate to code different signals simultaneously (Bair and Koch, 1996; Panzeri et al., 2010; Middleton et al., 2011). In the present work, we have shown that bursting motor neurons, usually seen as workhorses of muscle contraction, can also perform this task. They are able to use patterns of different time scales to simultaneously encode the conspicuous motor information and also information about how other CPG neurons are working. Furthermore, they may play a role in the regulation of neuronal firing patterns within the network or by the CNS.
These findings expand the view of the role attributed to CPG bursting neurons. As it happened with many other phenomena first observed in the STNS (Clarac and Pearlstein, 2007; Marder and Bucher, 2007), we hope our findings can lead to new insights in the investigation of neural coding in invertebrate and vertebrate nervous systems in the future.

\section{References}

Ayers J, Selverston AI (1984) Synaptic perturbation and entrainment of gastric mill rhythm of the spiny lobster. J Neurophysiol 51:113-125.

Bair W, Koch C (1996) Temporal precision of spike trains in extrastriate cortex of the behaving macaque monkey. Neural Comput 8:1185-1202.

Böhm H, Dybek E, Heizel HG (2001) Anatomy and in vivo activity of neurons connecting the crustacean stomatogastric nervous system to the brain. J Comp Physiol A 187:392-403.

Borst A, Theunissen FE (1999) Information theory and neural coding. Nat Neurosci 2:947-957.

Brocard F, Tazerart S, Vinay L (2010) Do pacemakers drive the central pattern generator for locomotion in mammals? Neuroscientist 16:139-155.

Butts DA, Weng C, Jin J, Yeh CI, Lesica NA, Alonso JM, Stanley GB (2007) Temporal precision in the neural code and the timescales of natural vision. Naure 449:92-95.

Campos D, Aguirre C, Serrano E, Rodriguez Ortiz FD, De Polavieja GG, Varona $P$ (2007) Temporal structure in the bursting activity of the leech heartbeat CPG neurons. Neurocomputing 70:1792-1796.

Canavier CC, Achuthan S (2010) Pulse coupled oscillators and the phase resetting curve. Math Biosci 226:77-96.

Carelli PV, Reyes MB, Sartorelli JC, Pinto RD (2005) Whole cell stochastic model reproduces the irregularities found in the membrane potential of bursting neurons. J Neurophysiol 94:1169-1179.

Chacron MJ, Longtin A, Maler L (2004) To burst or not to burst? J Comput Neurosci 17:127-136.

Clarac F, Pearlstein E (2007) Invertebrate preparations and their contribution to neurobiology in the second half of the 20th century. Brain Res Rev 54:113-161.

Ermentrout GB, Galán RF, Urban NN (2007) Relating neural dynamics to neural coding. Phys Rev Lett 99:248103.

Eyherabide HG, Samengo I (2010) Time and category information in pattern-based codes. Front Comput Neurosci 4:145.

Eyherabide HG, Rokem A, Herz AV, Samengo I (2008) Burst firing is a neural code in an insect auditory system. Front Comput Neurosci 2:3-7.

Galán RF, Ermentrout GB, Urban NN (2005) Efficient estimation of phaseresetting curves in real neurons and its significance for neural-network modeling. Phys Rev Lett 94:158101.

Goaillard JM, Taylor AL, Schulz DJ, Marder E (2009) Functional consequences of animal-to-animal variation in circuit parameters. Nat Neurosci 12:1424-1430.

Grashow R, Brookings T, Marder E (2010) Compensation for variable intrinsic neuronal excitability by circuit-synaptic interactions. J Neurosci 30:9145-9156.

Hooper SL, Guschlbauer C, von Uckermann G, Büschges A (2007) Different motor neuron spike patterns produce contractions with very similar rises in graded slow muscles. J Neurophysiol 97:1428-1444.

Kayser C, Montemurro MA, Logothetis NK, Panzeri S (2009) Spike-phase coding boosts and stabilizes information carried by spatial and temporal spike patterns. Neuron 61:597-608.

Kreuz T, Chicharro D, Greschner M, Andrzejak RG (2011) Time-resolved and time-scale adaptive measures of spike train synchrony. J Neurosci Methods 195:92-106.

Kumar A, Rotter S, Aertsen A (2010) Spiking activity propagation in neuronal networks: reconciling different perspectives on neural coding. Nat Rev Neurosci 11:615-627.

Latorre R, Rodríguez FB, Varona P (2006) Neural signatures: multiple coding in spiking bursting cells. Biol Cybern 95:169-183.

MacKay DJC (2003) Information theory, inference, and learning algorithms. Cambridge, UK: Cambridge UP.

Marder E, Bucher D (2007) Understanding circuit dynamics using the stomatogastric nervous system of lobsters and crabs. Annu Rev Physiol 69:291-316.

Marder E, Prinz AA (2002) Modeling stability in neuron and network function: the role of activity in homeostasis. Bioessays 24:1145-1154

Middleton JW, Yu N, Longtin A, Maler L (2011) Routing the flow of sensory 
signals using plastic responses to bursts and isolated spikes: experiment and theory. J Neurosci 31:2461-2473.

Morris LG, Hooper SL (1997) Muscle response to changing neuronal input in the lobster (Panulirus interruptus) stomatogastric system: spike number- versus spike frequency-dependent domains. J Neurosci 17:5956-5971.

Moulins M, Vedel JP, Nagy F (1979) Complex motor neurone in crustacea: three axonal spike initiating zones in three different ganglia. Neurosci Lett 13:231-236.

Nowotny T, Szücs A, Pinto RD, Selverston AI (2006) StdpC: a modern dynamic clamp. J Neurosci Methods 158:287-299.

Oprisan SA, Prinz AA, Canavier CC (2004) Phase resetting and phase locking in hybrid circuits of one model and one biological neuron. Biophys J 87:2283-2298.

Panzeri S, Brunel N, Logothetis NK, Kayser C (2010) Sensory neural codes using multiplexed temporal scales. Trends Neurosci 33:111-120.

Pinto RD, Elson RC, Szücs A, Rabinovich MI, Selverston AI, Abarbane HD (2001) Extended dynamic clamp: controlling up to four neurons using a single desktop computer and interface. J Neurosci Methods 108:39-48.

Reinagel P, Godwin D, Sherman SM, Koch C (1999) Encoding of visua information by LGN bursts. J Neurophysiol 81:2558-2569.

Russell DF, Hartline DK (1984) Synaptic regulation of cellular properties and burst oscillations of neurons in gastric mill system of spiny lobsters, Panulirus interruptus. J Neurophysiol 52:54-73.

Sabourin P, Pollack GS (2009) Behaviorally relevant burst coding in primary sensory neurons. J Neurophysiol 102:1086-1091.

Schleimer JH, Stemmler M (2009) Coding of information in limit cycle oscillators. Phys Rev Lett 103:248105.

Segundo JP, Sugihara G, Dixon P, Stiber M, Bersier LF (1998) The spike trains of inhibited pacemaker neurons seen through the magnifying glass of nonlinear analyses. Neuroscience 87:741-766.
Selverston AI (2010) Invertebrate central pattern generator circuits. Philos Trans R Soc Lond B Biol Sci 365:2329-2345.

Selverston AI, Russell DF, Miller JP (1976) The stomatogastric nervous system: structure and function of a small neural network. Prog Neurobiol 7:215-290.

Selverston AI, Rabinovich MI, Abarbanel HD, Elson R, Szücs A, Pinto RD, Huerta R, Varona P (2000) Reliable circuits form irregular neurons: a dynamical approach to understanding central pattern generators. J Physiol Paris 94:357-374.

Shannon CE (1948) A mathematical theory of communication. Bell Systems Tech J 27:379-423.

Sherman SM (2001) Tonic and burst firing: dual modes of thalamocortical relay. Trends Neurosci 24:122-126.

Steriade M, McCormick DA, Sejnowski TJ (1993) Thalamocortical oscillations in the sleeping and aroused brain. Science 262:679-685.

Szücs A, Pinto RD, Rabinovich MI, Abarbanel HD, Selverston AI (2003) Synaptic modulation of the interspike interval signatures of bursting pyloric neurons. J Neurophysiol 89:1363-1377.

Szücs A, Abarbanel HD, Rabinovich MI, Selverston AI (2005) Dopamine modulation of spike dynamics in bursting neurons. Eur J Neurosci 21:763-772.

Theiler J, Eubank S, Longtin A, Galdrikian B, Farmer JD (1992) Testing for nonlinearity in time series: the method of surrogate data. Physica D 58:77-94.

Tiesinga P, Fellous JM, Sejnowski TJ (2008) Regulation of spike timing in visual cortical circuits. Nat Rev Neurosci 9:97-107.

de Ruyter van Steveninck RR, Lewen GD, Strong SP, Köberle R, Bialek W (1997) Reproducibility and variability in neural spike trains. Science 275:1805-1808.

Zhurov Y, Brezina V (2006) Variability of motor neuron spike timing maintains and shapes contractions of the accessory radula closer muscle of Aplysia. J Neurosci 26:7056-7070. 